\title{
The Impact of Different Game Types and Sports on College Students' Physical Activity and Motivation in Basic Instruction Program Settings
}

\author{
Yang Song
}

Follow this and additional works at: https://researchrepository.wvu.edu/etd

\section{Recommended Citation}

Song, Yang, "The Impact of Different Game Types and Sports on College Students' Physical Activity and Motivation in Basic Instruction Program Settings" (2017). Graduate Theses, Dissertations, and Problem Reports. 6691.

https://researchrepository.wvu.edu/etd/6691

This Dissertation is protected by copyright and/or related rights. It has been brought to you by the The Research Repository @ WVU with permission from the rights-holder(s). You are free to use this Dissertation in any way that is permitted by the copyright and related rights legislation that applies to your use. For other uses you must obtain permission from the rights-holder(s) directly, unless additional rights are indicated by a Creative Commons license in the record and/ or on the work itself. This Dissertation has been accepted for inclusion in WVU Graduate Theses, Dissertations, and Problem Reports collection by an authorized administrator of The Research Repository @ WVU.

For more information, please contact researchrepository@mail.wvu.edu. 
The Impact of Different Game Types and Sports on College Students' Physical Activity and Motivation in Basic Instruction Program Settings

\author{
Yang Song \\ Dissertation submitted \\ to the College of Physical Activity and Sport Science \\ at West Virginia University \\ in partial fulfillment of the requirements for the degree of \\ Doctor of Philosophy in Kinesiology \\ With an emphasis in \\ Coaching and Teaching Studies \\ Stephen Harvey, Ph.D.,Chair \\ Sean M. Bulger, Ed.D \\ Emily M.Jones, Ph.D. \\ James C.Hannon, Ph.D \\ Karen Rambo-Hernandez, Ph.D
}

Department of Coaching and Teaching Studies

Morgantown, West Virginia

2017

Keywords: Game types, sports, college students', physical activity, motivation, basic instruction program.

Copyright 2017 Yang Song 


\begin{abstract}
The Impact of Different Game Types and Sports on College Students' Physical Activity and

Motivation in Basic Instruction Program Settings
\end{abstract}

Yang Song

Background/Purpose: Few researchers have investigated college students' physical activity levels and motivations within university Basic Instruction Programs (BIPs) when students engaged in different games (modified games, small-sided games, and full-sided games) from different sports categories (e.g., net/wall games and invasion games). Thus, the purpose of this study was to investigate college students' Moderate to Vigorous Physical Activity (MVPA) and motivations while playing different games in badminton and soccer classes. The study also examined how well motivation levels predict MVPA.

Methods/Analysis: Seventy-one college students (57 males and 14 females) from a rural Mid-Atlantic university participated in and finished the study. They came from three soccer classes and two badminton classes. The author utilized Actigraph GT3X triaxial accelerometers to collect MVPA data and the Intrinsic Motivation Inventory (IMI) questionnaires to measure motivation. The included IMI subscales are interest/enjoyment, perceived competence, and effort/importance. A two-way repeated measures ANOVA and a two-way repeated measures, within-between interaction MANOVA were utilized to examine the MVPA and IMI data respectively in the two different sports and the three different game forms. Two separate oneway repeated measures ANOVA with Bonferroni correction $(p=.025)$ were also utilized to test whether MVPA differed in the three games forms for each sport (i.e., badminton and soccer).Three multiple regression tests were conducted to examine how the IMI data and sports predict MVPA. One regression test was utilized for each of the game forms.

Results: Students in the soccer classes had statistically significant more MVPA than those in badminton. The game forms in which students had the most MVPA were different in the two sports. For example, students in soccer classes had most MVPA in full-sided games, but students in badminton classes had most MVPA in small-sided games. Students reported similar scores in the three IMI subscales when data were aggregated. However, the game forms in which students felt competent and made effort were different in the two sports. For example, students in soccer classes felt most competent and made the greatest effort in modified games, but students in badminton classes felt most competent and made the greatest effort in small-sided games.In modified games, interest was the only statistically significant predictor of MVPA. Perceived competence was a statistically significant predictor of MVPA in small-sided games and fullsided games.

Discussion: With similar motivation qualities between soccer and badminton, students in badminton classes had statistically significant less MVPA than those in soccer classes. The MVPA difference was due to the different nature of the sports and the range of student ability levels within each sport.

Conclusion: PE teachers should actively observe students' game play and make adjustments to game forms to find the optimal balance of MVPA and student motivation. 


\section{Acknowledgements}

There are never enough words to express my greatest appreciation and gratitude to my committee members in West Virginia University, who have guided and assisted me along this dissertation journey. I acknowledge my chair, Dr. Stephen Harvey, who inspired me on the project and spent numerous hours providing literature sources and editing. Dr. Hernandez, my statistics person on the committee, provided support for using the right statistic techniques to analyze data. I also wish to extend my gratitude to my committee members, Dr. Bulger, Dr. Jones, and Dr. Hannon, for their insightful comments to make the project better.

A special acknowledgment goes to my peers: David Robertson and Adam Keath. Both of them substituted me for my supervision classes while I was collecting data. Thanks to David for sharing his experience about higher education. Thanks to Adam for providing all kinds of technical supports. I would also like to thank my friend, Jiang Yang Huang, who encouraged me to pursue a doctoral degree in the United States and set a good example for me.

Lastly, I would like to thank my parents, siblings, and my wife. Thanks to my younger brother, Liang Song, and younger sister, Qing Qing Song. They have been taking my share of care for my parents while I am far away in the USA. Thanks to my wife, Ran Zhang, for taking care of the house and raising of our son. I feel very blessed to have full support from my family members. 


\section{Table of Contents}

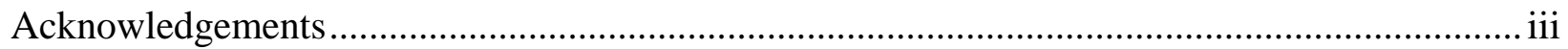

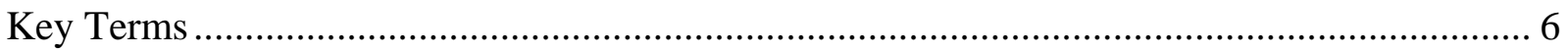

Modified games (MGs): ................................................................................................... 6

Small-sided games (SSGs): …………………………................................................ 7

Full-sided games (FSGs): .................................................................................................. 7

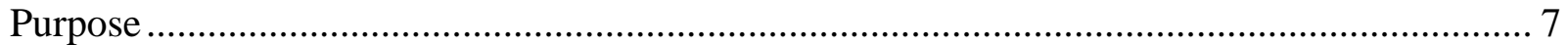

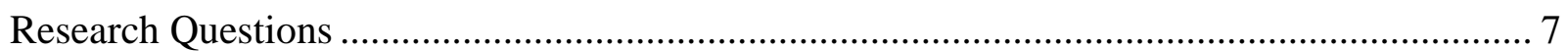

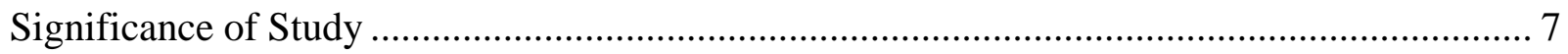

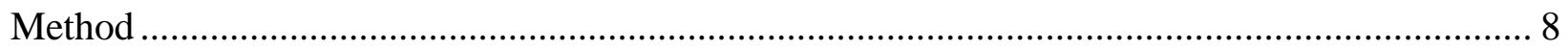

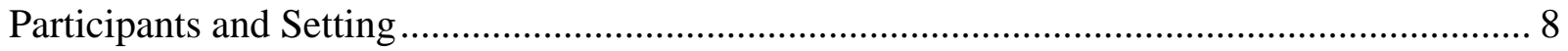

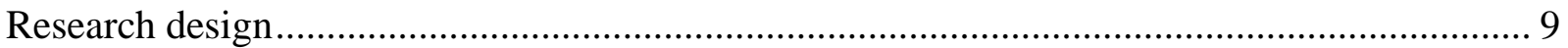

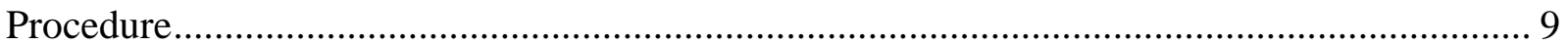

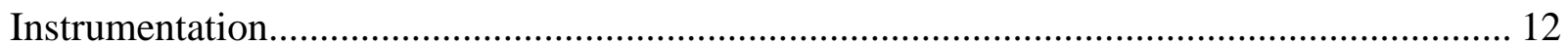

Physical activity data. ................................................................................................. 12

Intrinsic motivation inventory. ......................................................................................... 13

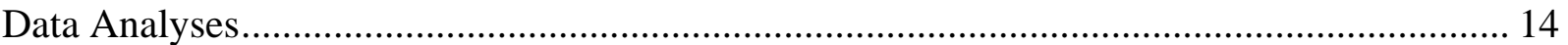

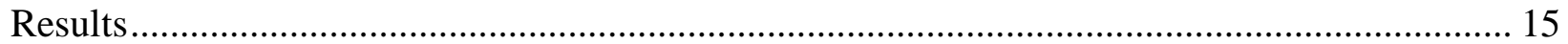

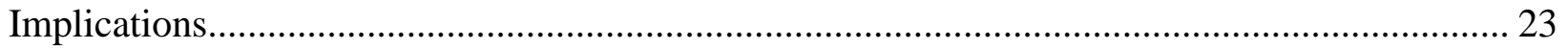

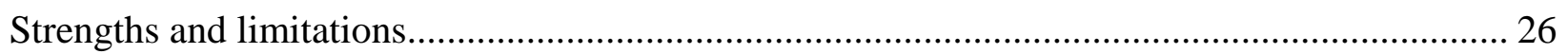

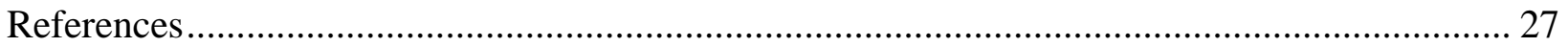

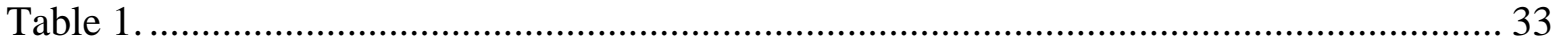

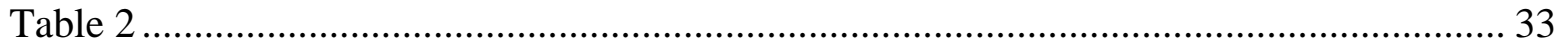

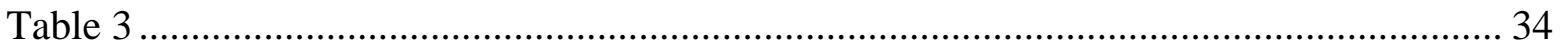

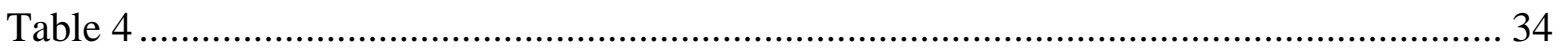

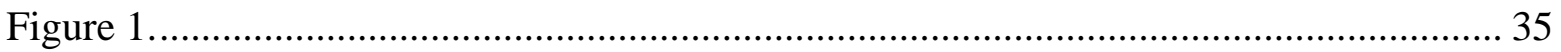

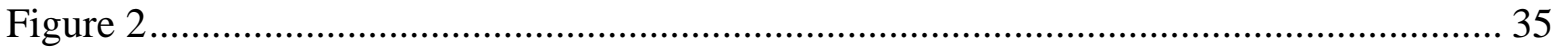

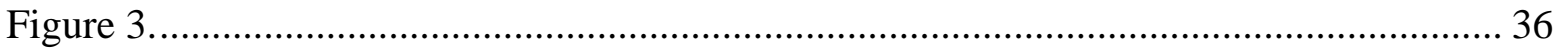

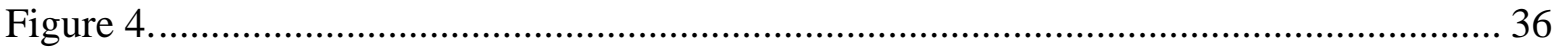

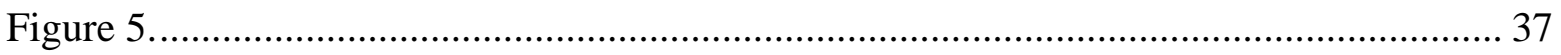

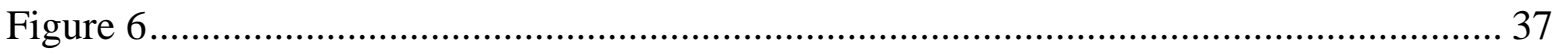

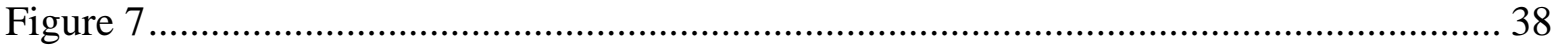

Appendix A: Extended Method ........................................................................................... 39 
Appendix B: Extended Review of Literature................................................................... 55

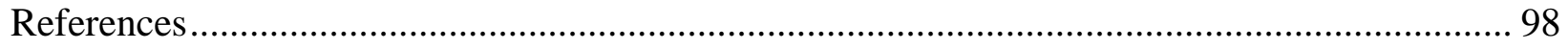

Appendix C: West Virginia University Informed Consent Form ......................................... 115

Appendix D:Intrinsic Motivation Inventory ................................................................ 117 
The Impact of Different Game Types and Sports on College Students’ Physical Activity and Motivation in Basic Instruction Program Settings

With the growing obesity epidemic, investigating students’ physical activity (PA) levels in physical education (PE) classes has become prevalent. One mode to potentially impact PA levels in PE classes is utilizing games as the main learning organizer, something which is advocated in many Game Centered Approaches (GCAs, Harvey \& Jarrett, 2014). Without a further overview of each of the GCAs, the common features of all GCAs according to Light (2013) are: (a) the design and manipulation of practice games and activities, (b) the use of questioning, (c) the provision of opportunities for dialogue, collective development and testing of solutions for tactical problems, and (d) building a supportive socio-moral environment. The advocators of Teaching Games for Understanding (TGfU, Bunker \& Thorpe, 1982), one of the most famous GCAs, provided PE practitioners with four guiding principles (Bunker \& Thorpe, 1986) — sampling (facilitating the integration of games with similar tactical possibilities), exaggeration (changing game structures to promote and exaggerate a particular aspect of a game), representation (small-sided games structured to suit the age and/or experience of the players), and tactical complexity (games should be taught sequentially from the least tactical complexity to the most tactical complexity) — to enable them to effectively shape games to fit the characteristics of students.

The most commonly used games in GCAs are modified games (MGs), small-sided games (SSGs), and full-sided games (FSGs). Researchers have documented the functions of using games in a variety of settings. For example, both MGs and SSGs are alternative training methods for traditional conditioning (e.g., Gabbett, 2002; Reilly \& White, 2005). Compared with FSGs, SSGs reduce complexity and increase the ratio of players' participation in decision-making, but, 
at the same time, preserve the basic variability aspects of the game. Moreover, SSGs are commonly utilized to maintain fitness (Gambel, 2004; Reilly \& White, 2005). MGs are also small-sided, but additionally comprise the principle of exaggeration to encourage students to focus on a particular aspect of the game, which subsequently encourages the links between specific techniques and tactics shaping student decision-making and associated skill execution. When students are introduced to a new game, they are usually encouraged to connect their possessed similar techniques and tactics to the new game. As a result, students can transfer old knowledge to new contexts while playing games. Contrast to the benefits of MGs and SSGs, researchers have demonstrated that frequent usage of FSGs would result in low moderate to vigorous physical activity (MVPA). For example, Roberts and Fairclough (2011) found that students were mostly inactive during class time. They believed that the overuse of FSGs (21\% of class time), compared to $4 \%$ class time of MGs, led to the low PA levels.

Researchers (e.g., Bell, Johnson, Shimon, \& Bale, 2013; Rampinini et al., 2007) investigated the effects of the number of players and pitch sizes on students'/players' physical activity (PA) levels. In general, these studies have demonstrated that game formats with fewer players elicit more PA levels than the game format with more players. For example, Rampinini et al. (2007) found that soccer players in a 3-a-side game could achieve 87-90\% heart rate (HR) max range, whereas, players in a 5-a-side game could only achieve 82-87 \% HR max range. Based on the findings of those studies, students are more active in MGs and SSGs than they are in FSGs. Moreover, studies found that SSGs will result in more opportunities to perform technical requirements (e.g., Bell, Johnson, Shimon, \& Bale, 2013; Platt, Maxwell, Horn, Williams, \& Reilly, 2001). For example, Bell et al. (2013) found that players on a 3 vs. 3 SSGs 
had more opportunities to perform skills such as passing, dribbling, and shooting than those on 5 vs. 5 SSGs

Healthy People (2020) provides the physical activity guidelines for adults in aerobic physical activity (at least 150 minutes/week at moderate intensity or 75 minutes/week at vigorous intensity) and in muscle-strengthening activity (two or more days a week). However, only about $20 \%$ of adults meet the guidelines for both aerobic and muscle-strengthening activity (Healthy People, 2020). With about 20 million students served in U.S. colleges and universities (American College Health Association, 2012), college/ university students, a major source of future generations of parents and policy-makers, should be a research targeted population for enhancing the proportion of adults achieving the Healthy People 2020 physical activity goals. Fortunately, most colleges/universities provide their students with physical activity opportunities in the form of a Basic Instruction Program (BIP) or Higher Education Physical Activity Program (HEPAP) (Stapleton, Taliaferro, \& Bulger, 2017). Moreover, it is crucial for adult learners to develop the appreciation for physical activity in BIPs or HEPAP because physical activity behaviors established during the college years will persist into adulthood (Sparling \& Snow, 2002). Researchers have also found that the lifestyles of adults affect the lifestyles of children. For example, Moore et al. (1991) found that children with active parents were about five times more active than those without active parents. The findings made it is vital to develop college students’ appreciation and participation in BIPs or HEPAP to achieve the Healthy People 2020 Physical Activity Guidelines for adults. However, this is not an easy task since adults are less active than children and adolescents are (Douglas, Collins, \& Warren, 1997).

Most GCA studies were utilized to investigate students PA levels during the entire PE class period, and few researchers examined the potential PA accumulations exclusively in game play 
periods. Moreover, most of those studies involved younger learners. It is recommended that k-12 students engage in moderate to vigorous physical activity (MVPA) levels for at least 50 percent of PE class time (IOM, 2013), even though findings were ambiguous as whether students are able to reach the 50\% MVPA (e.g., Miller et al., 2015; Van Acker et al.2010). The current study fills this gap by investigating college students’ MVPA when participating in different gametypes (i.e., MGs, SSGs, and FSGs) within two sports from two different game categories (i.e., badminton and soccer).

As for methods of collecting physical activity data, researchers have utilized self-report (Eston, Rowlands \& Ingledew, 1998), behavior observation instruments (Harvey et al., 2015), heart rate monitors (e.g., Van Acker et al., 2010; Yelling, 2000), pedometers (e.g., Hannon \& Ratliffe, 2005; Miller et al. 2015) and accelerometers (e.g., Arnett \& Lutz, 2003; Harvey et al., 2016) to investigate students'/players' PA levels in their studies. For the usage of devices to measure PA levels, Heyward and Gibson (2014) stated that accelerometers are the best devices to measure PA levels objectively because of their ability to monitor PA minute-by-minute, differentiate intensity levels, are feasible with people of all ages, are accurate with static and dynamic behaviors, and hold large amounts of data memory. They argued that heart rate monitors are most effective for measuring vigorous PA but less effective for moderate PA, which can be affected by other factors such as emotions, humidity, hydration, or temperature. Selfreport PA data usually over-report activity levels (Eston, Rowlands \& Ingledew, 1998). Pedometers only count steps and do not measure the intensity, duration or frequency of PA (Crouter, Schneider, Karabulut, \& Bassett, 2003). Given the advantages of accelerometers for collecting PA data, the author utilized them to collect data. 
Previous research (e.g., Carroll \& Loumidis, 2001) has demonstrated the strong correlations between students’ propensity to engage in physical activity in PE and their motivation. Understanding students' motivations for PE is helpful for teachers to adjust lessons to meet their needs, thus, enhance their motivation, and therefore PA levels. Self-determination theory (SDT; Deci \& Ryan, 1985) is a general psychology theory to explain human behaviors and it provides a valuable framework to understand students' motivation in PE. SDT assumes that when the three basic needs are met: autonomy (having choices), competence (abilities to control outcomes), and relatedness (involvement and connection with others), students are more likely to demonstrate higher levels of self-determined motivation, which would lead to positive intentions to participate in PE (e.g., Sun \& Chen, 2010).

SDT posits that behaviors are driven by both intrinsic motivations and extrinsic motivations. Intrinsic motivation refers to the engagement in a behavior for the sake of the behavior itself. Extrinsic motivation refers to the engagement in a behavior for the sake of other benefits. For example, when a boy chooses to play soccer, he is intrinsically motivated if he does so for the love of playing soccer, but he is extrinsically motivated if he treats playing soccer only as a way to get involved with his friends. The last motivation is amotivation, which means that a person is neither intrinsically nor extrinsically motivated. Based on SDT, the quality of motivation is on a continuum ranging from amotivation all the way up to intrinsic motivation. The core of SDT is the provisions to satisfy the three psychological needs and the progressions from amotivation, extrinsic motivation, to intrinsic motivation.

Many instruments have been designed to measure participants perceived levels of selfdetermined motivation related to a target activity in experimental psychology research. The Intrinsic Motivation Inventory (IMI, Ryan, 1982) is one such instrument. The original IMI 
includes six subscales. They are: (1) interest/enjoyment, (2) perceived competence, (3) effort, (4) value/usefulness, (5) pressure and tension, and (6) perceived choice. A seventh subscale, relatedness, was added subsequently. The IMI subscale items have been shown to be valid through factorial analysis studies (Deci \& Ryan, 2003). The authors of the current study only focused on the first three subscales. Some of the subscales were not selected since they did not fit the current study purposes. For example, students were assigned to play three games that were re-determined by the researchers, thus, the perceived choice subscale does not fit. The authors also did not put students in a situation where they would experience significant pressures during any of the games.

The current study will address college students’ MVPAs during game types (MGs, SSGs, and FSGs) in two sports (badminton and soccer). Badminton is one of the most popular sports in net/wall games, and soccer is one of the most popular sports in invasion games (Almond, 1986). Although Ainsworth et al. (2011) found that adults would get more MVPA from soccer than badminton. It is still necessary to investigate MVPA differences in the current study. First, Ainsworth and colleagues utilized subjective self-reported questionnaires to collect PA data. Second, the authors collected PA data only in regular games abiding by the official rules and court sizes rather than in the three different game types which may affect MVPAs differently.

\section{Key Terms}

For the purpose of the study, the definitions of the following terms are as they were in a previously published study (Roberts \& Fairclough, 2012).

Modified games (MGs): the class is engaged in a modified related game. Modification of the game includes rules (the ball or the projectile is not allowed over a certain distance, height), 
conditions and equipment (e.g. throw-catch badminton, using batting Ts, alternative scoring zones, rolling the ball instead of using hockey-sticks, throwing the ball instead of using a bat). The game reduces the dominance of skills and techniques. The numbers in the team must be equal for it to be considered a game (1 vs. 1, 2 vs.2, 3 vs. 3, 4 vs. 4) and not an overload practice (Roberts \& Fairclough, 2012, P.104).

Small-sided games (SSGs): the class is engaged in SSGs with no conditions. For example, a 3 vs. 3 cross-court game of basketball, which uses regulation size basketball hoops and there is no restriction on the skills and techniques, i.e. dribbling, lay-ups. A 6 vs. 6 small-sided soccer game with no conditions other than the numbers on the playing area (Roberts \& Fairclough, 2012, P.104).

Full-sided games (FSGs): the class is involved in a full version of the game including numbers and pitch/court size (Roberts \& Fairclough, 2012, P.104).

\section{Purpose}

The purpose of this study is to investigate college-aged students' PA levels and motivation in different game contexts (i.e., MGs, SSGs, and FSGs) and in different sports (badminton and soccer).

\section{Research Questions}

1. How do students' MVPAs differ in the different game contexts and sports?

2. How do students' motivation levels differ in different game contexts and sports?

3. To what extent do motivation levels predict PA levels?

\section{Significance of Study}


Even though researchers have conducted numerous studies concerning students’ PA or MVPA in GCAs interventions, to our knowledge, no studies have examined university students’ PA levels and motivations when they participate in different game contexts. Moreover, the MVPA was measured objectively and accurately by accelerometers across two sportsbadminton and soccer. The findings of this study will provide teachers with knowledge about the likely MVPAs derived from MGs, SSGs, and FSGs, and with knowledge about students’ motivations toward the different game forms.

\section{Participants and Setting}

\section{Method}

One hundred and twelve students from a rural mid-Atlantic University initially participated the study. Seventy-one students between the ages of 18 and 39 years old $(M=19.6, S D=3.1)$ completed MVPA data collection, and 67 of them finished the MVPA and IMI data collection. The students were from three soccer classes (40 males and 8 females) and two badminton classes (17 males and 6 females). The activity classes were general elective in nature. All the classes lasted five weeks and they were either in the format of three times a week (75 minutes a class) or twice a week (100 minutes a class). Before recruiting participants, the University Institutional Review Board (IRB) protocol was submitted and approved. All participants signed consent forms and received a data collection schedule. Students did not receive extra credit or penalties for choosing to participate or not participate the study. A Graduate Teaching Assistant (GTA) taught the three soccer classes. A different GTA taught the two badminton classes.

Based on G-Power 3.0.10 (Erdfelder, Faul, \& Buchner, 1996), the F tests- MANOVA: Repeated measures, within-between interaction, the effect size is 0.35 with total sample size of 
$67, p=.05$, power=0.8, number of groups of 5 (five classes), and repetitions of 3 (three types of games were played).

\section{Research design}

The study is a cross-sectional quasi-experimental design. It is cross-sectional design since both MVPA data and IMI data were collected from three soccer classes and two badminton classes in three-game type conditions: modified-games (MGs), small-sided games (SSGs), and full-sided games(FSGs). It is a quasi-experimental design because students chose the classes on their own, and, therefore, were not randomly assigned to the two- sport classifications.

Participants played the three game types in a fixed order. They played the MGs first, SSGs second, and FSGs third. Participants played each of the games for 15 minutes on three different days of class.

\section{Procedure}

No badminton classes were available for a pilot study, thus a pilot study was conducted only in soccer MGs and SSGs. However, the purpose of familiarizing the researchers with the data collection instruments was achieved. When it was the time for the formal study, the lead researcher held meetings with the two GTAs to inform them about the data collection schedules and the game formats. Moreover, the researcher stressed the importance to the two GTAs that researchers would not intervene in how they teach the classes except for embedding the three games on data collection days. GTAs of the university used the Sport Education model or a hybrid model of the Sport Education model and TGfU to teach activity classes (Meeteer, Housner, Bulger, Hawkins, \& Wiegand, 2012). Thus, using games in activity classes is a part of their already existing teaching repertoire. The request of having students play the three games on different days was a natural fit for the class schedule. Moreover, GTAs were required not to 
GAME TYPES ON PHYSICAL ACTIVITY AND MOTIVATION

10

provide any instructions, feedback, or encouragement when students were playing the games.

Researchers found that interactions between coaches with players would positively enhance players’ MVPA (e.g., Coutts et al., 2004; Hoff et al., 2002;). The non-interaction requirement would eliminate the influence.

Given the facts that GTAs spend most of the first class in administration duties, the researchers attended the second class to request the students' participation in the current study. After students received and signed consent forms, researchers collected necessary anthropometric data to assign accelerometers to them. The required data for programming accelerometers are gender, date of birth, weight (measured a bioimpedance scale OMRON HBF516B), height (measured by a portable stadiometer CHARDERHM-200P Portstad), dominant side, and race.

On the specific data collection days, GTAs asked participants to put on their accelerometers on the waist of the dominant side of their body at the beginning of the class. After the warm-up, GTAs introduced the game forms to students by explaining the games and having them play the game type (i.e., MGs, SSGs, and FSGs) for five minutes for familiarity purposes. Immediately after playing, GTAs provided opportunities for participants to ask questions about the games. GTAs taught contents in accordance with their planning for the rest of the class before having students play the official non-stop 15-minute games. To keep students playing the whole time, the GTAs granted students a two-minute water break right before the official gameplay. The researcher utilized a digital stopwatch to record the time. The researcher reminded the participants of the remaining game time at 10-minute, 5- minute, 3 - minute and 1-minute time points. 
GAME TYPES ON PHYSICAL ACTIVITY AND MOTIVATION

11

Participants in the badminton classes played the MGs and SSGs using half of the court with the middle line as one sideline and the doubles sideline as another sideline (white or grey part of Figure 1). The only difference between the badminton MGs and SSGs was that students were not allowed to utilize smashes in MGs, whereas, they were permitted to utilize all the skills they could perform in SSGs. Four students played the MGs and SSGs at the same time. In other words, two games happened simultaneously on a court. To reduce the time to retrieve shuttlecocks, three shuttlecocks were stood on the outer sidelines, but far away from the court, so as not to cause injury. Participants played a regulation full-court singles game as FSGs.

Participants in the soccer classes played the 6 vs. 6 MGs and 7 vs. 7 SSGs on a pitch size of 50 yards $\mathrm{x} 40$ yards (black or white half of Figure 2), which is the medium size of the recommend field size for US youth soccer 6 vs. 6 (US Youth Soccer, 2012). Another reason for choosing this size was the ability to have two MGs or SSGs arranged at the same time. In the soccer MGs, tall cones made up two small goals placed evenly on the sidelines. Each of the goals is six feet wide. In the SSGs, one regular size goal was placed in the center of each of the sideline. The main differences between MGs and SSGs in soccer were that no goalkeepers were present in MGs, but one goalkeeper defended a goal in SSGs. To keep 6 vs. 6 formats in both MGs and SSGs, even though it is 7 vs.7 in SSGs, researchers did not collect data from goalkeepers in the SSGs. Participants played the FSGs on a pitch size of 120 yards x 73 yards, which was the marked size on the field. Similar to placing extra shuttlecocks on the badminton sidelines, two soccer balls were placed evenly on each of the sidelines on the soccer field.

Immediately after playing each of the game forms, participants were provided with the IMI paper questionnaires and pencils to fill out the questionnaires, which were originally created by the Qualtrics system. The first author brought paper versions of the questionnaire to each of the 
GAME TYPES ON PHYSICAL ACTIVITY AND MOTIVATION

12

classes to avoid the situation where some students may not have been able to complete the questionnaire electronically. The first author collected the paper questionnaires, immediately transferring these paper versions of the IMI data to the Qualtrics system. After the initial data input, the researcher double-checked the accuracy of the transfer of paper records to the online system by exporting the each of the electronic datasets and double checking these against the initial paper records.

\section{Instrumentation}

Physical activity data. Actigraph GT3X triaxial accelerometers (validated by Kelly et al., 2013) were used to collect students’ PA data. On data collection days, accelerometers were placed in a clear bag that had the participants’ ID number written on the outside, which corresponded with the ID number of the accelerometer inside the bag. Immediately on entering the gymnasium, before the start of gameplay, all participants attached their accelerometers onto their waistbands with the assistance of members of the study team when needed. This procedure was pilot-tested with all classes in a previous lesson before the start of the study. Once the gameplay was completed, the devices were returned into the correct clear plastic bags, collected and placed into a box and taken back to the lead author's office. Here the devices were connected to a personal password-protected computer and the information downloaded via the Actigraph software.

The utilization of the Actigraph software permitted GT3X activity counts for each game at a 1-second epoch. Data were extracted by applying a filter with the specific times of the lesson, which had previously been noted during data collection. This enabled the mean percentage of time spent in MVPA to be calculated using the Troiano et al. (2008) cut-off points housed within the Actigraph software. The authors utilized objective data obtained with accelerometers from a 
GAME TYPES ON PHYSICAL ACTIVITY AND MOTIVATION

13

representative sample $(n=6329)$ of the U.S. population to determine the cut-off point for different levels for MVPA, and they found that the MVPA cut-off point for adults 18 years and older was 2020 counts per minute. Accelerometry MVPA data computed using these cut-off points were then exported from the Actigraph software to Microsoft Excel for subsequent data management before being imported into Version 21 of SPSS (SPSS Inc, Chicago, IL) for statistical analyses.

Intrinsic motivation inventory. The IMI is a multidimensional measurement instrument designed for assessing participants’ subjective experience related to a specific activity (e.g., Ryan, Mims, \& Koestner, 1983; Deci, Eghrari, Patrick, \& Leone, 1994). McAuley, Duncan, and Tammen (1989) validated the use of the IMI in PE settings. The original IMI includes six subscales, and include: (a) interest/enjoyment, (b) perceived competence, (c) effort, (d) value/usefulness, (e) pressure and tension, and (f) perceived choice. A seventh subscale, relatedness, was later added.

Data were collected on the scales of interest/enjoyment (7 items), perceived competence (6 items), and effort/importance (5 items). The IMI data were collected on a 7-point Likert scale ranging from 1 = "not true at all” to 7 = "very true”. There are two steps in scoring the IMI. First, items that were reverse scored were recoded. Second, subscale scores were calculated by averaging the scores across all the items on that subscale for each participant. The subscale scores were then used in the analyses of relevant questions. Reliability tests were conducted for each of the subscales, with results showing high reliability on each of the three sub-scales: interest/enjoyment ( $\alpha=.93)$, perceived/competence ( $\alpha=.94)$, effort/importance $(\alpha=.91)$. 
GAME TYPES ON PHYSICAL ACTIVITY AND MOTIVATION

14

\section{Data Analyses}

A two-way repeated measures ANOVA was utilized to test whether statistically significant MVPA differences existed among students from soccer classes and badminton classes (the main effect of sports on MVPA) and whether statistically significant MVPA differences existed among the three different game forms (the main effect of game forms on MVPA). The dependent variable was MVPA. The two independent variables were sports and game forms. Interactions between the sports and game forms are also reported if the interactions were statistically significant. Two separate one-way repeated measures ANOVA with Bonferroni correction ( $p$ $=.025)$ were also utilized to test whether MVPA differed in the three games forms for each sport (i.e., badminton and soccer).

A two-way repeated measures MANOVA was utilized to test whether statistically significant differences existed in the three IMI sub-scales between the two sports and the three different game forms. The dependent variables were the three IMI subscales (enjoyment, perceived competence, and effort), the two independent variables are sports and game forms. Statistically significant interactions were also reported.

Multiple regressions (where the grand mean centering technique was employed) were used to investigate the extent to which IMI scores and sports predicted MVPA, with one regression performed for each game form. The dependent variable was MVPA and the independent variables were IMI motivation (enjoyment/interest, perceived competence, and effort) and sports (badminton and soccer). All regressions tests were conducted in two steps. The first step (Model 1) was completed by entering only the sports variable (badminton or soccer) and the second step (Model 2) involved entering both the sports variable and the three motivation subscale variables 
GAME TYPES ON PHYSICAL ACTIVITY AND MOTIVATION

15

concurrently. With the addition of the motivation variables, the change of predicted variance of the dependent variables brought by the motivation data can be explained.

\section{Results}

In this section, results pertaining to each of the three different research questions will be reported.

Research question 1. How do students' MVPAs differ in the different game contexts and sports? Based on findings from a split plot ANOVA $(F(1,69)=29.1 ; p<.01)$, on average, students had statistically significant more MVPA in soccer $(\mathrm{M}=51.17$; $\mathrm{SD}=1.81)$ than they did in badminton $(\mathrm{M}=34.04 ; \mathrm{SD}=2.61)$ (Figure 3). Moreover, when data from the two sports were combined, students attained similar MVPA in the three-game forms (Figure 4). However, the interaction between game contexts and sports was statistically significant $(p<.05)$. For example, students in soccer classes attained the most MVPA in FSGs and the least MVPA in SSGs. In contrast, students in badminton classes attained the most MVPA in SSGs and the least MVPA in MGs (Figure 5).

Based on findings from a one-way repeated measures ANOVA, students in the badminton classes had similar MVPA in the three games $(F(2,44)=.461, p>.05)$. However, students in the soccer classes had similar MVPA in MGs and SSGs, but statistically significantly more MVPA in FSGs $(F(1.715,80.594)=10.60, p<.001)$ when compared to MGs and SSGs.

Research question 2. How do students' motivation levels differ in different game contexts and sports? Findings from the two-way repeated measures MANOVA, there were no statistically significant differences in motivation between the two sports (Table 1). For example, students from both classes viewed the games as interesting, with students scoring more than 5.2 points in the interest/enjoyment scale. Moreover, there were no statistically significant 
GAME TYPES ON PHYSICAL ACTIVITY AND MOTIVATION

16

differences in interest/enjoyment and perceived competence among the games. However, students perceived that they put statistically significantly more effort in SSGs and FSGs than that they did in MGs (Table 1).

Even though there were no statistically significant motivation differences between the two sports, the interaction patterns between the games and sports were statistically significant in the perceived competence subscale $(F(2,130)=4.3 ; p<.05)$. Students in badminton classes felt the most competent in SSGs games and the least competent in MGs. In contrast, students in soccer classes felt the most competent in MGs and the least competent in FSGs (Figure 6). In addition, the interaction between the games and sports was significant in terms of effort/importance $(F(2,130)=8.6 ; p<.01)$, with the interaction patterns the same as those seen in the perceived competence subscale. Students in badminton classes perceived they put the greatest effort into SSGs and least effort in MGs. Students in soccer classes perceived they put the greatest effort in MGs and least effort in FSGs (Figure 7).

Research question 3. To what extent do motivation levels predict PA levels?

Three multiple regressions were conducted to answer the research question with a regression for each of the game contexts (Table 2, Table 3, and Table 4). All the regressions were conducted with two steps. The first step was entering only the sports variable (badminton or soccer, Model 1) and the second step was entering both the sports variable and the three grandmean centered motivation variables at the same time (Model 2). The two-step entering helped detect the $R$ square change brought by the addition of the three motivation variables. Collinearity statistics Variance Inflation Factors (VIF) ranged from 1.03 to 2.46, which was below the multicollinearity criterion (10), thus all the variables were maintained for subsequent analysis. 
GAME TYPES ON PHYSICAL ACTIVITY AND MOTIVATION

17

In the regression models for MGs (Table 2), Sports is a statistically significant variable at $p=.01$ level, and it accounted for $20 \%$ of the variance of the dependent variable-MVPA. Based on the model, students in soccer classes had 17.63 units MVPA more than those in badminton classes (dummy coded as 0 ). When the three motivation variables were added into the model, the whole model accounted for $29 \%$ of the variance of the dependent variable. However, the addition of the motivation data did not make the change statistically significant. The interest/enjoyment variable was a statistically significant variable at a $p=.05$ level to predict MVPA. Based on the model, while holding all the other variables constant, every unit increase in interest/enjoyment would decrease 5.76 units MVPA.

In the regression models for SSGs (Table 3), Sports was a statistically significant variable $(p<.01)$, and it accounted for $12 \%$ of the variance of dependent variable-MVPA. Based on the model, students in soccer classes had 12.17 units MVPA more than those in badminton classes. When the three motivation variables were added into the model, the whole model accounted for $36 \%$ of the variance of the dependent variable. Moreover, the addition of the motivation variables made the change statistically significant at the $p=.01$ level. In the whole model (model 2), both the sports and perceived competence variables were statistically significant predictor variables $(p<.01)$. Based on the model, students in soccer classes had 16.12 units MVPA more than those in badminton classes. While holding all the other variables constant, every unit increase in the competence would increase 6.56 units of MVPA.

In the regression models for FSGs (Table 4), the patterns were similar with those in SSGs. Sports was a statistically significant variable $(p<.01)$ and it accounted for $37 \%$ of the variance of the dependent variable-MVPA. Students in soccer classes had 23.35 units MVPA more than those in badminton classes did. The whole model accounted for $44 \%$ of the variance of the 
GAME TYPES ON PHYSICAL ACTIVITY AND MOTIVATION

18

dependent variable. However, the addition of the variables did not make the change statistically significant. Both the sports $(p<.01)$ and perceived competence variables $(p<.05)$ were statistically significant predictor variables. Based on the model, students in soccer classes had 24.65 units MVPA more than those in badminton classes had. While holding all the other variables constant, every unit increase in perceived competence will increase 3.28 units of MVPA.

\section{Discussion}

The discussion will be in accordance with the sequence of the three research questions. They are the MVPA differences, motivation differences, and using motivation qualities to predict students MVPA in the different game types within each of the two sports.

Students in badminton classes had statistically significant less MVPA than those in soccer classes. The result aligns with previous studies (e.g., Ainsworth et al., 2011). The previous studies were conducted in regular games abiding by the official rules. Whereas, participants in the current study played the MGs, SSGs, and FSGs in each of the sports. Data showed that the different game formats did not change the overall MVPA pattern in badminton and soccer that players have more MVPA in soccer than they do in badminton. With similar motivation qualities (Table 1), the MVPA difference between the two sports is due to the different nature of the sports. For students at the beginning badminton level, they have difficulty keeping the rally long, and they need to retrieve shuttlecocks when the shuttlecocks land. Moreover, students play the games at a relatively slow pace, and they have to wait for the return of shuttlecocks to continue to play. The time to frequently retrieve and wait for the return of shuttlecocks restrict students from having higher MVPA. However, students at the beginning soccer level can keep moving 
GAME TYPES ON PHYSICAL ACTIVITY AND MOTIVATION

19

most of the time either for defensively guiding opponents or for offensively tracing the ball.

They do need to retrieve the balls, but at a much lower frequency.

The MVPA results demonstrated that the college students in badminton classes fell short of having more than 50\% MVPA during gameplay even though the counterparts in soccer classes barely achieved the goal (see Figure 1). The findings were not commensurate with previous studies (e.g., Arnett, 2001; Van Acker et al., 2010) where students’ MVPA was greater than this recommendation (about 60\% MVPA). Moreover, the participants in the two previous studies accumulated those high MVPAs from the whole class time. However, the college students in the study had their MVPA in gameplay context when they played each of the three games for a continuous 15 minutes. The MVPA that the college students had in the current study was much lower than the MVPA collected during gameplays (e.g., McCormick et al., 2012; Slingerland et al., 2014). For example, Slingerland et al. (2014) found that boys achieved 74\% MVPA and girls achieved 64\% MVPA during twenty-five-minute small-sided basketball games.

Compared with MVPA findings in other studies, the relatively lower MVPA in the current study may contribute to several differences. First, Van Acker et al. (2010) and Slingerland et al. (2014) collected MVPA data by heart rate monitors, whereas the data for the current study were collected by accelerometers, which have been suggested to be more accurate devices for measuring MVPA (e.g., Heyward \& Gibson, 2014). Second, the participants of the two studies were middle school students, whereas the participants in the current study were college students. It is not clear whether the age differences lead to the MVPA differences. After all, adult learners are less active than younger leaners (e.g., Douglas et al., 1997; Grunbaum et al., 2002). To some extent, the fact that students in the badminton classes shared the court with others while playing the MGs and SSGs may also contribute to the lower MVPA. For example, when a male student 
GAME TYPES ON PHYSICAL ACTIVITY AND MOTIVATION

20

was about to return a shuttlecock on his right side of the court, he may stop trying when he saw her (the other player sharing the same-side court) was trying to return the shuttlecock on her left side of the court.

The MVPA attained in the three badminton classes were not significantly different. This suggests that PE teachers can utilize a mixture of MGs, SSGs and/or FSGs when teaching badminton without compromising MVPA. However, it is necessary to point out that badminton students demonstrated the statistically significant better quality of perceived competence and effort/importance in SSGs than they did in MGs and FSGs. When combining both MVPA and motivation data, SSGs are the best game formats for badminton classes.

Contrary to the findings by Mallo and Navarro (2008) that students would get significant PA levels when no goalkeepers presented, the university students in the soccer classes had similar MVPA in MGs where no goalkeepers were used as they had in SSGs where goalkeepers were employed. Additionally, and contrary to previous findings in invasion games with middle school students (e.g., Roberts \& Fairclough, 2011), the university students in the soccer classes had the highest MVPA in FSGs. However, they also reported the lowest motivation quality in FSGs.

In terms of motivation data, students from badminton classes and soccer classes shared a similar quality of interest/enjoyment, perceived competence, and effort and importance when the data were aggregated across the three game contexts. It is interesting to find that students demonstrated similar interaction patterns between games and sports in the perceived competence and effort/importance subscales. In other words, perceived competence and effort/importance are highly associated. For example, students from badminton felt the most competent in SSGs and 
GAME TYPES ON PHYSICAL ACTIVITY AND MOTIVATION

21

they made the greatest effort in SSGs. They felt the least competent in MGs and they made the least effort in MGs.

Even though students played the MGs and SSGs on the same sized court, the rules of the MGs prevented students from using smash shots, whereas, in SSGs, students were permitted to use all techniques and tactics. In addition, by the time when students played the MGs, the teacher had not taught the smashes yet, thus it was reasonable to design the MGs without smashes. To have students understand the MGs and to have them more involved, the PE teacher needs to emphasize why the specific MGs are necessary and beneficial for the development of techniques and tactics when they firstly introduce MGs (e.g., Alfieri, Brooks, Aldrich, \& Tenenbaum, 2011). With the stipulations of the importance of MGs, students are more likely to see the objective of the MGs. A good example of using MGs to emphasize the usage of clears and drop shots in badminton is when the teacher can explicitly state the focus of the MGs is for the students to use clears to move their opponents to the deep corners of the court and subsequently follow this shot with a drop shot to the front of the court near the net. The purpose of the badminton MGs is to, therefore, find the correct moments to employ drop shots after the clear.

Students in the badminton classes reported less quality of perceived competence and effort/importance in FSGs. Based on the first author's previous BIP teaching experience, most students were beginners. It was probably the same case for those students in the badminton classes. Even though they felt the most comfortable in SSGs, they were likely to find it was much harder to utilize the techniques and tactics in FSGs with an almost doubled-size playing area. In FSGs, students may find it was harder to place the shuttlecocks accurately on areas close to the sidelines without over hitting the shuttlecocks or they may feel much harder to defend their spaces without missing the coming shuttlecocks. 
GAME TYPES ON PHYSICAL ACTIVITY AND MOTIVATION

22

Students from soccer classes reported the highest score in perceived competence and effort/importance in MGs where two goals were placed and no goalkeepers existed. Even though no studies were found about the impact of one extra goal on students' playing behaviors, students were expected to get more involved with the presence of two goals. They could play more offensively and found it was easier to score. When students scored more points, they felt that they were capable, and they would try harder to score. That was why perceived competence data aligned well with effort/perceived competence.

Data showed that students in the soccer classes felt the least competent and perceived they put in the least effort in FSGs even though they had the most MVPA in FSGs. Werner, Bunker, and Thorpe (1996) emphasized that games should be taught sequentially from the least tactical complexity (target games) to the most tactical complexity (invasion games). As one of the most popular invasion games, soccer, is one of the most complicated sports in the world (Almond, 1986). Players need to keep running to track the ball and other players to set up offense opportunities or defense strategies. Players with the ball also need to keep dribbling it at high speed or use skilled footwork to avoid being tackled by defense players. This was probably the case for the students in the soccer classes when they played the game on a 120 yards x 73 yards pitch size, which is on the bigger side for a recommended full-size soccer pitch. The game was set at this size because there were markers signifying the size of the full-size pitch on the specific field that was used.

It is interesting that students in the soccer classes reported the least scores in the perceived competence and effort/import scales, but they had the most MVPA in FSGs. Due to the size of the FSGs field, students had longer distance sprints on the field to chase opponents defensively and chase the ball offensively. That was why they had more MVPA. At the same time, the field 
GAME TYPES ON PHYSICAL ACTIVITY AND MOTIVATION

23

was so large that they found it was much harder to use skills competently and why they presented lower quality of motivation data.

As for the multiple regressions, it is not surprising to find that sports is a statistically significant predictor of MVPA in all the models because students in soccer classes had statistically significant more MVPA than those in badminton classes. After adding the motivation data to the model, the full model did explain more variance of the dependent variable. However, the change of explained variance of the dependent variable was only statistically significant in the SSGs. In the SSGs and FSGs, perceived competence was a statistically significant predictor of MVPA. In other words, students who perceived themselves as more competent in both the SSGs and FSGs were likely to possess greater MVPA.

From a motivation perspective, having students feel competent is the key to enhancing their MVPA. Given the characteristics of students such as current levels of technique and tactical development, gender, social compatibility, and ethnicity, PE teachers should make continuous modifications to accommodate those characteristics. When students make progress, the games should be harder. When students struggle, the games should be easier. Constant adjustment is the key. For example, Van Acker et al. (2010) utilized the same-gender defense rules in their units, and they believed this rule contributed to the girls 'higher MVPA. The same-gender defense may also work for other games like basketball, soccer, and hockey.

\section{Implications}

To our knowledge, no studies have investigated college students’ MVPA and motivation for different sports and different game contexts systematically. The current study helps teachers develop an increased understanding of the potential influences of sport and game types on 
GAME TYPES ON PHYSICAL ACTIVITY AND MOTIVATION

24

students' MVPA and their motivations. Thus, teachers can accordingly adjust the use of the three game formats to balance students' MVPA and motivations. Conflicting with previous findings that students had low MVPA when FSGs were utilized the most, students in soccer classes had the most MVPA in FSGs. Researchers found that adult learners were less active than younger learners (e.g., Douglas et al., 1997; Grunbaum et al., 2002). With the participants in the previous studies middle-school students (e.g., Roberts \& Fairclough, 2011) and the participants in the current studies adult learners, it is not clear whether the MVPA difference is caused by the age disparity.

The three IMI motivation subscales are utilized to predict students' MVPA. It is surprising to find that interest/importance is a statistically significant negative predictor of MVPA in MGs and a negative predictor in SSGs and FSGs. Since the overall reported scores for the interest/enjoyment were over 5.2 out of 7, the assumption for this situation is that students who had less MVPA also viewed the games were interesting. Further studies are needed to verify this claim. Effort/importance is not a statistically significant predictor in all the three-game forms. However, perceived competence is a statistically significant predictor of MVPA in both SSGs and FSGs. A student with higher perceived competence is predicted to gain greater MVPA. Moreover, a student reported higher perceived competence are likely to pay greater effort to play the games.

Even though students in soccer classes attained the most MVPA in FSGs, it does not mean that PE teachers should mainly utilize FSGs as the main learning organizer for soccer, after all, the students also demonstrated the lowest motivation qualities across all subscales in FSGs. The principle of exaggeration (i.e., Bunker \& Thorpe, 1986) rationalized the utilization of MGs, which stated that changing game structures, such as rules, equipment, and play space, to promote 
GAME TYPES ON PHYSICAL ACTIVITY AND MOTIVATION

25

and exaggerate a particular aspect of a game. The principle of representation (i.e., Bunker \& Thorpe, 1986) provided the theoretic support for using SSGs, which stated that SSGs structured to suit the age and/or experience of the players. The SSGs are developed that contain the same tactical structures of the adult game but are played with adaptations to suit players’ characteristics. We must realize that PE classes are not only about MVPA, they are also about motivation. Even though students in the soccer classes had the most MVPA in FSGs, they also reported the lowest motivation qualities at the perceived competence and effort/importance. Thus, we should refute the idea that PE teachers should mainly use FSGs as the main learning organizer. It is clearer to refute the idea when it comes to badminton classes, given the fact that students in badminton had the best MVPA (even though not statistically significant) and the best motivation qualities in the perceived competence and effort/importance subscales in SSGs instead of FSGs. Even though students may not have the most MVPA in MGs and SSGs, they could perform more technique requirements in MGs and SSGs when the pitches were reduced (Bell et al., 2013; Platt et al., 2001).

The key findings of the study were that PE teachers should find the most parsimonious balance between MVPA and motivation. Specifically, finding the most appropriate field/court size for MGs and SSGs is one of the key factors in increasing student MVPA and motivation. PE teachers should actively observe students’ playing, realize their characteristics, and thus adjust games to ensure they meet the developmental needs to their students. In terms of this current study, the instructors could enlarge the soccer MGs and SSGs pitch size from 50 yards x 40 yards to 60 yards x 50 yards to assist students in increasing their MVPA quality of motivation than in original FSGs. 
GAME TYPES ON PHYSICAL ACTIVITY AND MOTIVATION

26

\section{Strengths and limitations}

The current study possesses several strengths. First, accelerometers were utilized to objectively measure MVPA. Second, the quasi-experimental design enables the researchers to conduct the study in a non-interference and natural teaching and learning environment. Finally, the researchers systematically investigated the MVPA and motivation not only in different game formats but also in two sports from different game categories.

There are several limitations in the study. First, there is a relative lack of GCA literature concerning adult learners. The literature of the current study mainly come from studies with younger participants. Further research with adult learners is needed to further confirm the results of the study. Second, the badminton and soccer classes were general elective classes, and there were no levels of skill differentiation in any of the classes studied. Therefore, it may have been possible there were more intermediate players in one class than in another class. Gender effects were not examined even though the ratio of genders were almost equal since 6 of 23 in the badminton classes were females and 8 of 48 in the soccer classes were female. Third, no student learning data were included. It is best to include authentic assessment data to show that students learned in addition to the gaining of MVPA. Finally, due to the quasi-experimental design, we did not manipulate the game sequence, which was fixed in the order of MGs-SSGs-FSGs. 
GAME TYPES ON PHYSICAL ACTIVITY AND MOTIVATION

27

\section{References}

Ainsworth, B. E., Haskell, W. L., Herrmann, S. D., Meckes, N., Bassett Jr, D. R., Tudor-Locke, C., ... \& Leon, A. S. (2011). 2011 Compendium of physical activities: a second update of codes and MET values. Medicine and Science in Sports and Exercise, 43(8), 1575-1581.

Alfieri, L., Brooks, P. J., Aldrich, N. J., \& Tenenbaum, H. R. (2011). Does discovery-based instruction enhance learning?.American Psychological Association, 103(1), 1-18

Almond, L. (1986). Reflecting on themes: A games classification. Rethinking games teaching. (D. Bunker, R. Thorpe, \& L. Almond, Eds.). England: University of Technology, Loughborough, Department of Physical Education and Sports Science.

American College Health Association. (2012, June). Healthy Campus 2020. Retrieved from http://www.acha.org/HealthyCampus/index.cfm

Arnett, M. G. (2001). The effect of sport-based physical education lessons on physical activity. Physical Educator, 58(3), 158-167.

Bell, K., Johnson, T. G., Shimon, J., \& Bale, J. (2013). The effects of game size on the physical activity levels and ball touches of elementary school children in physical education. Journal of Kinesiology and Wellness. 1, 1-5

Bunker, D., \& Thorpe, R. (1982). A model for the teaching of games in secondary schools. Bulletin of Physical Education, 18(1), 5-8.

Bunker, D., \& Thorpe, R. (1986).The curriculum mode. Rethinking games teaching. (R. Thorpe, D. Bunker, \& L. Almond, Eds.). Loughborough, UK: University of Technology, Department of Physical Education and Sports Science. 
GAME TYPES ON PHYSICAL ACTIVITY AND MOTIVATION

28

Carroll, B., \& Loumidis, J. (2001). Children’s perceived competence and enjoyment in physical education and physical activity outside of school. European Physical Education Review, 7(1), 24-43.

Coutts AJ. Murphy AJ. Dascombe BJ. (2004). The effect of direct supervision of a strength coach on measures of muscular strength and power in young rugby league players. The Journal of Strength and Conditioning Research, 18(2), 157-164.

Crouter, S. E., Schneider, P. L., Karabulut, M., \& Bassett Jr, D. R. (2003). Validity of ten electronic pedometers for measuring steps, distance, and kcals. Medicine and Science in Sports and Exercise, 35(5), 283-288

Deci, E. L., Eghrari, H., Patrick, B. C., \& Leone, D. R. (1994). Facilitating internalization: The self-determination theory perspective. Journal of Personality, 62(1), 119-142

Deci, E. L., \& Ryan, R. M. (1985). The general causality orientations scale: Self-determination in personality. Journal of Research in Personality, 19(2), 109-134.

Deci, E. L., \& Ryan, R. M. (2003). Intrinsic motivation inventory. Self-determination theory. 267

Douglas, K. A., Collins, J. L., Warren, C., Kann, L., Gold, R., Clayton, S., ... \& Kolbe, L. J. (1997). Results from the 1995 national college health risk behavior survey. Journal of American College Health, 46(2), 55-67.

Eston, R. G., Rowlands, A. V., \& Ingledew, D. K. (1998). Validity of heart rate, pedometry, and accelerometry for predicting the energy cost of children's activities. Journal of Applied Physiology, 84(1), 362-371.

Erdfelder, E., Faul, F., \& Buchner, A. (1996). GPOWER: A general power analysis program. Behavior Research Methods, Instruments, and Computers, 28(1), 1-11. 
GAME TYPES ON PHYSICAL ACTIVITY AND MOTIVATION

29

Gabbett, T. J. (2002). Training injuries in rugby league: an evaluation of skill-based conditioning games. The Journal of Strength and Conditioning Research, 16(2), 236-241.

Grunbaum, J. A., Kann, L., Kinchen, S. A., Williams, B., Ross, J. G., Lowry, R., \& Kolbe, L. (2002). Youth risk behavior surveillance-United States, 2001. Journal of School Health, 72(8), 313-328.

Hannon, J. C., \& Ratliffe, T. (2005). Physical activity levels in coeducational and singlegender high school physical education settings. Journal of Teaching in Physical Education, 24(2), 149-164.

Harvey, S., \& Jarrett, K. (2014). A review of the game-centered approaches to teaching and coaching literature since 2006. Physical Education and Sport Pedagogy, 19(3), 278-300.

Harvey, S., Smith, M. L., Song, Y., Robertson, D., Brown, R., \& Smith, L. R. (2016). Gender and School-Level Differences in Students’ Moderate and Vigorous Physical Activity Levels When Taught Basketball Through the Tactical Games Model. Journal of Teaching in Physical Education, 35(4), 349-357.

Harvey, S., Song, Y., Baek, J. H., \& van der Mars, H. (2015). Two sides of the same coin: Student physical activity levels during a game-centered soccer unit. European Physical Education Review, 22(4), 411-429

Healthy People 2020. Retrieved from https://www.healthypeople.gov/2020/topicsobjectives/topic/physical-activity

Heyward, V. H., \& Gibson, A. (2014). Advanced fitness assessment and exercise prescription 7th edition. In A.N. Tocco; K.Matz; \& S.Huls (Eds), Using technology to promote physical activity (pp.63-68).Champaign, IL: Human kinetics. 
GAME TYPES ON PHYSICAL ACTIVITY AND MOTIVATION

30

Institute of Medicine. (2013). Educating the student body: Taking physical activity and physical education to school. In H.W.Kohl III \& H.D. Cook (Eds.), Status and trends of physical activity behaviors and related school policies (pp.32-65). Washington, D.C. The National Academies Press

Mallo, J., \& Navarro, E. (2008). Physical load imposed on soccer players during small-sided training games. Journal of Sports Medicine and Physical Fitness, 48(2), 166-171.

McAuley, E., Duncan, T., \& Tammen, V. V. (1989). Psychometric properties of the Intrinsic Motivation Inventory in a competitive sport setting: A confirmatory factor analysis. Research Quarterly for Exercise and Sport, 60(1), 48-58.

Meeteer, W., Housner, L., Bulger, S., Hawkins, A., \& Wiegand, R. (2012). Applying Sport Education in university basic instruction courses. In P. Hastie (Eds.), Sport Education international perspectives (pp.58-72). New York, NY: Routledge

Miller, A., Christensen, E. M., Eather, N., Sproule, J., Annis-Brown, L., \& Lubans, D. R. (2015). The PLUNGE randomized controlled trial: Evaluation of a games-based physical activity professional learning program in primary school physical education. Preventive Medicine, 74, 1-8.

Moore, L. L., Lombardi, D. A., White, M. J., Campbell, J. L., Oliveria, S. A., \& Ellison, R. C. (1991). Influence of parents' physical activity levels on activity levels of young children. The Journal of pediatrics, 118(2), 215-219.

Platt, D., Maxwell, A., Horn, R., Williams, M., \& Reilly, T. (2001). Physiological and technical analysis of 3 vs. 3 and 5 vs. 5 youth football matches. Insight, 4(4), 23-24. 
GAME TYPES ON PHYSICAL ACTIVITY AND MOTIVATION

31

Rampinini E. Impellizzeri FM. Castagna C. Abt G. Chamari K. Sassi A. Marcora SM. (2007).

Factors influencing physiological responses to small-sided soccer games. Journal of Sports Sciences, 25(6), 659-666.

Reilly, T., \& White, C. (2005). Small-sided games as an alternative to interval training for soccer players. Science and football V, 355-358

Ryan, R. M. (1982). Control and information in the intrapersonal sphere: An extension of cognitive evaluation theory. Journal of Personality and Social Psychology, 43(3), 450462.

Roberts, S., \&Fairclough, S. (2011). Observational analysis of student activity modes, lesson contexts and teacher interactions during games classes in high school (11-16 years) physical education. European Physical Education Review, 17(2), 255-268.

Sparling, P. B., \& Snow, T. K. (2002). Physical activity patterns in recent college alumni. Research Quarterly for Exercise \& Sport, 73, 200-205. doi:10.1080/02701367.2002.10609009

Stapleton, D. T., Taliaferro, A. R., \& Bulger, S. M. (2017). Teaching an old dog new tricks: Past, present, and future priorities for higher education physical activity programs. Quest, 1-18.

Sun, H., \& Chen, A. (2010). A pedagogical understanding of the self-determination theory in physical education. Quest, 62(4), 364-384.

Van Acker, R., Carreiro da Costa, F., De Bourdeaudhuij, I., Cardon, G., \& Haerens, L. (2010). Sex equity and physical activity levels in coeducational physical education: exploring the potential of modified game forms. Physical Education and Sport Pedagogy, 15(2), 159173. 


\section{GAME TYPES ON PHYSICAL ACTIVITY AND MOTIVATION}

32

Werner, P., Thorpe, R., \& Bunker, D. (1996). Teaching games for understanding: Evolution of a model. Journal of Physical Education, Recreation and Dance, 67(1), 28-33.

Yelling, M., Penney, D., \& Swaine, I. L. (2000). Physical activity in physical education: A case study investigation. European Journal of Physical Education, 5(1), 45-66. 
GAME TYPES ON PHYSICAL ACTIVITY AND MOTIVATION

33

Table 1.

Motivation Data in Different Sports and Different Game Contexts

\begin{tabular}{|c|c|c|c|c|c|c|c|c|c|c|}
\hline \multirow[b]{3}{*}{ Motivation } & \multicolumn{4}{|c|}{ Sports } & \multicolumn{6}{|c|}{ Game Contexts } \\
\hline & \multicolumn{2}{|c|}{ Badminton } & \multicolumn{2}{|c|}{ Soccer } & \multicolumn{2}{|c|}{ MGs } & \multicolumn{2}{|c|}{ SSGs } & \multicolumn{2}{|c|}{ FSGs } \\
\hline & Mean & SD & Mean & SD & Mean & $\mathrm{SD}$ & Mean & SD & Mean & $\mathrm{SD}$ \\
\hline Interest & 5.40 & .20 & 5.21 & .14 & 5.26 & 1.13 & 5.39 & 1.12 & 5.16 & 1.28 \\
\hline Competence & 5.01 & .25 & 4.74 & .17 & 4.83 & 1.18 & 4.97 & 1.31 & 4.69 & 1.48 \\
\hline Effort & 4.61 & .22 & 4.90 & .15 & 4.50 & 1.17 & $4.91 *$ & 1.28 & 4.81 & 1.31 \\
\hline
\end{tabular}

Note: ${ }^{*} p<.05$

Table 2

Summary of Hierarchical Regression Analysis for Variables Predicting MVPA in MGs (N = 67)

\begin{tabular}{lcccccc}
\hline & \multicolumn{3}{c}{ Model 1 } & \multicolumn{3}{c}{ Model 2 } \\
\cline { 2 - 6 } Variable & $B$ & SE B & $\beta$ & $B$ & SE B & $\beta$ \\
\cline { 2 - 6 } Constant & 32.93 & 3.58 & 38.11 & 4.24 & \\
Sports & 17.63 & 4.32 & $.45^{* *}$ & 10.06 & 5.49 & .26 \\
Interest/Enjoyment & & & -5.76 & 2.45 & $-.36^{*}$ \\
Competence & & & 2.49 & 1.84 & .16 \\
Effort & & & 4.21 & 2.62 & .27 \\
$R^{2}$ & & & & .29 & \\
$F$ for change in $R^{2}$ & & $16.66^{* *}$ & & 2.36 & \\
\hline
\end{tabular}


GAME TYPES ON PHYSICAL ACTIVITY AND MOTIVATION

34

Table 3

Summary of Hierarchical Regression Analysis for Variables Predicting MVPA in SSGs $(N=67)$

\begin{tabular}{lcccccc}
\hline & \multicolumn{3}{c}{ Model 1 } & \multicolumn{3}{c}{ Model 2 } \\
\cline { 2 - 6 } Variable & $B$ & SE B & $\beta$ & $B$ & SE B & $\beta$ \\
\hline Constant & 35.05 & 3.37 & & 32.36 & 3.00 & \\
Sports & 12.17 & 4.06 & $.35^{* *}$ & 16.12 & 3.66 & $.46^{* *}$ \\
Interest/Enjoyment & & & -1.05 & 2.06 & -.07 \\
Competence & & & 6.56 & 1.44 & $.53^{*}$ \\
Effort & & & -.35 & 1.86 & -.27 \\
$R^{2}$ & & & & .36 & \\
$F$ for change in $R^{2}$ & & $8.98^{* *}$ & & & & \\
\hline
\end{tabular}

Table 4

Summary of Hierarchical Regression Analysis for Variables Predicting MVPA in FSGs ( $N=$ 67)

\begin{tabular}{lcccccc}
\hline & \multicolumn{3}{c}{ Model 1 } & \multicolumn{3}{c}{ Model 2 } \\
\cline { 2 - 7 } Variable & $B$ & SE B & $\beta$ & $B$ & SE B & $\beta$ \\
\cline { 2 - 7 } Constant & 33.70 & 3.15 & 32.82 & 3.08 & \\
Sports & 23.35 & 3.81 & $.61^{* *}$ & 24.65 & 3.73 & $.64^{* *}$ \\
Interest/Enjoyment & & & & -1.29 & 1.88 & -.09 \\
Competence & & & 3.28 & 1.47 & $.27^{*}$ \\
Effort & & & .93 & 1.77 & -.07 \\
$R^{2}$ & & & & .44 & \\
$F$ for change in $R^{2}$ & & $37.6^{*}$ & & & 2.48 & \\
\hline
\end{tabular}

Note for the three tables. Sports was represented as one dummy variable with badminton serving as the reference group; Interest, competence, and effort were centered at their means; ${ }^{*} p<.05 .{ }^{* *} p<.01$. 
GAME TYPES ON PHYSICAL ACTIVITY AND MOTIVATION

35

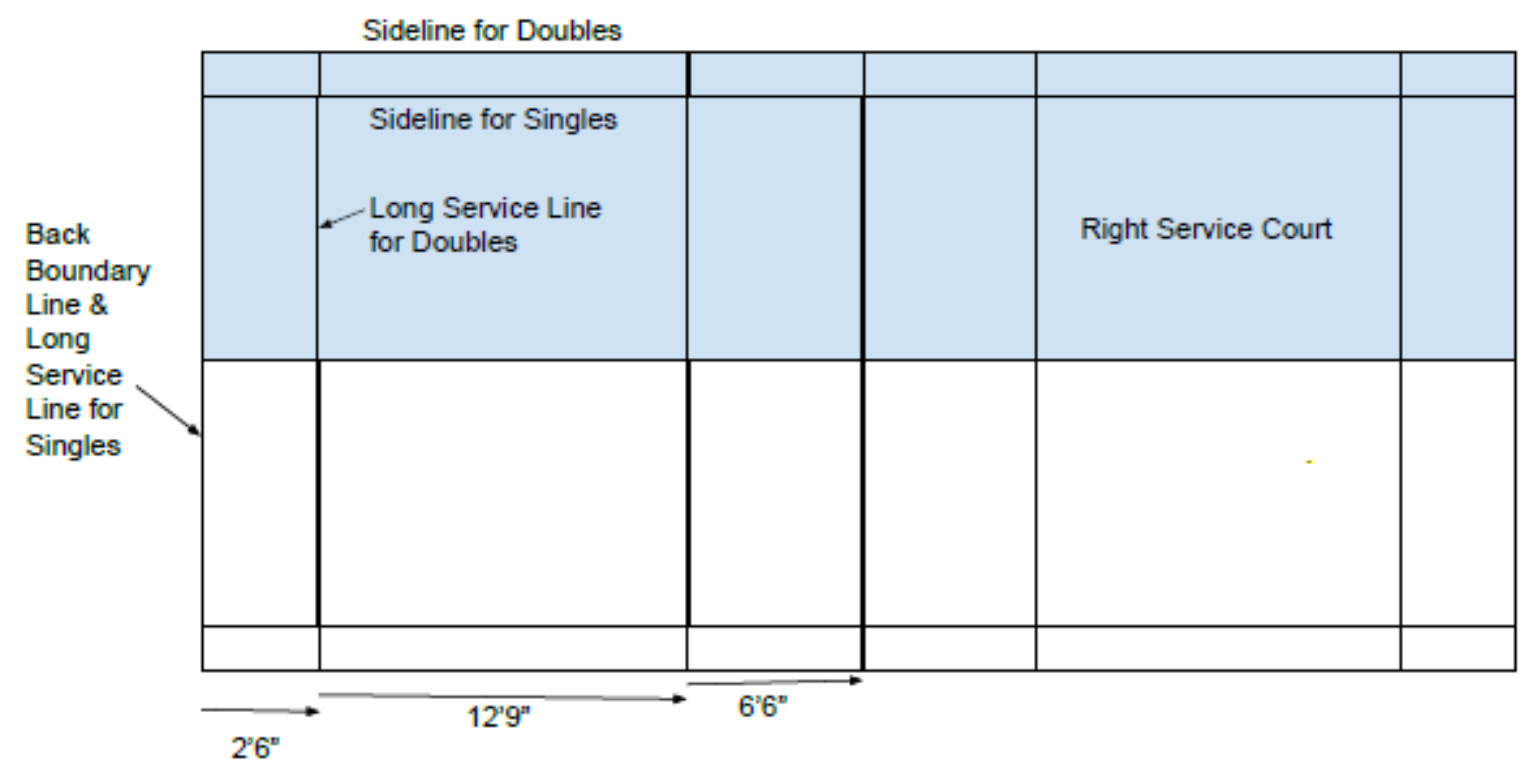

Figure 1. Badminton MSGs, SSGs, and FSGs

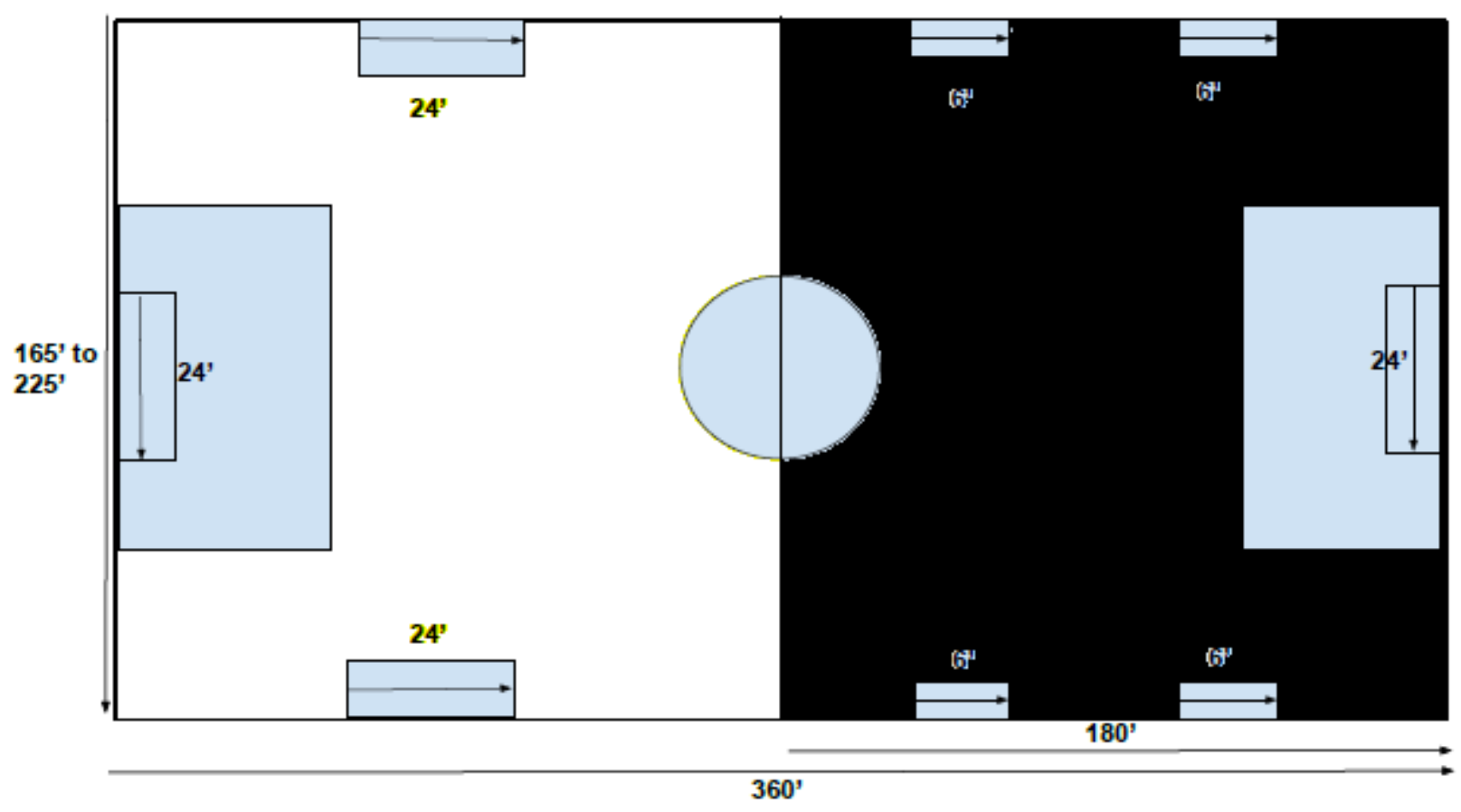

Figure 2. Soccer MSGs, SSGs, and FSGs 
GAME TYPES ON PHYSICAL ACTIVITY AND MOTIVATION

36

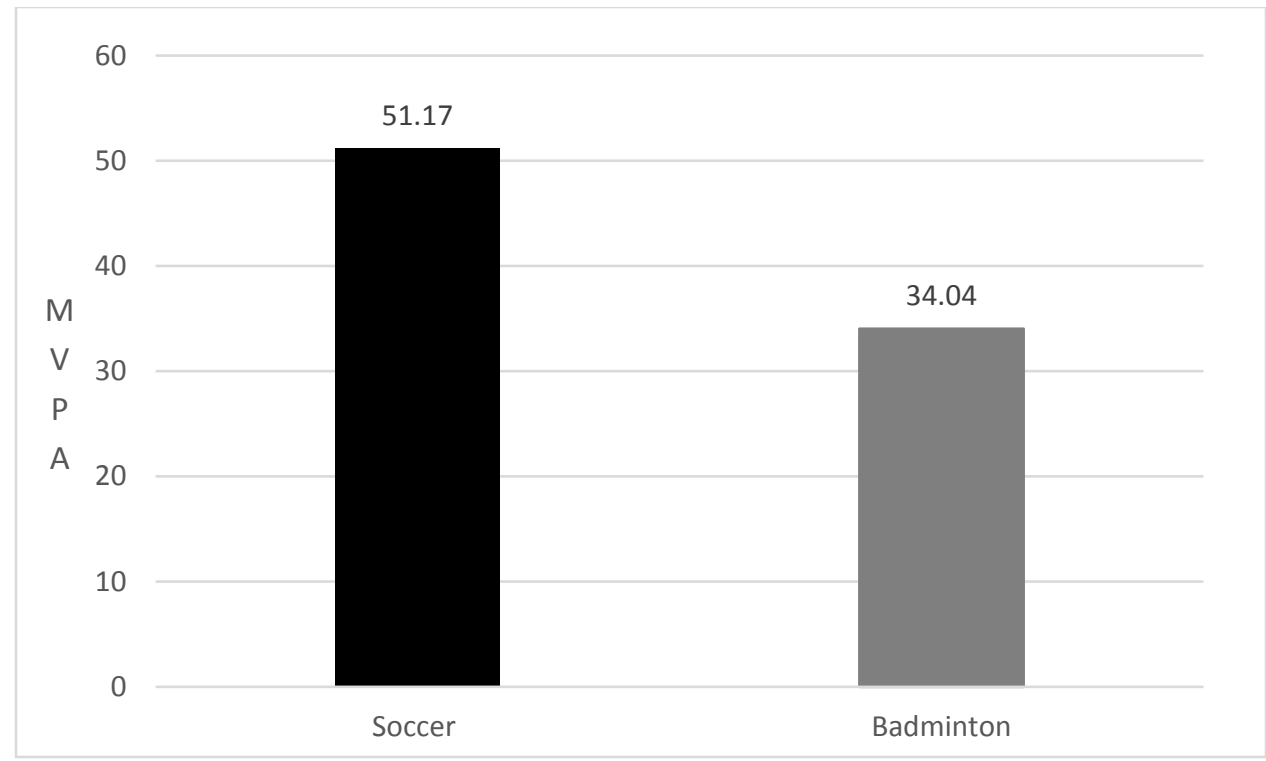

Figure 3. Aggregated MVPA data in soccer and badminton classes

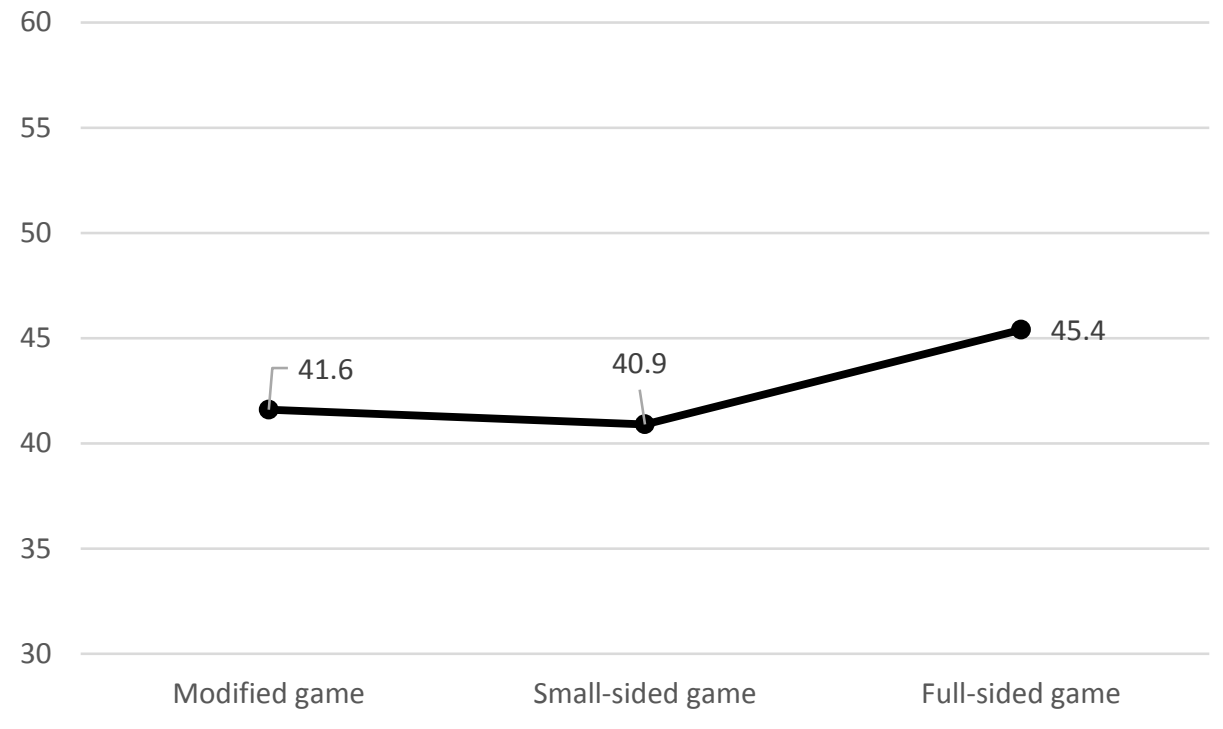

Figure 4. Aggregated MVPA data in different game contexts 
GAME TYPES ON PHYSICAL ACTIVITY AND MOTIVATION

37

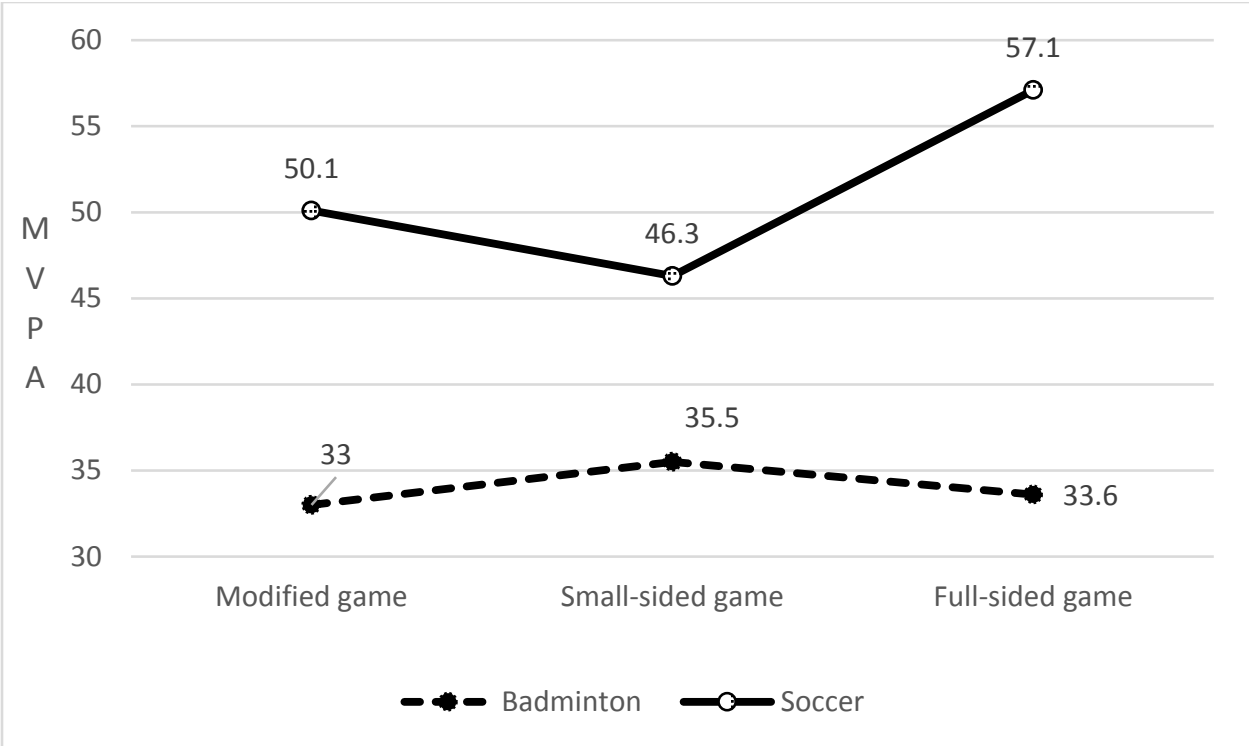

Figure 5. Badminton and soccer MVPA data in different game contexts

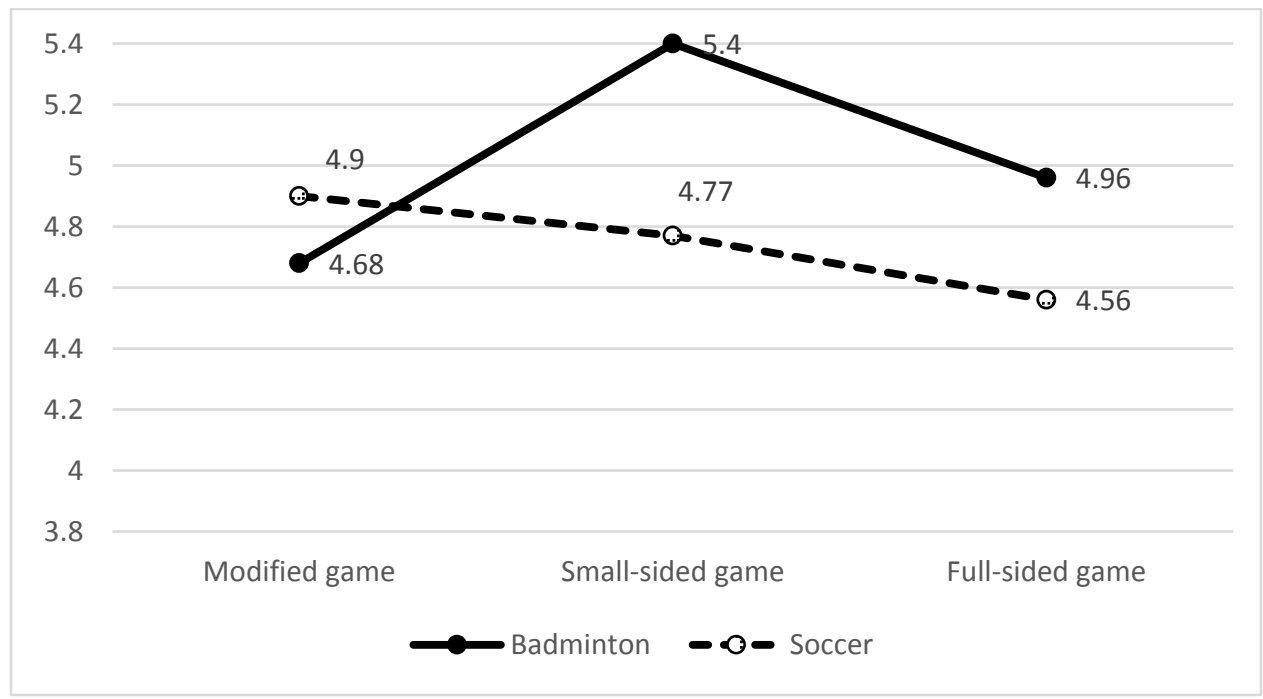

Figure 6. Perceived competence in game contexts and sports 
GAME TYPES ON PHYSICAL ACTIVITY AND MOTIVATION

38

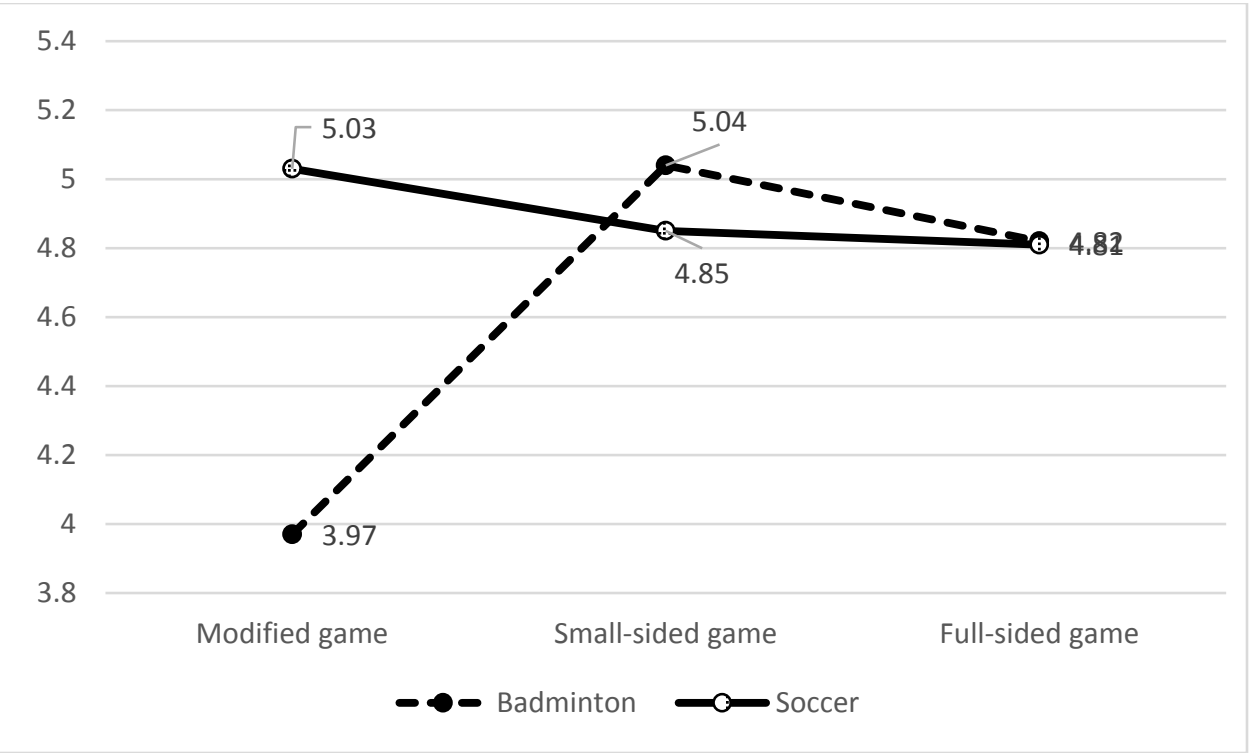

Figure 7. Effort/importance in game contexts and sports 
GAME TYPES ON PHYSICAL ACTIVITY AND MOTIVATION

39

\section{Appendix A: Extended Method}

This chapter will present the content in the following order: (a) participants and setting, (b) research design, (c) procedures, (d) instrumentation, (e) data analysis, and (f) limitations.

\section{Participants and Setting}

Participants. Participants will be recruited from the Mid-Atlantic University students who enrolled in the five classes during last five-week BIP classes (3/28-4/29) of the spring 2016 semester. The maximum number of students allowed in each class is 25, thus no more than 125 students are expected to enroll in the classes. The final number of participants will be decided by the number of students who will choose to participate in the study. Participants will come from two badminton classes and three outdoor soccer classes. Based on my previous teaching experience, most of the students are freshmen and the majority of them are males. One GTA will teach the three soccer classes and another one will teach the two badminton classes. Both of the GTAs have taught the related class before.

As for the estimation of sample size, I will use G-power software (Erdfelder, Faul, \& Buchner, 1996) to do the estimation. The F tests- MANOVA: Repeated measures, withinbetween interaction, a total sample size of 66 is needed to gain a medium-to-large effect size of 0.35 (Cohen, 1988). The number of groups is five since the students come from five classes. The number of measurements is three, as I will collect data once each for the modified, small-sided, and full-sided game context. 


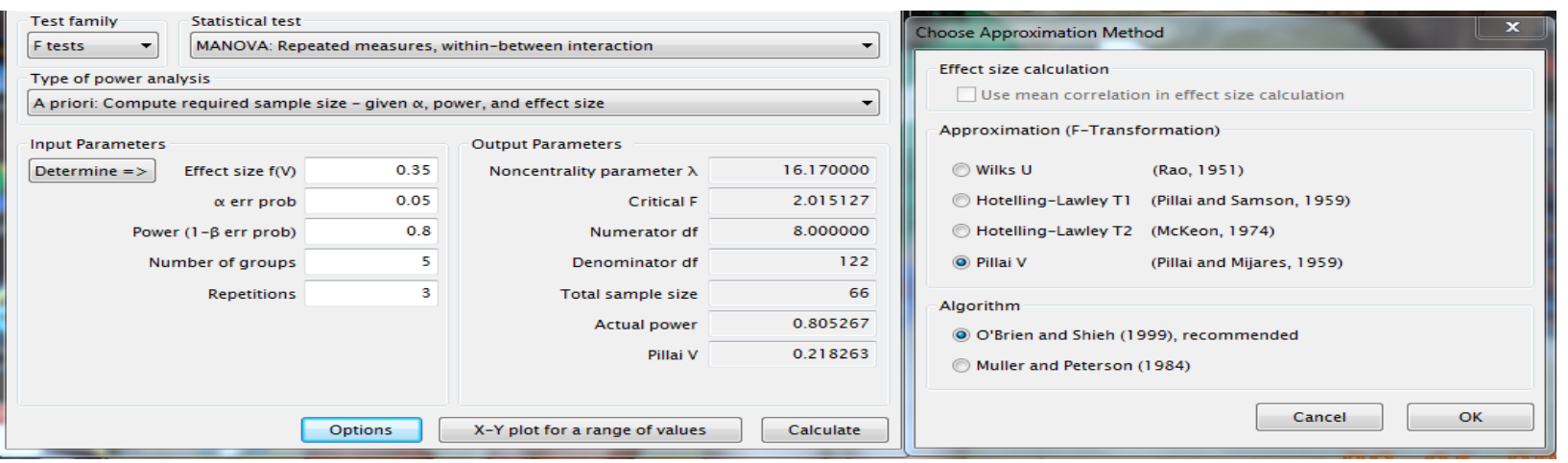

Figure 3, G-power analysis

I select Pillai V in the Approximation (F-Transformation) and O’Brien and Shieh (1999) in the Algorithm. The Pillai V was recommended by Bredenkamp and Erdfelder (1985) and Faul, Erdfelder, Lang, and Buchner (2007). Faul et al. (2007) documented the advantages of O’Brien and Shieh (1999) over Muller and Peterson (1984). The advantages included: (1) Unlike the method of Muller and Peterson, it provides the exact noncentral $F$ distribution whenever the hypothesis involves at most $s=1$ positive eigenvalues; (2) its approximations for $s>1$ eigenvalues are almost always more accurate than those of Muller and Peterson's method (which systematically underestimates power); and (3) it provides a simpler form of the noncentrality parameter. Moreover, the usage of Pillai V is the default set in the G-power analysis software.

Institutional Review Board approval. I will submit the protocol to the Institutional Review Board (IRB) at West Virginia University. The study poses low risks of or harm to participants. Participants will be provided a consent form and a data collection schedule sheet (Figure 4). Participants will be informed that it is totally their choice to either participate or not. They will not get any punishment in any formats. Moreover, participants can withdraw from this study at any time. Participants will be asked to wear accelerometers on their waists at the beginning of classes and they will be asked to finish an SDT questionnaire immediately following the gameplay. It takes about 5-8 minutes to finish the questionnaire. 
GAME TYPES ON PHYSICAL ACTIVITY AND MOTIVATION

41

I will keep all the physical activity and motivation data on a password-protected computer in the Health and Education Building at WVU. I will keep the data confidential, and only designated researchers and I will have access to the data.

Settings. All the classes in the study belong to the Basic Instruction Program (BIP). The motto of BIP at West Virginia University is "play to be fit and be fit to play.” The BIP provides a variety of individual, team, leisure, and recreational sports for students to take for 1-2 academic credits. The classes are generally elective for students who are not majoring in physical education teacher education. All the classes are offered either in 8-week or in 5-week formats and are open to both undergraduate and graduate students. Students are usually graded on four domains, which are psychomotor (skills of the sport), fitness (muscular and endurance), cognitive (rules and strategy of the sport), and affective (sportsmanship and participation).

Graduate Teaching Assistants (GTAs) with physical education backgrounds or with expertise will teach all of the BIP classes. The soccer classes are held on the Evansdale campus soccer fields, and the badminton classes are held in the Student Recreation Center.

\section{Research Design}

Nature of the study. The design of this study is a quantitative quasi-experiment, and the data will be collected at three points in time. It is a quantitative study, since both the physical activity and motivation data are quantitative in nature, and the data will be analyzed by SPSS 22 statistic software (IBM, 2013). Physical activity data will be collected by Actigrpah GT3X triaxial accelerometers, which can visually display physical activity data on computers in the range of sedentary, moderate to vigorous, and vigorous formats through its associated software program 'Actilife’. Motivation data will be in a 7-point Likert scale format. 
GAME TYPES ON PHYSICAL ACTIVITY AND MOTIVATION

42

The quasi-experimental design is determined by the fact that I have no control to assign students to which class. Students choose which class to enroll in. Moreover, the sequence of game types that students will be involved in is fixed instead of randomized. The fixed gameplay sequence is MGs at the beginning of a unit, SSGs in the middle of a unit, and FSGs at the end of a unit. The fixed game play order may act as a contributing factor to affect the two dependent variables (MVPA and motivations). However, the order is practical by the rationale that when students are involved in a new unit, it is easier for them to play MGs where rules are simplified and courts are reduced in size. Moreover, MGs are developmentally appropriate for students, since those games are designed to focus on a specific skill or a specific game problem. When students are technically and tactically ready, they can gradually progress from playing MGs to SSGs and finally to FSGs.

The nature of cross-sectional design lies in the fact that the study involves two badminton classes and three soccer classes. Both physical activity data and motivation data in each game type will only be collected once in a class; however, those data will be collected more than once from different classes. For example, I will collect physical activity data and motivation data in a modified game context in a badminton class, and I will also collect the same data from another badminton class. This is the nature of cross-sectional design (details about data collection schedule in figure 4).

Games for this study. The full-sided badminton game is a regular singles game. In the SSGs, students will play on a half court singles court using the singles long service line as the back boundary and doubles sidelines (see the gray or yellow half court). For the badmintonMGs, students will play half court singles court without being able to use a smash shot. 
GAME TYPES ON PHYSICAL ACTIVITY AND MOTIVATION

43

For the full-sided game, students will play an 11 vs. 11 full-sided regulation soccer game on a regular-size field (the whole field-120 yards x 73 yards). In the small-sided soccer games, students will play 6 vs. 6 games using half of the soccer field (see the yellow part of the court-50 yards x 40 yards). One regular size goal will put on the center of each of the sideline. For the MGs (see the gray part of the court, students will play 6 vs. 6 on the same courts as they played in SSGs. However, two smaller goals (6 feet wide) will be evenly put on the sidelines with an eight-foot distance between, and no defenders will guard the goals.
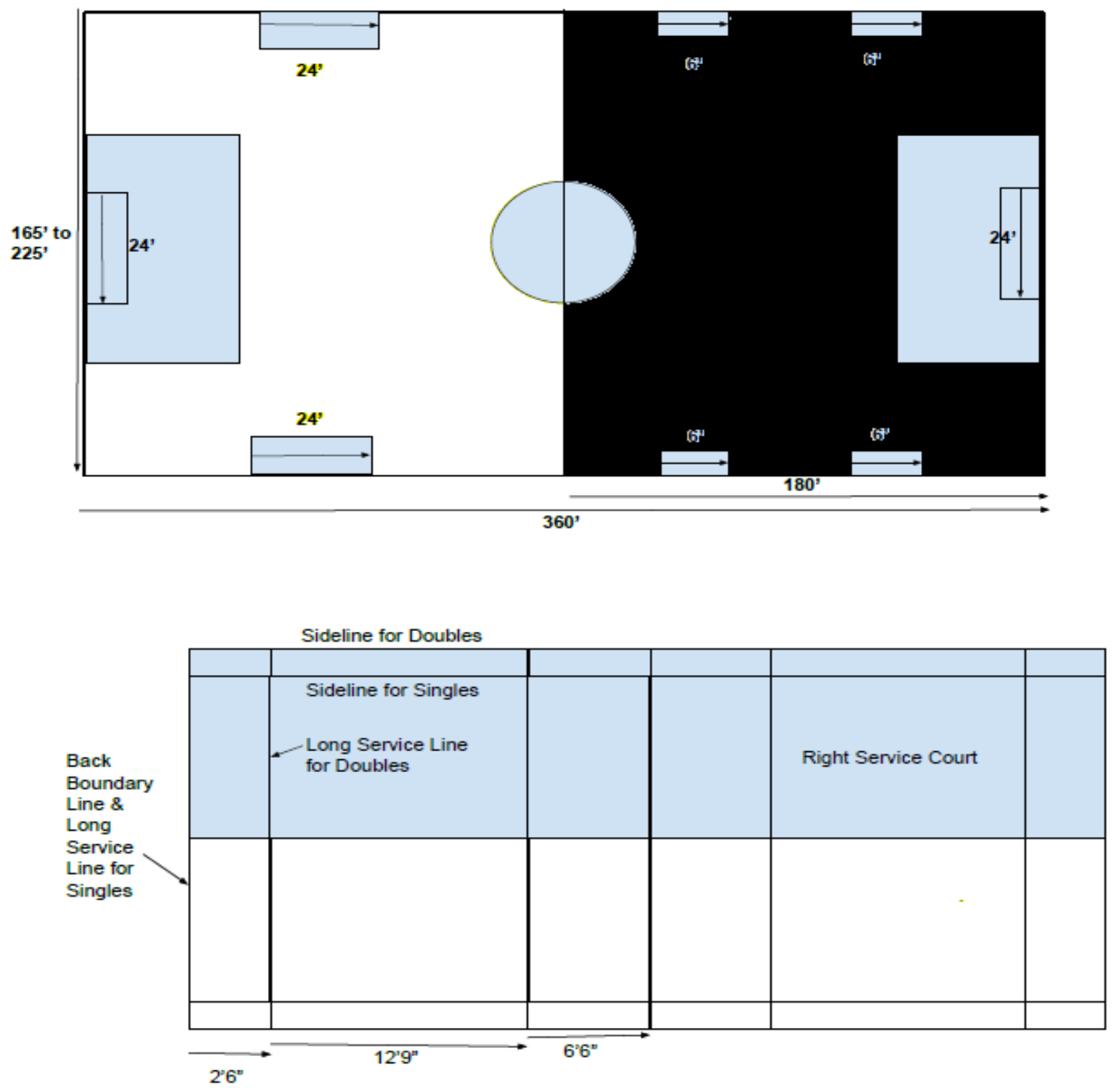
GAME TYPES ON PHYSICAL ACTIVITY AND MOTIVATION

44

\section{Procedure}

Pilot study. I will conduct a pilot study before formally starting to collect data. Before I do the pilot study, I will have a meeting with the GTAs teaching the classes involved in the study. The pilot study will help to familiarize me with the utilization of the study instruments. I will do the pilot study in one badminton and one soccer class on the week from 2/29-3/4. I will present the data collected in my proposal.

In order to keep the classes from any influences, I will not intervene in how the GTAs teach. I will only tell them not to provide instructions or encouragement during game play periods. I will follow the standardized procedures in the pilot study and formal data collection period. The standardized procedures that I will follow are:

1) Make sure that all the accelerometers are more than $80 \%$ charged.

2) Recruit participants; collect weight and height data. I will recruit participants at the second class of each badminton and soccer unit during the formal data collection period. Before I can officially program accelerometers, I will need to collect students’ weight data, which will be measured by a full body sensor (OMRON HBF-516B), and height data, which will be measured by a height measurement scale (CHARDERHM-200P Portstad. I will have the measurements done one class before official data collection.

3) Create and print IMI questionnaire. In order to reduce the repeated measure impact, the WVU Qualtrics system will be utilized to create the 18 - item questionnaire. The system can be used to randomize the order of the 18 items each time the participants complete the survey, since they will complete it three times, once after each game form (full-sided, small-sided, and small-sided modified game). I will print the questionnaires and take them to class. I also have pens and pencils ready for students to use. 
GAME TYPES ON PHYSICAL ACTIVITY AND MOTIVATION

45

4) Program accelerometers for students. Input required data such as weight and height. Other bio-data such as gender, date of birth, ethnicity, and the dominant limb will also need to program accelerometers. I will program an accelerometer for each student, and the student will have the same accelerometer each time. Accelerometers are numbered based on their serial number, thus the same student will wear the same-numbered accelerometer each time.

5) Have students wear accelerometers at the beginning of a class. Students are encouraged to wear them on the dominant side of their waist. I will make a note for each student, and I put the students' full name and the corresponding accelerometer number on the note. I also put each note in a small sealed plastic bag, which is also numbered. I put each note into a corresponding plastic bag. I will also make a laminated paper on which I put all the accelerometer numbers and students names.

6) After GTAs take attendance, GTAs will inform the game that students will play on that day, and have students play the game for 5 minutes as a warm-up game.

7) I will synchronize time with Actilife software time, and write down the exact time for the beginning and end of game play.

8) I will collect accelerometers immediately after the game play. I will remind students to pay attention to negative questions- the questionnaire items requiring reverse scores.

9) I will issue and collect paper IMI questionnaires immediately after collecting accelerometers.

10) Download MVPA data through ActiLife software. I will connect all the accelerometers used in this study to a computer installed with the ActiLife software. The MVPA data can be downloaded and shown in Excel sheets. 
GAME TYPES ON PHYSICAL ACTIVITY AND MOTIVATION

46

11) I will transfer data on paper IMI questionnaires to Qualtrics, Excel sheets, and SPSS.

12) I will Create folders. In order to facilitate the accessibility of data, I will create three electronic folders on my office computer, and each of the folders will be passwordprotected. The three folders will be named "the MGs," "SSGs," and “FSGs.” Under each folder, I will have more folders named after the class name and the data collection dates. For example, a folder named “Badminton modified game 012516 8-915am” means that the data are collected on January $25^{\text {th }}$, 2016, and are from a badminton modified game.

13) Both MVPA data and motivation data will be put into one of the folders named "the MGs,” “SSGs,” and “FSGs.” Moreover, I will back up the data in my personal computer.

Formal data collection. One week before the starting of the classes (3/28/2016), I will arrange a meeting with the GTAs who will teach the classes involved in the study. I will discuss with them the procedures I require for the study and how we can fit the required study game forms into their teaching schedule. Instructors use the Sport Education model or a hybrid model of the Sport Education model and TGfU to teach their BIP classes. Thus, they will be utilizing some of the game forms required for my study as part of their normal teaching of their BIP classes, particularly during the 'application task'. For example, the daily application task requires that students be placed in a specific game form by the GTA in order to apply skills learned that day in the first portion of the class. The study will, therefore, not cause much disruption to the 'normal' class schedule. By the end of the meeting with the GTAs, we will have agreed what day they will play each game form (e.g., Monday - modified game, Wednesday - small-sided game, Friday - full-sided game).

I will go to each class to collect data on specific dates (see figure 4). On the specific data collection day, students will play the selected game form (i.e. modified, or small-sided, or full- 
GAME TYPES ON PHYSICAL ACTIVITY AND MOTIVATION

47

sided game) for 15 minutes. The GTAs will brief the students about each game form and use a whiteboard to explain the rules. The GTAs will provide opportunities for participants to ask questions about the game form before play begins. Moreover, GTAs will have students to play the game as a warm-up game for 5 minutes before they will formally start to play the same game. After the warm up game, GTAs will divide the students into different playing groups in soccer classes or pair students to play with each other in badminton classes. The preparation period is about 3 minutes. Students in soccer classes will play two 15- minute MGs on the data collection day, and it is the same case for SSGs. In order to keep the data collection at the same time and control the influence of fatigue, I will only collect data from those who will play during the first 15-minute game. I will collect data on the next class from those students who played the second 15-minute game previously.

Extra efforts will be made to maximize the time that students will spend in gameplay. For example, during a badminton application task, extra badminton birdies will be put around the boundaries. Similarly, during the application task in soccer classes, extra soccer balls will be put around the boundaries and goals.

In order to limit the impact of teachers' instructions and encouragement on students' physical activity levels, GTAs are required not to provide any instructional information or encouragement during application tasks. 
GAME TYPES ON PHYSICAL ACTIVITY AND MOTIVATION

48

Data collection schedule

\begin{tabular}{|c|c|c|c|c|c|c|c|}
\hline & & & & & Modified & Small-sided & Small-sided \\
\hline & Class time & $3 / 1-3 / 4$ & 28-Mar & $3 / 30,3 / 31$ & 4/4 4th & 4/11 7th & 4/20 11th \\
\hline Soccer & MWF 900-1015 & \multirow{8}{*}{ Pilot study } & \multirow{8}{*}{$\begin{array}{c}\text { Study } \\
\text { meeting } \\
\text { with } \\
\text { GTAs }\end{array}$} & \multirow{8}{*}{$\begin{array}{c}\text { Consent } \\
\text { form, } \\
\text { weight } \\
\text { and } \\
\text { height }\end{array}$} & 1 & 1 & 1 \\
\hline Badminton & MWF 9-1015 & & & & 1 & 1 & 1 \\
\hline Soccer & MWF $11-1215$ & & & & 2 & 2 & 2 \\
\hline & & & & & & & \\
\hline & & & & & 5-Apr & 12-Apr & 19-Apr \\
\hline Badminton & TR 8-940am & & & & 1 & 1 & 1 \\
\hline Soccer & TR $1230-1410$ & & & & 2 & 2 & 2 \\
\hline & & & & & & & \\
\hline
\end{tabular}

- Number means the data collection sequence on that specific day

Figure 4. Data collection schedule

\section{Instrumentation}

Physical activity data collection instrument. Sixty Actigraph GT3X triaxial

accelerometers will be used to collect students’ physical activity data. Kelly et al. (2013)

validated that the Actigraphs GT3X could accurately measure physical activity compared to oxygen consumption. They validated the device by having 52 college students perform slow walking, fast walking and running on treadmills. Like all triaxial accelerometers, the Actigraph GT3X triaxial accelerometer is able to measure vibration simultaneously in three perpendicular axes (X, Y and Z). Combining with the use of ActiLife software, the amount of MVPA is able to be computed and extracted for subsequent analysis. The computation of MVPA is enabled with cut-off points for the counts per minute determined through the accelerometer as it is worn by participants. Troiano et al. (2008) utilized objective data obtained with accelerometers from a representative sample ( $n=6329$ ) of the U.S. population to determine the cut-off point for different levels for MVPA, and they found that the MVPA cut-off point for adults 18 years and older was 2020 counts per minute. Based on the finding of this study, I set the MVPA cut-off point as 2020 counts per minute in the current study. Through the utilization of the 
GAME TYPES ON PHYSICAL ACTIVITY AND MOTIVATION

49

accelerometer, I will be able to determine differences in MVPA during different forms of gameplay in terms of MVPA, which will be outlined in the procedures section.

Intrinsic motivation inventory. The IMI is a multidimensional measurement device designed for assessing participants' subjective experience related to a target activity in laboratory experiments. IMI has been used in experiments related to intrinsic motivation and self-regulation (e.g., Ryan, Mims \& Koestner, 1983; Deci, Eghrari, Patrick, \& Leone, 1994). The original IMI includes six subscales. They are interest/enjoyment, perceived competence, effort, value/usefulness, pressure and tension, and perceived choice. The seventh subscale, relatedness, has been added, although the validity of this subscale has yet to be established. The IMI subscales have a different number of items, but all of the items have been shown to be valid through factorial analysis studies (Deci \& Ryan, 2003). An item should be included when it has a factor loading of more than 0.6 on the appropriate subscale and no cross loading above 0.4.

The IMI data will be collected on a 7-point Likert scale ranging from 1 = "not true at all” to 7 = "very true”. McAuley and Duncan (1989) validated the use of IMI in PE settings. In their study, 116 undergraduate students enrolled in a required PE class used the IMI questionnaires to measure their experience with a basketball shooting task. The researchers incorporated four of the six subscales of IMI. The four subscales included were interest/enjoyment, perceived competence, effort, and pressure/tension. The perceived choice and value/usefulness subscales were not included. In terms of the current study, only the interest-enjoyment, perceive competence, and effort subscales will be included.

The reliabilities of these subscales were determined by coefficient alpha (Cronbach, 1951). McAuley and Duncan (1989) found the overall scale was internally consistent with an alpha coefficient of .85. The exact alpha coefficient for each subscale was interest/enjoyment $(\alpha=.78)$, 
GAME TYPES ON PHYSICAL ACTIVITY AND MOTIVATION

50

perceived/competence ( $\alpha=.80)$, effort ( $\alpha=.84)$, and pressure/tension $(\alpha=.68)$. The authors also did confirmatory factor analyses and found that the model would be better with the deletion of the item ("while playing this basketball game, I was thinking about how much I enjoyed it) and the item ("I am satisfied with my performance at this game”). I will keep these two items. The authors emphasized that it was because of the relatively less competitive nature of the shooting game that it was better to delete those two items. Whereas the competition in both badminton and soccer will be more intense than the basketball shooting game, thus it is better to incorporate those two items. The reliability test for each subscale in the study was interest/enjoyment ( $\alpha=.93$ ), perceived/competence ( $\alpha=.94)$, effort/importance $(\alpha=.91)$.

There are two steps to score the IMI instrument. First, reverse score the items for which an (R) is shown after them. To do that, subtract the item response from 8, and use the resulting number as the item score. Second, calculate subscale scores by averaging across all of the items on that subscale. The subscale scores are then used in the analyses of relevant questions.

\section{Data Analyses}

For the first research question, “how do students’ physical activity levels differ in the different game contexts and sports?”, a two (sports: badminton and soccer) by three (game forms: MGs, SSGs, and FSGs) factorial design (Figure 5) will be used to address the question. The dependent variable is MVPA. The two independent variables are sports and game forms. A two-way repeated measures ANOVA will be utilized to test whether the main effect of sports on MVPA exists, and this is the comparison between MVPA(b) and MVPA (s). The test will also be used to determine whether the main effect of game forms on MVPA exists, and this is the comparison among $\operatorname{MVPA}_{(\mathrm{m}),} \operatorname{MVPA}_{(\mathrm{s})}$, and $\operatorname{MVPA}_{(\mathrm{f}) \text {. }}$ 
GAME TYPES ON PHYSICAL ACTIVITY AND MOTIVATION

51

I will report any statistically significant interaction between the sports and game forms. An example of interaction is whether the difference between MVPA $_{(b m)}$ and MVPA(bs) in badminton differ from the difference between MVPA $_{(\mathrm{sm})}$ and $\mathrm{MVPA}_{(\mathrm{ss})}$ in soccer.

Figure 5. Two-way ANOVA design

\begin{tabular}{|c|c|c|c|}
\hline & Badminton & Soccer & Average \\
\hline Modified games & MVPA $_{(\mathrm{bm})}$ & MVPA $_{[\mathrm{sm})}$ & MVPA $_{(\mathrm{m})}$ \\
\hline Small-sided games & MVPA $_{(\mathrm{bs})}$ & MVPA $_{[\mathrm{ss}]}$ & MVPA $_{[\mathrm{s}]}$ \\
\hline Full-sided games & MVPA $_{(\mathrm{bf})}$ & MVPA $_{(\mathrm{sf})}$ & MVPA $_{(\mathrm{f})}$ \\
\hline Average & MVPA $_{(\mathrm{b})}$ & MVPA $_{[\mathrm{s}]}$ & \\
\hline
\end{tabular}

Figure 5. Two by three ANOVA design

$b=b a d m i n t o n ; s=s o c c e r ; m=$ modified game; $s=$ small-sided games; $f=$ full-sided games ;bm= badminton modified games; bs= badminton modified games; bf=badminton full-sided games; sm= soccer modified games; ss=soccer small-sided games; sf= soccer full-sided games

For the second research question “How do students’ motivation levels differ in different game contexts and sports?” a two (sports: badminton and soccer) by three (game forms: MGs, SSGs, and FSGs) factorial design will be used to address the question. Specifically, a two-way Multivariate Analysis of Variance (MANOVA, Figure 6) will be used to address the question. The dependent variables are the three IMI subscales (enjoyment, perceived competence, and effort), the two independent variables are sports and game forms. The main effect of sports on motivation will be examined. This is the comparison between enjoyment(b). and enjoyment(s); competence (b) and competence (s); and effort (b) and effort (s). The main effect of game forms on motivation will be examined. This is comparison among enjoyment(m), enjoyment(s) and enjoyment(f); competence (m), competence (s), and competence (f) ; effort (m), effort (s) and effort (f). I will report any statistically significant interaction between sports and game forms. One interaction example is whether the difference between enjoyment (bm) and enjoyment (bs) in badminton differ from the difference between enjoyment (sm) and enjoyment (bs) in soccer. 
GAME TYPES ON PHYSICAL ACTIVITY AND MOTIVATION

52

Figure 6. Two-way MANOVA design

\begin{tabular}{|c|c|c|c|}
\hline & Badminton & Soccer & Average \\
\hline \multirow{3}{*}{ Modified games } & Enjoyment ${ }_{[\mathrm{bm}]}$ & Enjoyment $_{[\mathrm{sm}]}$ & \multirow{3}{*}{$\begin{array}{l}\text { Enjoyment }_{[\mathrm{m}]} \\
\text { Competence }_{[\mathrm{m}]} \\
\text { effort }_{[\mathrm{m}]}\end{array}$} \\
\hline & Competence $[\mathrm{bm}]$ & Comptence $_{[\mathrm{sm}]}$ & \\
\hline & Effort $_{[\mathrm{bm}]}$ & Effort $_{[\mathrm{sm}]}$ & \\
\hline \multirow{3}{*}{ Small-sided games } & Enjoyment $_{\text {(bs) }}$ & Enjoyment $_{\text {[ss] }}$ & \multirow{3}{*}{$\begin{array}{l}\text { Enjoyment }_{[s]} \\
\text { Competence }_{[s]} \\
\text { effort }_{[s]}\end{array}$} \\
\hline & Competence (bs) & Comptence $_{[\mathrm{ss}]}$ & \\
\hline & Effort $_{\text {[bs] }}$ & Effort $_{[\mathrm{ss}]}$ & \\
\hline \multirow{3}{*}{ Full-sided games } & Enjoyment $_{\text {(bf) }}$ & Enjoyment $_{\text {(sf) }}$ & \multirow{3}{*}{$\begin{array}{l}\text { Enjoyment }_{[\mathrm{f}]} \\
\text { Competence } \\
\text { effort }_{\text {(f) }}\end{array}$} \\
\hline & Competence (bf) & Comptence $_{\text {(sf) }}$ & \\
\hline & Effort $_{\text {(bf) }}$ & Effort $_{\text {(sf) }}$ & \\
\hline Average & $\begin{array}{c}\text { Enjoyment }_{[b]} \\
\text { Competence }_{(b)} \\
\text { effort }_{(b)}\end{array}$ & $\begin{array}{c}\text { Enjoyment }_{[s]} \\
\text { Competence }_{[s]} \\
\text { effort }_{[s]}\end{array}$ & \\
\hline
\end{tabular}

Figure 6. two by three MANOVA design

$\mathrm{m}=$ moified games; s=small-sided games; $\mathrm{f}=$ full-sided games ; bm= badminton modified games; bs= badminton modified games; bf=badminton full-sided games; $s \mathrm{~m}=$ soccer modified games; ss=soccer small-sided games; sf= soccer full-sided games

For the last research question, “To what extent do motivation levels predict physical activity levels?” a multiple regression will be used to address the question. The dependent variables are MVPA and the independent variable is IMI motivation (enjoyment/interest, perceived competence, and effort) and sports (badminton and soccer). Data from the accelerometers can be generated and downloaded directly to the computer installed with the Actilife software.

Three multiple regression tests will be conducted to test how the IMI subscales and sports predict physical activity levels. One for each of the game types (MGs, SSGs, and FSGs) is needed. The regression formula is:

$$
M V P A=b_{0}+b_{1} \times \text { interest }+b_{2} \times \text { competence }+b_{3} \times \text { effort }+b_{4} \times \text { sport }+ \text { error }
$$

where $b_{0}$ is the constant, $b_{1}, b_{2}, b_{3}$, and $b_{4}$ are the coefficients for each subscale, and error is the variance that regression formula cannot account for. Take $b_{1}$ as an example to explain the 
GAME TYPES ON PHYSICAL ACTIVITY AND MOTIVATION

53

meaning of each of the coefficient. When there is no interaction, $b_{1}$ means that when all the other variables hold constant, each change of interest will lead to a $b_{1}$ units change of MVPA. When there is an interaction, the equation will be $M V P A=b_{0}+b_{1} \mathrm{x}$ interest $+b_{2} \mathrm{x}$ competence $+b_{3} \mathrm{x}$ effort $+b_{4}$ x sport $+b_{5}$ x interest $\mathrm{x}$ sports + error. $b_{1}$ means that when all the other variables hold constant, each change of interest will lead to a $\left(b_{1}+b_{5}\right)$ units change of MVPA.

I will check the relationships between each independent variable and the dependent variable. The independent variable/variables which does/ do not highly correlate with the dependent variable (MVPA), will be deleted. I will also do the multicollinearity check to see the relationships among the independent variables using correlations. If there is a high correlation between two of the independent variables, which means that one variable is redundant, the variable fitting better will be kept, and the other one will be deleted. After those tests, the nonredundant independent variables in the analysis will be the best fitting model, and the best fitting model will be used to make predictions about the dependent variable.

Dummy variables will be used to code for the sports (badminton and soccer). Since there are only two levels for the variable, only one dummy variable is needed. Badminton is coded as 0 , and soccer is coded as 1 . The third research question is about how well IMI data predict MVPA data. This research question is at level 1. Whereas level 2 variables such as the characteristics of badminton and soccer classes are ignored, thus grand-mean centering is appropriate (Enders \& Tofighi, 2007). Through this technique, a new variable can be created by subtracting the grand-mean value from the original value. 
GAME TYPES ON PHYSICAL ACTIVITY AND MOTIVATION

54

\begin{tabular}{|c|c|c|c|c|c|c|c|c|c|c|}
\hline MVPA & Enjoyment & \begin{tabular}{|c|}
$\begin{array}{c}\text { Perceivedco } \\
\text { mptence }\end{array}$ \\
\end{tabular} & Effort & Sport & $\begin{array}{c}\text { Mean_enj } \\
\text { oyment }\end{array}$ & $\begin{array}{c}\text { Mean_compe } \\
\text { tence }\end{array}$ & Mean_effort & devenjoym... & \begin{tabular}{|c|} 
devcomptenc \\
$\mathrm{e}$
\end{tabular} & deveffort \\
\hline 59.0 & 5.2 & 5.1 & 5.2 & & 5.2 & 5.1 & 5.1 & .0 & .0 & .1 \\
\hline 47.0 & 5.0 & 5.4 & 5.6 & & 5.2 & 5.1 & 5.1 & -.2 & 3 & .5 \\
\hline 57.0 & 5.6 & 5.1 & 4.9 & 1 & 5.2 & 5.1 & 5.1 & .4 & .0 & -.2 \\
\hline 53.0 & 5.0 & 4.8 & 4.7 & & 5.2 & 5.1 & 5.1 & -.2 & -.3 & -.4 \\
\hline
\end{tabular}

Figure 7. SPASS data sample with dummy variables and centered means

\section{Limitations}

1.The quasi-experimental design of this study determines the low generalization.

2.The participants are limited to the college students who will enroll in the 2016 spring BIP classes.

3.Different GTAs as instructors may work as a contributing factor. The GTAs may present different teaching styles or manifest different personalities. Those factors may also affect students’ motivation for participation and students’ physical activity levels. 
GAME TYPES ON PHYSICAL ACTIVITY AND MOTIVATION

55

\section{Appendix B: Extended Review of Literature}

The 2008 Physical Activity Guidelines for Americans recommended that adults should participate in aerobic activities at moderate intensity for at least 150 minutes a week, or at vigorous intensity for more than 75 minutes weekly. However, data showed that only 43.5 percent of adults in 2008 achieved those goals. Most recently, Healthy People (2020) aims to increase the proportion to 47.9 percent. The Healthy People (2020) goal looks dismal to achieve when we check the activity levels of high school students. For example, Centers for Diseases Control and Prevention survey (CDC, 2013) demonstrated that only 29\% high school students achieved the recommended 60-minute daily activity goal (Physical Activity Guidelines for Americans, 2008; IOM, 2013), and as high as 15.2\% high school students did not participate in any kind of physical activity (PA) more than 60 minutes in any day. When individuals grow

older, they spend less time participating in physical activities (Mowling, Elier, Brock, \& Rudisill, 2004). Moreover, people are much less active during the transition from adolescence to early adulthood (Caspesen, Pereira, \& Curran, 2000; Healthy People, 2010). With a low percentage of active high school students, we will expect the even lower percentage of active adults. Sedentary lifestyles also lead to other health problems and other problems.

Researchers demonstrated that sedentary lifestyles associate with many health problems. For example, Strong et al. (2005) found a relationship between the onset of chronic diseases and inactive lifestyles. The most common chronic diseases include cardiovascular disease, cancer, and diabetes. In addition, sedentary lifestyles also lead to increase of body mass index (BMI). For example, Ng et al. (2014) found that from 1980 to 2013, the proportion of adults with BMI of 25 or greater increased from $28.8 \%$ to $36.9 \%$ for men and from $29.8 \%$ to $38 \%$ for women. Moreover, sedentary lifestyles also associate with poor academic performance. For instance, 
GAME TYPES ON PHYSICAL ACTIVITY AND MOTIVATION

56

Carlson et al. (2008) found that girls enrolled in a higher amount of physical education did better in mathematics and reading. Even though Carson et al., did not find the better academic achievements occur among boys, CDC (2010) found that one or more positive associations among physical education and indicators of cognitive skills and academic achievement exist in both genders. In other words, children with less physical education time are more likely to perform worse academically.

With the awareness of the problems caused by sedentary lifestyles, it is helpful to understand why people could not spend enough time participating in physical activities. Compared to simple lifestyles in children and adolescents, college students had to divide their time between school, work, and family (Sallis, 2000). The complicated lifestyles kept college students from highly engaging in physical activities. How to successfully cope with complex lifestyles is out of the scope of this article. With about 20 million students served in U.S. colleges and universities (American College Health Association, 2012), employees and faculties of colleges and universities, where students pursue education, shall and should bear responsibilities to provide their students the opportunities to engage in physical activities. Moreover, evidence suggests that the PA behaviors developed during the education period will have a life-long impact on students’ whole adulthood (Keating, Guan, Pinero, \& Bridges, 2005).

Fortunately, as an avenue to help students participate in sports, sports-related classes such as physical education (PE) or health-related fitness (HRF) are provided in most colleges and universities. Students would develop their physical fitness awareness (Perman et al., 1997), establish healthy diet (Tassitano et al.,2010), and enhance sports skills from those classes (Strand, Egeberg, \& Mozumdar, 2010; Wharf Higgins, Lauzon, Yew, Bratseth, \& McLeod, 2010). 
GAME TYPES ON PHYSICAL ACTIVITY AND MOTIVATION

57

It is apparent that university students are less physically active than children and adolescents. For example, Healthy People (2010) data showed that about 65\% high school students regularly engage in vigorous activity, the number is compared to $32 \%$ of young adults (18 to 24 years old) and 23\% of adults. Even though young adults were less active than children and adolescents, as the predominant source of young adults - college students, the number of PA studies concerning college students is much less than those concerning the other two groups.

One potential way to develop university students' active lifestyles is the utilization of game-focused PE lessons. Many studies have demonstrated that students in game-focused PE lessons could spend more than $50 \%$ of the class time at moderate to vigorous physical activity levels (e.g., Arnett \& Lutz, 2003; Harvey, Song, Baek \& Van der Mars,2015). Using games as the learning organizer is one of the major characteristics of Teaching Games for Understanding (TGfU, Bunker \& Thorpe, 1982) and other game-centered approaches (GCAs). The guiding principles of TGfU and GCAs — sampling, exaggeration, and representation — advocate the usage of modified games and SSGs as the main learning organizers. FSGs are usually encouraged to be used when students are technically and tactically ready, and when students are able to effectively play modified games and small-sided games. No research has been done to examine college students' PA level gains when they play different games and sports. It is also helpful to examine students' motivation towards different games and sports. The two perspectives mentioned above are the focus of the current study, which will examine West Virginia University students’ PA and motivation differences when they play different games in soccer and badminton classes. The information about the PA differences among sports (soccer and badminton) can be used to guide the College of Physical Activity and Sport Sciences (CPASS), the provider of the PA classes, to correspondingly adjust the amount of different basic 
GAME TYPES ON PHYSICAL ACTIVITY AND MOTIVATION

58

instruction program (BIP) classes. Moreover, the findings of this study will inform PE teachers of the knowledge about the potential PA gains from different game types and sports and about students' motivations toward different game types and sports. With the knowledge, PE teachers will be able to balance the use of different game types in classes to keep students engaged and motivated.

\section{Theoretical Framework}

The emergence of utilization of games as teaching organizer. Mauldon and Redfern (1969) proposed that games could be used to help children develop psychomotor skills. They advocated that games could be the primary way to teaching physical education classes if games could provide educational opportunities for all children. They mainly advocated: (a) developmental stages in games, (b) utilization of a problem-solving approach in game situations, and (c) grouping of games into game categories. Inspired by Mauldon and Redfern's initial work, Ellis (1983) and Almond (1986) categorized games based on tactical similarities. Ellis’s categories included territory, field, court, and target games. Almond's categories included invasion, net/wall, fielding/run scoring, and target games. The two classifications were essentially the same except for some subtle subcategories. For example, Ellis broke down territory games into goal (basketball) and line (American football). Whereas, Almond broke down invasion games based on which part is utilized to wield the ball (foot-football, handhandball, and stick-stickball). The prevalence of games classification systems paved the way for the conceptualization and emergence of TGfU and other GCAs.

We can identify the four-game classifications and the main features of each game type to understand games. The four games are invasion games, net/wall games, striking/fielding games, and target games. Each of the game types is described in a paragraph. 
GAME TYPES ON PHYSICAL ACTIVITY AND MOTIVATION

59

There are two opponents in invasion games. One is an attacker and another is a defender. The purpose of the attacker is to invade the defender's territory. The attacker gets a point when he or she has completed the task, when the ball is or other objects are carried or caught with the foot, hand, or specific racket across a specific line (e.g. baseline), thrown or shot into a goal or specific target (e.g. basket) in the opponents’ territory (Pearson, Webb \& McKeen, 2005). The essence of invasion game is that the offensive team members try to invade the spaces on the defensive team to score points, and try to prevent defensive team members from getting the ball. The most common invasion games include soccer, basketball, football, rugby, and hockey.

Net/wall games involve two individuals or two opposing teams, who are divided by a net or share the match field. The essence of this game is that an offensive player tries to send an object to another side of the field in such a way that the opposing player can not hit it back before the object lands (Retrieved from http://www.thephysicaleducator.com/resources/games/net-wall/). The most common net/wall games include badminton, tennis, table tennis, volleyball, and squash.

Striking/field games involve two opposing teams. The players from an offensive team try to hit the ball into a specified area, whereas, players from a defensive team try to catch the ball and take it to a designated area. The offensive players usually hit the ball accurately and powerfully to make it harder for defensive players to catch, whereas defensive players try to catch the ball as quickly as possible before it lands on the floor or ground (Retrieved from http://www.thephysicaleducator.com/resources/games/striking-fielding/). The most common striking/fielding games include baseball, softball, cricket, and kickball.

Target games involve both opposed target games and no defense target games. In the opposed target games, players can knock or block the balls to score and to defend (e.g., 
GAME TYPES ON PHYSICAL ACTIVITY AND MOTIVATION

60

billiards). In no defense target games, players score when they throw or strike an object to a predetermined target (Retrieved from http://www.thephysicaleducator.com/resources/games/target/ ). The players totally control the process to throw or strike. Golf and bowling are the most popular nondefense target games.

Since games are utilized frequently in TGfU and other GCAs, theoretical framework about games is most associated with theoretical framework about TGfU or other GCAs. In GCAs lessons, modified games and small-sided games are specifically designed to simulate tactical problems existing in FSGs. Modifications of rules, courts, and the number of players and so on are usually made to simulate tactical problems. Teachers in GCAs usually allow students to play modified games or small-sided games first. This is different from traditional PE classes, where a PE teacher starts a class by demonstration of a skill, having students practice the skill in a variety of drills. Students in GCAs are provided the opportunities to play games first to try to solve the tactical problems by associating their previous sports experiences with the new games. Students in GCAs are more active learners than their counterparts in skill-based approaches since they try to solve problems voluntarily, (Roberts \& Fairclough, 2012).

In order to promote the abilities to solve tactical problems, teachers usually inform the students of the tactical problems in the games before having students play the games. For example, in a Frisbee "Yard Game”, a modified game, students get various points based on where they catch the disc. The tactical problem in the "Yard Game" is how to elude defenders and get to open space to catch. When students are playing, teachers would actively observe how students play the games. Teachers would judge whether students use right techniques or tactical senses to solve the problem(s). When teachers realize that students need to be equipped with necessary techniques or with the right tactical senses to play the games effectively, they usually 
GAME TYPES ON PHYSICAL ACTIVITY AND MOTIVATION

61

gather students in the whole class format or small group format to have a discussion about the difficulties students encountered during the game play and about how students tried to solve the tactical problem(s). The discussion format is entirely different from the common direct instruction by directly telling students what to do, how to do, or when to do it. Having discussions with students about game play is the questioning technique of GCAs. The questioning technique is another demonstration that GCAs promote active learning, whereas students must play the specially designed games first. The key for designing games is having modifications and purpose of the games easily understood so that students can quickly participate in the games. If the games are too complicated, teachers will spend too much time explaining the games and students will lose interest.

Game-centered approaches (GCAs). Since the initial advocacy of TGfU as the first gamecentered approaches (GCAs), at least in the English-speaking world, the TGfU approach has attained great attention, both theoretically and practically. GCAs is a broader collective term for approaches centered in games. In all GCAs, game play is the main organizing center of learning. The most common GCAs include TGfU, Tactical Games Model (TGM), Play Practice (PP), and Game Sense (GS), although other variations also exist, e.g., The Tactical Decision Learning Model (TDLM), The Games Concept Approach (GConA), Invasion Games Competence Model (ICGM) and Ball School (see Harvey \& Jarrett, 2014). Without a further overview of each of the GCAs, the common features of all GCAs according to Light (2013) are:

a.The design and manipulation of practice games and activities

b.The use of questioning

c.The provision of opportunities for dialogue, collective development and testing of solutions 
GAME TYPES ON PHYSICAL ACTIVITY AND MOTIVATION

62

for tactical problems and

d. Building a supportive socio-moral environment

The following paragraphs will describe TGfU in details. Influenced by the work of Mauldon and Redfern’s (1969) problem-based approach to teaching gymnastics, Bunker and Thorpe (1982) created the TGfU approach in Loughborough University. They created this approach to address the concerns in the traditional skill-based teaching approaches, in which teachers instruct students the proper techniques in all kinds of drills. The skill-based approach implies that students must master the skills first before they can utilize them in a game situation. The priority in this approach is the skill mastery. As a result, teachers spend less time teaching students the proper usage of the skills and strategies. Bunker and Thorpe (1982) further stipulated the drawbacks of skill-based approaches. They found that students in the skill-based teaching approaches had little success in performance based PE; students knew little about games and possessed some inflexible skills, which are commonly not generalized in gameplay, and students lacked of decision-making capacity and depended on coach/teacher to make decisions for them. With overemphasis on skill mastery, teachers usually left little time or no time for students to play games. Even when games teaching and coaching did occur in skillbased approaches, the development of skills would dominate classes in highly structured formats. In the structured formats, PE teachers always start with demonstration and verbally describing the skills. They allocate a large block of time for students to practice those skills in different drills and set aside the left time for game play. The gameplay students get usually are limited.

For all the drawbacks mentioned in skill-based approaches, the most complaint that teachers and coaches filed against skill-based approaches was that the skills learned laboriously in all kinds of drills broke down in gameplay. Bunker and Thorpe (1982) developed the alternative 
GAME TYPES ON PHYSICAL ACTIVITY AND MOTIVATION

63

approach-TGfU- to address the low generalization from skills learned from drills to game

performance. They proposed that games rather than drills provided better contextual

requirements needed to develop “skillful” performers as long as the games are developmentally

appropriate and “conditioned” to highlight specific tactical situations, therefore, games should be the central feature of TGfU lessons. The TGfU model is shown in the Figure 1.

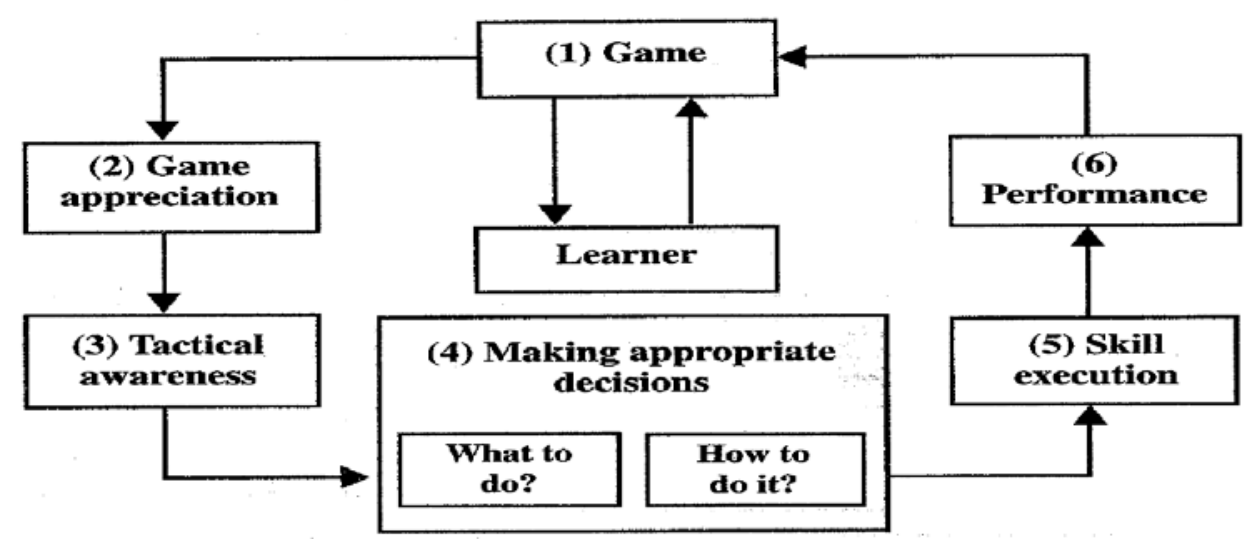

Figure 1. The Teaching Games for Understanding model (from Bunker and Thorpe, 1982)

The stages of the TGfU model. Teachers and coaches must understand the elements and guide pedagogical principles of TGfU in order to theoretically understand thoroughly and practically utilize this approach effectively. There are six of them, and they are (1) game formsuse of a variety of developmentally appropriate games, (2) game appreciation — intentional use of rules to help children understand how they shape games, (3) tactical awareness- promoting understanding of how tactics should be used in game play, (4) decision-making-helping children understand "what to do" or the ability to recognize cues and predict possible outcomes during a game situation- and "how to do it" or the selection of appropriate responses, (5) skill execution — producing the required movement in the context of the game; and (6) performance- 
GAME TYPES ON PHYSICAL ACTIVITY AND MOTIVATION

64

“observed outcome”, which should be a "measure of the appropriateness of the response as well as the efficiency of the technique” (Bunker \& Thorpe, 1982, p.6). We must recognize that the declarative knowledge (what to do) does not necessarily lead to the procedural knowledge (how to do it). Kirk, Brooker, and Brailuka (2000) found that students in a TGfU basketball unit developed declarative knowledge of strategies early in the learning process, but the students could not be able to utilize the strategies in games even when the technical demands of the task were simplified. In other words, the students were not able to transfer the declarative knowledge to procedural knowledge. The authors believed that the unsuccessful transfer was due to the low abilities to recognize visual cues in game play situations.

In addition to the six TGfU stages, there are four pedagogical principles for guiding understanding and promoting utilization. Those principles will help teachers design developmentally appropriate games. Teachers would utilize the principles to conceptualize or modify games to highlight important aspects of tactical problems.

The four guiding pedagogical principles are as follows (Bunker \&Thorpe, 1986):

(a) Sampling: The use of modified games and sports for children to experience adult versions of games; the selection of games from the same category to demonstrate common tactical problems. The modified games should present the same tactical structure as FSGs (adult games), whereas in order to accommodate age and ability differences between young children and adults, modifications should be made, such as modifications as to courts, rules, and equipment. The games classification systems have been developed to facilitate the integration of games with similar tactical possibilities within the sampling procedure (Thorpe et al., 1984).

(b) Exaggeration: Changing game structures, such as rules, equipment, and play space, to promote and exaggerate a particular aspect of a game. For example, teachers could set a long 
GAME TYPES ON PHYSICAL ACTIVITY AND MOTIVATION

65

narrow badminton court that only leaves space for drop shots and clears to exaggerate the tactical problem of defending and attacking space near and far on the court. Using a different scoring system is another way to exaggerate the development of shots and decision-making capabilities to shoot the balls to expected high scoring areas. For instance, in a basketball lesson focusing on a layup, the teacher in the class could emphasize the importance of layups by changing the scoring rules. The rules can be set that layups will be counted as two points, and all the other shots will be counted as one point.

(c) Representation: Small-sided games structured to suit the age and/or experience of the players. The small-sided games are developed that contain the same tactical structures of the adult game, but are played with adaptations to suit players’ characteristics (Thorpe et al., 1984). For example, the small-sided soccer games could be 5 vs 5, 6 vs 6 , or 7 vs 7 , compared to 11 vs. 11 full-sided soccer game.

(d) Tactical complexity: Werner, Bunker, and Thorpe (1996) emphasized that games should be taught sequentially from the least tactical complexity to the most tactical complexity. Target games are generally less complex, followed by net/wall, fielding games, and finally complex team invasion games. Consequently, the authors recommend that games should be taught from target games to invasion games.

One striking characteristic of TGfU is that it is the student-centered approach. From figure 1, we can see that the learner is at the center of the whole approach. All the elements center on the learner. Teachers play the role of facilitators. They design different small-sided games and modified games to suit students’ learning characteristics such as abilities and learning outcomes. Students' learning start from the play in small-sided games and modified games, which are the learning organizers of TGfU approach. When students play the small-sided games, they play the 
GAME TYPES ON PHYSICAL ACTIVITY AND MOTIVATION

66

games abiding by the official rules but with fewer players playing. When modifications are made to equipment, rules, and playing areas in the games, students are playing modified games. In order to effectively promote learning, small-sided games should be designed to contain most of the problems that exist in the adult game. Small-sided games are most age appropriate for young students since they can play the small-side games whereas the adult games may still be beyond the reach of many. For example, the most common small-sided game in basketball for young students is 3 vs. 3 rather than 5 vs. 5 . Even though they are playing the small-sided games, they also need to address the tactical problems in adult basketball such as when to run a fast break, when to drop into the zone, when to mark one-on-one, and when to set up a play (Thorpe \& Bunker, 1984). Modified games are usually exaggerated to address certain tactical problems. For example, when a teacher intends to address the tactical problem of defending and attacking the net in tennis, the teacher could make modifications to the court size. The teacher could ask students to play on half of the tennis court with one player positioned at baseline and one player positioned at the service box. The baseline player can hit groundstrokes, whereas the player in the service box can only hit volleys and drop shots.

\section{Motivation Theory}

The fact that motivation is a key component in active engagement is well established (Solmon, 2003). Understanding students motivations for PE is helpful for teachers to make adjustments to meet their needs, thus enhance their PA levels. Self-determination theory (SDT;

Deci \& Ryan, 1985) is a general psychology theory to explain human behaviors and it provides a valuable framework to understand students' motivation in PE. The fundamental assumption behind SDT is that human beings are self-organized systems oriented towards growth and development (Deci \& Ryan, 2000). 
GAME TYPES ON PHYSICAL ACTIVITY AND MOTIVATION

67

Understanding the three basic psychological needs in SDT-autonomy, competence, and relatedness (Deci \& Ryan, 1985) — is the first step to understand students’ motivation in PE. When these needs are satisfied, the students are more likely to show greater self-determined motivation, which would lead to positive intentions to participate in PE courses later. The next three paragraphs are dedicated to depicting the three needs.

Autonomy means that students feel they have choices and do not feel that they are controlled or compelled to do something (Deci,1975). Autonomy support refers to the provision of choices and acknowledgment of the perspectives of others and minimization of pressure (Deci, Eghrari, Patrick, \& Leone, 1994). For example, a PE teacher supporting autonomy will see the situation from students’ perspective and encourage them to make their own decisions. The teacher will neither impose his/her perspective on students nor attempt to make students change (Williams, Gagne, Ryan, \& Deci, 2002). Students are more likely to perceive the learning environment is autonomy supportive when at least two of the components of autonomy support are present. Students will not perceive the learning environment is autonomy supportive when none or only one of the components of autonomy support is present. In the autonomy-supportive environment, language usage is important. For example, controlling phrases such as “you are obliged,” you should," and "you have to" should not be used to a large extent whereas phrases such as “we ask you to”, “you can,” and “you might” should be used to give participants a chance to determine whether they intend to participate or not (Vansteenkiste, Simons, Soenens, \& Lens, 2001; Vansteenkiste, Simons, Lens, Sheldon, \& Deci, 2004).

Competence reflects the belief in one's abilities and capacities to control outcomes (Harter, 1978). Relative to no feedback, positive feedback enhanced intrinsic motivation when individuals feel responsible for the competent performance since positive feedback foster 
GAME TYPES ON PHYSICAL ACTIVITY AND MOTIVATION

68

perceived competence, which tends to enhance intrinsic motivation (Boggiano \& Ruble, 1979).

Whereas, relative to no feedback, negative feedback dwindles intrinsic motivation, since negative feedback fosters perceived incompetence, which tends to undermine intrinsic motivation (Deci \& Casico, 1972).

Relatedness concerns the need to feel involved and connected with others, and be supported by others (Baumeister \& Leary, 1995; Reis, Sheldon, Gable, Roscoe, \& Ryan, 2000). When the sense of secure relatedness is hallmarked in contexts, intrinsic motivation will be more likely to flourish. For example, students could show greater intrinsic motivation when they perceived their teachers as warm and caring (Ryan \& Grolnick ,1986; Ryan, Stiller, \& Lynch, 1994). Overall, relatedness plays a role mainly in the maintenance of intrinsic motivation, not like autonomy and competence, each of which plays the most powerful influences on intrinsic motivation.

We can understand the three basic needs from constructivist learning theories. For example, Piaget's cognitive theory stipulates that a child could learn only when the child is allowed to actively explore the surrounding learning environment. Satisfaction of autonomy is corresponded with the active exploration claim. In an autonomy-supportive environment, teachers provide students with minimal imposed demands, goals, and pressured evaluations. Teachers should provide students with necessary information and encourage them to use the information to solve problems by themselves and in their own ways (Shen, McCaughtry, Martin, \& Falman, 2009). Meeting the relatedness need will lead to learning from Vygotsky's social constructivist theory, which emphasizes on how one's culture affects cognitive development and how social interaction affects cognitive development. He argued that a child can learn things only when the child is a member of a learning community where the child can interact with 
GAME TYPES ON PHYSICAL ACTIVITY AND MOTIVATION

69

knowledgeable others such as teachers and peers (Vygotsky, 1978). Learning may not occur if a learner merely acts as a lone scientist (Dahlberg, Moss, \& Pence, 1999). As for competence, it is the most important predictor of performance (Feltz,1988). In addition, it was found positively correlated with peer acceptance (Weiss \& Duncan,1992) and with more physical activity levels (Carroll \& Loumidis, 2001).

Based on the SDT (Deci \& Ryan, 1985), people’s behaviors are driven by both intrinsic motivations and extrinsic motivations. Intrinsic motivation refers to the engagement in a behavior for the sake of the behavior itself. Extrinsic motivation refers to the engagement in a behavior for the sake of other benefits. For example, when students participate in running, they are intrinsically motivated if they run just because they like running, but they are extrinsically motivated if they run just because they have to do so to please their PE teachers or to avoid bad grades.

An individual would self-determine his/her current needs and self-regulate his/her action to meet the needs (Deci \& Ryan, 1985). There are three different states of motivation in SDT. They are amotivation, extrinsic motivation, and intrinsic motivation. Human beings are often in one state or mixed motivation states. 

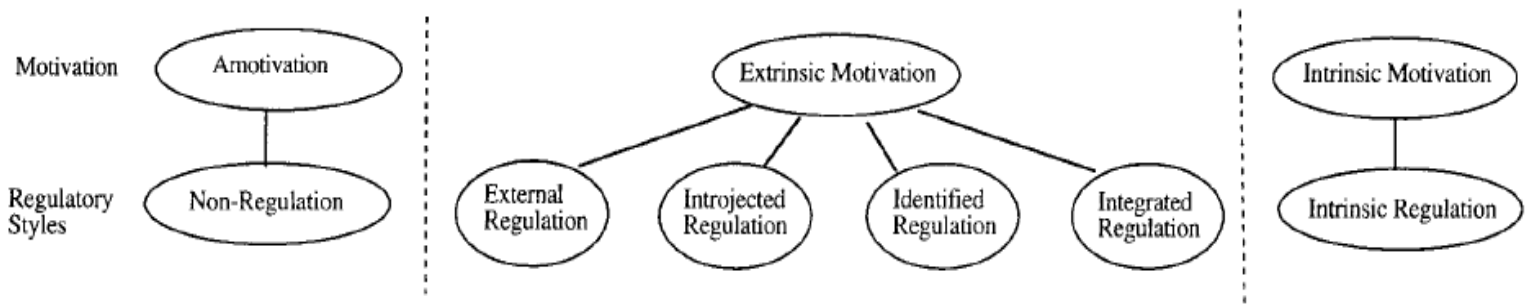

External

Nonintentional

Nonvaluing,

Incompetence,

Regulatory

Processes
Compliance,

External

Rewards and

Punishments
Somewhat Internal

Personal Importance,
Conscious Valuing
Congruence,

Awareness,

Synthesis

With Self
Interest,

Enjoyment Inherent

Satisfaction

Figure 2. The self-determination continuum showing types of motivation with their regulatory styles, loci of causality, and corresponding process (Deci \& Ryan, 2000)

A core of SDT focuses on understanding and utilizing externally imposed processes to regulate extrinsic motivation. There are four regulations in SDT. They are external regulation, introjected regulation, identified regulation, and integrated regulation. They are on a continuum, and individuals are expected to progress from one motivation state to another and finally to the intrinsic motivation (see figure 2).

At the far left of the self-determination continuum is amotivation, which means that an individual is neither intrinsically nor extrinsically motivated. A person is in an amotivated state when the person does not feel competent to perform an activity or behavior, or does not value it or does not expect any positive outcomes from it (Ryan, 1995). 
GAME TYPES ON PHYSICAL ACTIVITY AND MOTIVATION

71

When a person performs an activity or behavior only with the existence of external contingencies such as rewards or punishments, the person has extrinsic motivation for the activity. The second type of extrinsic motivation is introjected regulation. When a person selects to perform a behavior only to avoid guilt or anxiety, or to attain ego enhancements, the person is taking the regulation but not fully accepting it as his or her own. A more autonomous, or selfdetermined form of extrinsic motivation is regulation through identification. A person is at this motivation state when the person consciously accepts the value of a behavior goal or regulation, and the person believes that the behavior is important. The most autonomous form of extrinsic motivation is integrated regulation. A person is at the integrated regulation motivation state when the person not only accepts the value of the behavior but also integrates the value of the behavior with other values and needs. Even though actions characterized by integrated motivation share many qualities with intrinsic motivation, the actions are still considered extrinsically motivated, since they are done to attain separable outcomes rather than for their inherent enjoyment.

At the far right of the continuum is the intrinsic motivation. A person has intrinsic motivation for an activity when the person performs an activity or behavior for the sake of the activity or behavior itself such as enjoyment (Deci \& Ryan, 2000). The ultimate goal of SDT is having people reach intrinsic motivation state since it is interest and enjoyment that drive people to engage in lifelong behaviors. The process transferring from one motivation state to another is the internalization of motivation, whereby individuals become more self-determined to engage in behaviors over time as the extrinsic motivations become more internalized.

From the SDT respective, the ultimate goal for PE teachers is to develop students' intrinsic motivations for PE. PE, as other subject matter areas in school, is taught in a structured learning environment in which tasks are usually designed and implemented by teachers. Students need to 
GAME TYPES ON PHYSICAL ACTIVITY AND MOTIVATION

72

listen to instruction and make effort to participate with interest, thus students may perceive their teachers are controlling. Deci and Ryan (1985) emphasized that with the provision of external factors, extrinsically motivated behaviors could occur. In order to elicit students’ extrinsic motivated behaviors, teachers and school administrators should build the application of SDT around externally imposed regulatory mechanisms to transfer students’ extrinsic motivation to intrinsic motivation (Sun \& Chen, 2010). For instance, a student only goes to play basketball when he or she is invited by friends. When the external social support exists (provision of external factors — relatedness in SDT), the student will go to play basketball. The external factors can play a role of regulation to guide behavior. At the beginning of a new school year, a PE teacher can choose to teach sports such as flag football, basketball, and softball. If the teacher can give the choice to students which sport of the three they want to learn, students are more likely to be motivated. During the classes, if the teacher can let students design their modified games, students are more likely to be motivated. The students' autonomy needs, as the external factors, are satisfied here. Only when students have good experience of extrinsically motivated behaviors first, they may achieve intrinsically motivated behaviors. The question is how PE teachers provide the external factors to elicit students’ extrinsic motivation.

\section{Key Terms}

For the purpose of the proposed study, the definition of the following terms are defined as they were in a previously published study (Roberts \& Fairclough, 2012)

Modified game (MGs): the class are engaged in a modified related game. Modification of the game includes:rules (the ball or the projectile is not allowed over a certain distance, height), conditions and equipment (e.g. throw-catch badminton, using batting Ts, alternative scoring zones, rolling the ball instead of using hockey-sticks, throwing the ball instead of using a bat). 
GAME TYPES ON PHYSICAL ACTIVITY AND MOTIVATION

73

The game reduces the dominance of skills and techniques. The numbers in the team must be equal for it to be considered a game (1 vs. 1, 2 vs.2, 3 vs. 3, 4 vs. 4) and not an overload practice (Roberts \& Fairclough, 2012, P.104).

Small-sided game (SSGs): the class were engaged in SSGs with no conditions. For example, a 3 vs. 3 cross-court game of basketball, which uses regulation size basketball hoops and there is no restriction on the skills and techniques, i.e. dribbling, lay-ups. A 6 vs. 6 smallsided soccer game with no conditions other than the numbers on the playing area (Roberts \& Fairclough, 2012, P.104).

Full-sided game (FSGs): the class were involved in a full version of the game including numbers and pitch/court size (Roberts \& Fairclough, 2012, P.104).

\section{Purpose}

The purpose of this study is to compare students' physical activity levels and motivation in different game contexts (i.e., modified games, SSGs, and FSGs) and in different sports (badminton and soccer).

\section{Research Questions}

1.How do students' MVPA differ in the different game contexts and sports?

2.How do students' motivation levels differ in different game contexts and sports?

3.To what extent do motivation levels predict physical activity levels?

\section{Hypothesis}

Null hypothesis for MVPA: $H_{0}: \mu_{1}=\mu_{2}=\mu_{3} ; \mu_{4}=\mu_{5}$ 
GAME TYPES ON PHYSICAL ACTIVITY AND MOTIVATION

74

Students in different game types will attain similar MVPA; Students in badminton class and soccer class will attain similar MVPA

$\mu_{1}=$ Students mean MVPA in FSGs

$\mu_{2}=$ Students mean MVPA in SSGs

$\mu_{3}=$ Students mean MVPA in modified games

$\mu 4=$ Students mean MVPA in badminton classes

$\mu_{5}=$ Students mean MVPA in soccer classes

Study hypothesis for MVPA: $H_{1}: \mu_{1}<\mu_{2}=\mu_{3} ; \mu_{4}>\mu_{5}$

Students will attain less MVPA in FSGs than SSGs and modified games. However, students will attain similar MVPA when they played SSGs and modified games on the same field. This hypothesis was based on literature. For example, Rampinini et al. (2007) found that players in 3vs.3 games attained more MVPA than players in 5vs.5 games. Roberts and Fairclough (2011) found that students were mostly inactive during class time when FSGs were mainly utilized.

Moreover, students will attain more MVPA in soccer classes than they do in badminton classes. This assumption is based on the findings of calories burned in different sports. Ainsworth et al. (2011) found that people will get about 7 metabolic equivalent of task (MET) in casual soccer games compared to 5.5 MET in casual badminton games, and 10 MET in competitive soccer games compared to 7 MET in competitive badminton games. However, there are two differences between the current study and the study by Ainsworth et al. (2011). First, the MVPA data in the current data will be collected by accelerometers. Whereas, the MET results that Aineworth et al. (2011) made were based on self-reported physical activity data. Second, the MVPA data in the current study will be aggregated from modified games, SSGs and FSGs when 
GAME TYPES ON PHYSICAL ACTIVITY AND MOTIVATION

75

MVPA comparison between soccer and badminton is made. However, Ainsworth et.al. (2011)

collected the data only in regular games abiding by the official rules and court sizes.

Null hypothesis for motivations: $H_{0}: \mu_{1}=\mu_{2}=\mu_{3} ; \mu_{4}=\mu_{5}$

Students in different game types will have similar motivations; students in badminton class and soccer class will have similar motivations

$\mu_{1}=$ Students mean motivations in FSGs

$\mu_{2}=$ Students mean motivations in SSGs

$\mu_{3}=$ Students mean motivations in modified games

$\mu 4=$ Students mean motivation in badminton classes

$\mu_{5}=$ Students mean motivation in soccer classes

Study hypothesis for motivations: $H_{1}: \mu_{1}>\mu_{2}>\mu_{3} ; \mu_{4}>\mu_{5}$

Students will have highest motivation in full-side games, second high motivation in SSGs, and least motivation in modified games. Even though no studies have been found to support this assumption. However, when possible, students always prefer FSGs to SSGs. They may not realize the benefits of modified games, and they may have the least motivation for modified games.

Students will have higher motivation in badminton classes than in soccer classes. This hypothesis is based on a motivation study in four game categories. Mandigo, Holt, Anderson, and Sheppard (2008) and Smith et al. (2015) found that students in invasion games experienced lower positive motivation than they did in net/wall games. 
GAME TYPES ON PHYSICAL ACTIVITY AND MOTIVATION

76

\section{Significance of Study}

Even though the guiding principles of TGfU - sampling, exaggeration, and representation, advocate the usage of modified games, SSGs, and FSGs as the main learning organizer, no study has been conducted to systematically investigate university students' physical activity levels and motivations when they participant in the three game types.

Different from most other physical activity studies (e.g., CDC, 2013), which utilized the self-reports technique to ask participants to recall the kinds and intensity of sports they involved in the past days, weeks, or months, the physical activity data in this study will be collected by accelerometers. Physical activity data collected by accelerometers are more accurate and objective than data collected by self-report technique. Self-report physical activity data usually over-report activity levels (Eston, Rowlands \& Ingledew, 1998). For example, in a national survey, $49 \%$ of adults self-reported that they engaged in 30 minutes per day of moderate exercise, 5 to 7 days per week, whereas accelerometer data indicated that only 5\% of adults achieved the claimed goal (Troiano, et al., 2008).

As for benefits brought by this study, the findings will provide teachers with knowledge about the likely MVPAs from MGs, SSGs, and FSGs and with knowledge about students’ motivations toward the different game forms. Teachers should make a dynamic balance using the different game forms when enhancing students’ physical activities, or applying specific techniques or tactics is the priority. Moreover, the study will provide theoretical support to utilize the fixed game play formats to organize university students’ learning when students can demonstrate similar or slightly upwards trends in terms of physical activity and motivation. The game play formats follow the sequence: modified games at the initial of a unit, and gradually progress to SSGs and FSGs. 
GAME TYPES ON PHYSICAL ACTIVITY AND MOTIVATION

77

The following paragraphs aim to present a review of the use of modified games, SSGs, and FSGs. As emphasized at the introduction, TGfU and other GCAs utilize games as the learning organizer, which is the most prevalent feature in all GCAs, consequently, some of the reviewed literature concerning games derives from GCA studies. Moreover, this chapter also presents a review of the use SDT or its element/elements in physical education settings or related areas. Finally, this chapter also presents studies concerning students’ physical activity levels in games studies.

\section{Learning Theories Underpinning the Use of Games}

Modified games or SSGs are effective methods to prompt students learning if the games are specifically designed to simulate tactical problems. The use of games as learning organizers can be best underpinned by the constructivism theories of learning. Jerome Bruner (early constructivism view), Lev Vygotsky (social constructivism view) and Jean Piaget (cognitive constructivism view) contributed dramatically to the development of constructivism. The core of constructivism is that meaningful learning occurs when people actively construct personal knowledge structures, and when people create a personal interpretation of external ideas and experiences (Snowman \& Biehler, 2012). Constructivist learning theories assume that "learning is an active process that is student-centered in the sense that, with the teacher's help ,learners select and transform information, construct hypotheses, and make decisions” (Chrenka, 2001, p.694; italics added on ).

Bruner is one of the early notable scholars who contributed significantly to the development of constructivism. The concept of discovery learning was his most famous work. He advocated that teachers should not utilize the preselected and prearranged materials to instruct, but teachers should present problems with students and help students seek solutions 
GAME TYPES ON PHYSICAL ACTIVITY AND MOTIVATION

78

(Snowman \& Biehler, 2012). The preselected instructions are most common in direct instruction when teachers choose the drills to refine skills. In GCAs, teachers usually have students play a modified game or small-sided game, which is specifically designed to tackle specific tactical problems. This point of view demonstrates the benefits of modified games and SSGs. As constructivism claims that meaningful learning happens when people actively construct their knowledge structures, since students have tried to solve tactical problems designed in the games, they are active learners. Moreover, as active learners, students are more likely to follow teachers' instructions.

Bruner also emphasized that it is impossible for students to discover every fact or principle on their own. Learning from others holds the same benefits of personal discovery. He emphasized that discovery learning can be used to understand how ideas connect with each other, how to link old knowledge to the new, and how to solve problems (Snowman \& Biehler, 2012). Having students play the game first presents them the opportunity to solve the problems. When students have trouble solving the problems, the teacher assists. The successful application of the transfer of previously mastered techniques and familiar tactical awareness is the link that Bruner emphasized.

Social constructivism's perspective of learning claims that when people are taught effectively how to use psychological tools (such as language and math) and are provided the opportunities to use those tools in authentic, real-life activities, they are more likely to create a common, or shared, understanding of some phenomenon (Burton, Lee, \&Younie, 2009). People's knowledge is rarely identical to others' since knowledge is the combined results of personal experience and reactions to the environment. When people have opportunities to interact with others, they will have the opportunity to attain different perspectives of a 
GAME TYPES ON PHYSICAL ACTIVITY AND MOTIVATION

79

phenomenon. Systematic open-minded discussions are instrumental in helping individuals create personal views (Azevedo, 2009; Paavola, Lipponen, \& Hakkarainen, 2004).

When students play MGs or SSGs, they are encouraged to find solutions for the tactical problems in the games. A teacher observes students playing to find out whether students have difficulties playing the games. During or after students’ gameplay, teachers usually gather students to ask meaningful and instructional questions to promote tactical understanding. The use of questioning and discussion techniques may happen in the format of individual, small group, or whole-class instruction. In addition to the questioning and discussion used by teachers, students are also encouraged to have discussions with each other or in small group formats (Grehaigne et al., 2005). Moreover, since students play games in an authentic context to apply techniques, they are more likely to understand the game situation in a whole in the real games situations rather than in decontextualized drills or station practices situations. Jean Piaget (1968) proposed that learning is a dynamic process comprising successive stages of adaption to reality during which learners actively construct knowledge by creating and testing their own theories of the world. Some elements of the use of modified games and SSGs indicate the alignment to this constructivism. For example, intentional modification of rules, courts, equipment help students understand how those modification shape games; promoting active solving of tactical problems in the initial gameplay; helping students understand "what to do" or the ability to recognize cues and predict possible outcomes during a game situation intensively requires students to understand the rules, incorporate sight, hearing to recognize cues, and predict what will be the possible outcomes based on the perceived cues. All of those are intensively involved with cognitive learning. 
GAME TYPES ON PHYSICAL ACTIVITY AND MOTIVATION

80

It is clear that some benefits of utilization of games could fit more than one constructivism theories. For example, the utilization of questioning and discussion mainly fit in social constructivism. However, it also fits in cognitive constructivism, since students' responses to the questioning, leading the discussion, or answering in discussion are cognitive in nature. Light (2013) has proposed the notion of Complex Learning Theory (CLT), which encapsulates these various forms of constructivism and applies this to GCAs such as TGfU and GS. He stipulates that the core features of CLT link to the learning that occurs in GCAs because:

a. They are aligned more with a Neo-Darwinist notion of learning as an ongoing process of adaptation.

b. They see cognition as being a social process and not only an intra-individual one.

c. They reject objectivist 'representations'” accounts of cognition in favor of the idea that learning involves processes of interpretation in which there is no pre-given external reality.

In summary, CLT is based on the assumption that learning, as in GCAs, is a complex process of adaptation that is social and interpretative in nature.

\section{Physical Activity Levels in Games}

Benefits of using small-sided games. Small-sided games are most commonly used in invasion games. For example, Aguiar, Botelho, Lago, and Macas (2012) emphasized that the large pitch and the complex interactions of 22 players determine the complexity of soccer. The complexity of the game can be addressed by SSGs, which would reduce interactions and increase the ratio of players' participation in decision-making, but at the same time preserve basic 
GAME TYPES ON PHYSICAL ACTIVITY AND MOTIVATION

81

variability aspects of the game. Maximum benefits could be achieved when the training stimuli are similar to competitive demands (Bompa, 1983; Dellal et. al., 2008; Gabbett \& Mulvey, 2008). For example, Dellal et al. (2008) compared elite soccer players' heart rate responses when they engaged in short-duration intermittent running (i.e., 30 seconds of exercise interspersed with 30 seconds of recovery) and when they engaged in different SSGs (i.e., 1 vs. 1, 2 vs. 2, 4 vs. 4 with and without a goalkeeper). The authors found that SSGs could not only match the intensity of short-duration intermittent running, but also bring more variety mixing physical, technical, and tactical perspectives.

In addition to providing similar stimuli that match requirements, SSGs are good avenues to maintain fitness (Gambel, 2004; Reilly \& White, 2005.). For example, Reilly and White (2005) were interested in what were the differences in muscular power, agility, skill, aerobic capacity, and aerobic power in professional soccer players when they were in six weeks of aerobic interval training and in a small-sided training games format of the same length of time. Statistics showed that SSGs could supplant aerobic interval training as the desirable method to maintain fitness.

Many researchers have focused the usage of SSGs from a variety of aspects such as the number of players, pitch size, presence/ absence of teacher/coach encouragement. Studies have demonstrated that a different number of players in SSGs could elicit different physiological, perceptual, and time-motion characteristics (Hill-Haas, Dowson , Couts, \& Rowsell, 2009; Owen, Twist, \& Ford, 2004; Rampinini et al.,2007). In general, these studies have demonstrated that the formats with fewer players elicit greater heart rate than the ones with more players do. For example, Rampinini et al. (2007) found that soccer players in a 3-a-side game could achieve 87-90\% HR max Range, whereas, players in a 5-a-side game could only achieve 82-87 \% HR max Range. 
GAME TYPES ON PHYSICAL ACTIVITY AND MOTIVATION

82

Moreover, studies found that smaller side games will result in more opportunities to perform technical requirements (Bell, Johnson, Shimon, \& Bale, 2013; Platt, Maxwell, Horn, Williams, \& Reilly,2001). For example, Bell et al., (2013) found that players on a 3 vs. 3 SSGs had more opportunities to perform skills such as passing, dribbling, and shooting than those on 5 vs. 5 SSGs

Pitch size could determine the space for players to run or to receive the ball and complete the pass. Therefore, pitch size must be considered when a game is designed. In general, studies (e.g Casamichana \& Castellano, 2010; Jones \& Drust,2007, Kelly \& Drust, 2008) have found that with the same number of players playing, the bigger the pitch is, the smaller amount of observed techniques is. For example, Casamichana and Castellano (2010) found that when players played 5 vs. 5 games on $75 \mathrm{~m}^{2}, 175 \mathrm{~m}^{2}$, and $275 \mathrm{~m}^{2}$ soccer pitches, they demonstrated significantly fewer techniques such as interception, control and dribble, control and shoot, clearance, and putting the ball in. However, Kelly and Drust (2008) found soccer players in their study demonstrated a higher number of shots and tackles in smaller pitches. They explained that the bigger number of tackles would be caused by the relatively smaller area per player, which causes more tackles. The authors also explained that the proximity of goals would lead to the bigger number of shoots.

Teachers and coaches should realize that the number of players and the pitch of the field are usually interdependent. Therefore, when a 5 vs. 5 game is reduced to a 3 vs. 3 game, not only the number of players is reduced, the size of pitch should also be correspondingly reduced. As Owen et al.(2004) suggested, it is important to make reasonable adjustments about how many players should be arranged to play on a certain pitch size. Overall, adding more players to a certain pitch 
GAME TYPES ON PHYSICAL ACTIVITY AND MOTIVATION

83

size of field could increase the total number of technical actions, but could decrease the total number of technical actions per player

In addition to the benefits in simulating competition, fitness requirements and so on, studies have well documented that encouragement from coaches and teachers could positively influence players’ physiological response to SSGs (e.g., Coutts et al., 2004;

Hoff et al., 2002; Rampinini et al.,2007). For example, Rampinini et al. (2007) investigated the differences of twenty adult amateur soccer players’ heart rate rating of perceived exertion during sixty-seven training sessions when encouragement was provided and was not provided by the coach or the fitness trainer. The authors found that when the encouragement was provided, players had higher heart rates and perceived greater exertion.

The research demonstrated that coaches/teachers could adjust training/practicing intensity during SSGs by varying the number of players, the pitch sizes, and the provision of encouragement or not. Obviously, it is not a simply math problem to judge that it is better to have fewer players, smaller pitch size, and the provision of encouragement that would definitely result in more intense training or practicing. Other factors such as the total number of players or students, the available court spaces, the needs of other coach or teacher behaviors, must be considered to create the optimal balanced practice/training opportunities.

\section{Using modified games and the differences between small-sided games and modified}

games. By definition, modified games are those games with modification of rules, conditions and equipment, and SSGs are the games that fewer players are playing on a proportionally sized court/field with adherence to the same rules of FSGs. For example, a 3 vs. 3 basketball game on one basket is a modified game, since the full-sided game requires team members to attack the other team's basket, and one basket for both teams determines the nature of the game is a 
GAME TYPES ON PHYSICAL ACTIVITY AND MOTIVATION

84

modified game. However, a 3 vs. 3 basketball game on a proportionally smaller size court with each team attacking the other team's basket is a small-sided game, since the game keeps the basic features of a full-sided game.

The benefits of using MGs were also well documented even though many studies focused on the effects of SSGs on training, and far fewer studies focused on the effects of MGs. For example, Gabbett (2002) found that the incidence of injuries that adult rugby players suffered in the MGs (26 per 1000 training hours) was much lower than the incidence of injuries that players suffered in traditional conditioning activities (90.9 per 1000 training hours). Gabbett (2006) found adult rugby players in the skill-based conditioning games made significant improvement in all the tested areas (measurements of speed, muscular power, agility, and maximal aerobic power), whereas players in the traditional conditioning only improved in some of the tested areas. Moreover, players in the skill-based conditioning games scored more points in attack. As a result, the author suggests the MGs could work as a safer and more effective alternative to fitness/conditioning training.

Research about MGs centered a variety of modifications. For example, Hill-Haas, Coutts, Dawson, and Rowsell (2010) examined sixteen male youth soccer players’ time-motion characteristics when different modifications were made to game plays. The authors made two modifications during the game play. The modifications were that players must sprint the width and jog the lengths of the pitch, and a goal can only be counted when all players from the offensive team were in front two zones. The authors found that the participants could have longer distance traveled, higher intensity running, and more of sprints when the two modifications were made. This study demonstrated that using specific modifications could help researchers achieve desired outcomes. 
GAME TYPES ON PHYSICAL ACTIVITY AND MOTIVATION

85

Mallo and Navarro (2008) investigated the effects of inclusion of a goalkeeper on the demands of soccer players. They found that there were significant differences in terms of the distance covered and mean heart rate between the games with and without goalkeepers. During the games without goalkeepers, the players covered 747-749 meters during a 5-minute game and achieved mean heart rate about 173 beats per minute, compared to 638 meters and 166 beats per minute during the games with goalkeepers. According to the authors, when goalkeepers exist, the players tried to organize defensively to protect their goal, which would lead to less intensity in the game.

It is obvious that the size and the number of goals could affect the intensity of soccer games. However, I only found one study about the effect of scoring models on players’ heart rate variability. Duarte et al. (2010) compared teenage soccer players' heart rate variability during 4 vs. 4 SSGs when the players used line goal to score, in which dribbling past an extended line happened, and when the players used double goal, in which two two-meter side goal were presented, and when the players used only one three-meter central goal. The authors found that the heart rate variability from low to high followed the order "line goal”, “double goal” and “central goal”. The results suggested that the line goal constrains imposed the most randomness in cardiovascular stimulation of all individuals, followed by double goal and central goal.

Measuring physical activity in modified games and SSGs. In physical education contexts, researchers have been increasingly concerned with how games can be utilized as a means for students to meet recommended physical activity levels (IOM, 2013) measured by the achievement of 50\% of class time spent in MVPA (e.g., Hannon \& Ratliffe, 2005; Yelling, Penney, \& Swaine, 2000). The most commonly used devices to measure MVPA in research include heart-rate monitors, pedometers, and accelerometers. Moreover, behavior observation 
GAME TYPES ON PHYSICAL ACTIVITY AND MOTIVATION

86

systems are also commonly used to measure students' MVPA. The following paragraphs will be dedicated to introduce studies using those devices and systems.

Van Acker, Carreiro da Costa, De Bourdeaudhuij, Cardon, and Haerens (2010) utilized heart-rate monitors to measure boys’ and girls’ MVPA in the modified game- Korfball. Korfball is one kind of invasion game, and it looks like a basketball game with some modifications. In this game no dribbling is allowed, and students must be actively running, passing, and receiving. The team formation was four males and four females and only the same sex defense was allowed. The authors demonstrated that with the MGs implemented, both boys and girls in their study achieved the 50 percent MVPA recommendation. The authors stipulated that the constant moving requirements found both highly-skilled and less-skilled students actively engaged. Moreover, girls engaged more MVPA than boys did in the Korfball classes. The authors explained the higher MVPA in girls was partially because girls were more acceptable to the neutral sex game.

Harvey et al. (2015) investigated middle school students’ physical activity levels in a TGfU soccer unit. Eighty-five students from three classes participated in the study. Different from other researchers who utilized heart rate monitors, pedometers, or accelerometers to measure MVPA, the authors utilized the System for Observing Fitness Instruction Time (SOFIT, McKenzie, 2012) to measure MVPA. Researchers used the system to code students’ physical activity based on students’ body posture (such as lying, standing, walking, and running) in every twenty seconds interval. The researchers utilized MGs (e.g. modifying the size and shape of the playing areas, restricting players to certain zones of the field, altering the number and size of the goals used, etc.) to teach the unit. Results revealed that students attained an average 56.9\% MVPA. 
GAME TYPES ON PHYSICAL ACTIVITY AND MOTIVATION

87

A number of studies have focused on examining physical activity during games and/or small-sided game play within physical education. For example, Yelling et al. (2000) used heart rate monitors to measure MVPA of six seventh grade girls (five highly and one average skilled) during a six-lesson netball unit. The students mainly engaged in drill practices in three of the six classes, and they were mainly engaged in game play for the other three classes. The authors found that those girls spent more time in the moderate to vigorous heart rate reserve (HRR) zone (about 60\% class time) when the lesson context was the game play-dominated, compared to the skill-dominated lesson context (about 50\% class time in the moderate-to -vigorous HRR zone). The limitation of this study lies in the low number of participants. Only six participants were available and five of them were highly skilled. The highly skilled students may spend more time in MVPA. Those facts may affect the study’s generalization.

Slingerland, Haerens, Cardon, and Borghouts (2014) also utilized heart rate monitors to measure MVPA. They found that the boys in the study achieved about 74\% MVPA when they played a 4 vs. 4 half court with two baskets basketball games, and the girls achieved about 64\% MVPA during the same modified basketball games. The authors emphasized that the relatively high 64\% MVPA for girls may attribute to the utilization of the modified game format. McCormick et al. (2012) also utilized heart rate monitors to measure MVPA. However, they compared twelve male high school basketball team players’ MVPA and VPA when they played in 3vs.3 SSGs and in 5vs.5 FSGs. In their study, each game lasted eight minutes. The clock did not stop and foul calls were made but there were no free throws in the games. The authors found that no significant differences in terms of MVPA and VPA when the players played the SSGs and the FSGs. The players got about 98\% MVPA and about 68\% VPA during both the game forms. There is a $24 \%$ difference in terms of MVPA among the male participants in the two 
GAME TYPES ON PHYSICAL ACTIVITY AND MOTIVATION

88

studies. The differences may be caused by two factors First, the participants in McCormick et al. (2012) were high school basketball-team players, whereas, those from Slingerland et al. (2014) were students in PE classes, thus the skill levels were different. Second, the game play duration in McCormick et al. (2012) was only eight minutes, compared to a twenty-five minute game play session in Slingerland et al. (2014). Based on the definition of SSGs and MGs in the study, the 4 vs. 4 half court with two baskets basketball games is a small-sided game. Consequently, Slingerland et al. (2014) conducted the study in a small-side game context.

Both Van Acker et al., (2010) and Yelling (2000) selected the heart rate monitor to measure physical activity levels for the adolescent boys and girls. Heart rate monitors can be effectively used to monitor vigorous physical activities, however, they may not be as effective to detect moderate physical activities, since a moderate change in heart rate could also be affected by other factors such as emotions, humidity, hydration, or temperature (Heyward \& Gibson, 2014).

In addition to the use of heart rate monitors to measure physical activity levels, researchers also used other instruments such as pedometers and accelerometers. For example, Hannon and Ratliffe (2005) used digit-walker pedometers to investigate coeducational and single-gender game-play on the activity levels of Caucasian and African-American high school physical education students. They found males $(n=23)$ were more active than females and Caucasian students were more active than African American students. The male high school students had 96.1 (19.5) average steps per minute, whereas female students (n=40) attained 50.9 (17.2) average steps per minute. Researchers also utilized accelerometers, which is more advanced to measure physical activity levels (Heyward \& Gibson, 2014). For example, Arnett and Lutz (2003) investigated 68 middle school girls’ MVPA levels during small-sided soccer and floor hockey classes over two 12-lesson units. Accelerometers were utilized to measure MVPA. All 
GAME TYPES ON PHYSICAL ACTIVITY AND MOTIVATION

89

the drills and games never included more than three students per side, and all the SSGs were in the 3 vs 3 format. The girls were divided into low, medium and highly skilled groups. The authors found that all levels of girls achieved 50\% class time MVPA goal (average 56\% class time MVPA). Prior to publishing this article, Arnett (2001) utilized the same design on 13 female college students, who achieved 61\% MVPA.

On the contrary, a few researchers found that students were unable to reach $50 \%$ class time in MVPA when games were utilized as the main learning organizer. For example, Miller et al. (2015) investigated the efficacy of a GCA on 168 6th graders' physical activity levels, measured via pedometers. The authors found that both students in the intervention group and control group did not reach 50\% MVPA. The intervention group students reached 36.6\% MVPA and control group students reached 24.9\% MVPA.

A number of reviewed studies indicated that the usage of both MGs and SSGs would help students achieve 50\% class time MVPA (e.g., Arnett \& Lutz, 2003; Van Acker et al., 2010). Studies have not reached the similar MVPA levels when FSGs were mainly utilized. For example, Roberts and Fairclough (2011) found that students were mostly inactive during class time. The authors believed that much less time in MGs (4\%) and excessive time (21\%) in FSGs contributed to the low physical activity levels of students. Another factor that contributed to the low physical activity levels was that teachers spent excessive time verbally promoting technical behavior and management. Moreover, McCormick et al. (2012) compared teenage players’ MVPA and VPA during 3 vs.3 SSGs and 5 vs.5 FSGs. No statistically significant differences were found in terms of MVPA and VPA when the players played the SSGs and the FSGs.

Based on research evidence, it is irrational for teachers to rely too much on FSGs as learning organizers to enhance MVPA. There are two reasons. First, using too many FSGs, 
GAME TYPES ON PHYSICAL ACTIVITY AND MOTIVATION

90

especially at the beginning of a unit, could be considered "roll out the ball” style teaching.

Second, it is not developmentally appropriate for students to play FSGs when they are not technically and tactically ready for the more complicated FSGs.

Researchers also found that the possible impact of teacher behaviour on students’ MVPA. For example, Patterson and Van der Mars (2008) investigated the functional relationship between teachers' use of distant interaction and target students' MVPA. About 300 third to fifth grade students from five classes participated in the study. The students were observed live when they were far away from their teachers, or were video recorded when they were positioned closely with their teachers. The authors found that when the teacher interacted with students in close proximity, the students positioned closely to the teacher had higher MVPA. Whereas, students positioned far away had lower MVPA. This study demonstrated the importance of teacher positions during teaching, thus implied that teachers should actively rotate among different student groups from time to time. In order to reduce teacher effect, I will inform instructors to keep their usual teaching styles when I come to the class to collect data.

In summary, researchers have measured physical activity levels by heart-rate monitors (e.g., Van Acker et al., 2010; Yelling, 2000), by pedometers (e.g., Hannon \& Ratliffe, 2005) or by accelerometers (e.g., Arnett \& Lutz, 2003) or by instruments (Harvey et al., 2015). Van Acker et al. (2010) demonstrated that with the modifications of rules—no dribbling and same sex defense in their study, both boys and girls achieved 50\% MVPA goals. Others, for example, Arnett (2001) and Arnett and Lutz (2003) demonstrated that with the use of SSGs, students of all skill levels could achieve 50\% class time MVPA. Some of the authors of the reviewed articles did not actually distinguish SSGs from MGs. The games were the mixture of SSGs and MGs, and the authors just called the mixed games as SSGs (e.g., Hill-Haas et al., 2010). Since the 
GAME TYPES ON PHYSICAL ACTIVITY AND MOTIVATION

91

researchers did not separate MGs and SSGs, it was impossible to attribute the attained MVPA to the MGs (the modifications made) or to the SSGs, (fewer players were on the courts). More studies are needed to examine students’ MVPA during MGs. MGs not only include new sports such as Korfball (Van Acker et al., 2010) but also include popular sports with modifications. For example, a basketball game when scoring occurs only layups are made is a modified game. In my study, I will compare students’ MVPA between MGs and SSGs.

\section{Research Concerning SDT}

Two theories of motivation are most popular to understand people's motivation for exercise. They are achievement goal theory (Ames, 1992; Dweck \& Leggett, 1988) and SDT (Deci \& Ryan, 1985).The essence of achievement goal theory depends on how individuals approach learning tasks, and how they view the concepts of ability. When individuals define success or competence in self-referenced terms, and they attribute success to effort instead of abilities, those individuals hold task-oriented conceptions of ability (mastery goals). Conversely, when individuals define success or competence by norm-referenced values -defining success by comparing with others' performance-, and they believe that it is ability instead of effort that leads to success, those individuals hold an ego-oriented conception of ability (performance goals).

Task, authority, recognition, grouping, evaluation and time (TARGET, Ames, 1992) are utilized most frequently to check whether a person's conception of their ability is task-oriented or ego-oriented. Researchers found that task-oriented goals are more related to intrinsic motivations than ego-oriented goals are. People with task-oriented goals tend to hold positive attitudes toward learning, thus selecting challenging tasks and effective study strategies, whereas those with ego-oriented goals do not hold genuine interest of the activities/ behaviors; thus they 
GAME TYPES ON PHYSICAL ACTIVITY AND MOTIVATION

92

usually select easier tasks, hold trivial learning strategies, and tend to withdraw when confronted with difficulties (Dweck \& Leggett 1988;Bortoli, Bertollo, Comani, \& Robazza, 2011).

Researchers have used the structures of achievement goal theory such as TARGET to predict the levels of student intrinsic motivation. Achievement goal theory can be used to predict SDT structures. However, SDT can, arguably provide researchers with a more robust measurement of the quality of student motivation. This is because SDT has separate constructs to address autonomy, competence and relatedness. These separate constructs provide researchers the capacity to assess motivation multi-dimensionally (refer to details of my sole literature review document).

In order to understand students’ motivation for sports, PE teachers must understand how to use rewards. Intangible rewards, such as positive verbal feedback, enhanced intrinsic motivation; in contrast, tangible rewards such as gifts or money thwarted intrinsic motivation (Cameron \& Pierce, 1994; Deci, Koestner, \& Ryan, 1999). Edmunds, Ntoumanis, and Duda (2008) found students in the SDT-based teaching style demonstrated greater need satisfaction and they are more autonomously motivated to engage in PA. The students' class attendance was statistically significant greater than those in the typical teaching style. Chatzisarntis and Hagger (2009) found that students taught by autonomy-supportive teachers reported stronger intentions to exercise during leisure time and participated more frequently in leisure-time physical activities.

Mandigo, Holt, Anderson, and Sheppard (2008) examined how teachers’ autonomy support impacted 380 girls’ and 379 boys’ motivation experience in all of the four game categories. They found that girls reported higher levels of optimal challenge, perceived autonomy support, and enjoyment. In contrast, boys reported higher levels of perceived competence. Students participated in net/wall games reported the highest self-determination 
GAME TYPES ON PHYSICAL ACTIVITY AND MOTIVATION

93

motivation, whereas, those in invasion games reported lowest. This study demonstrated the effect that the provision of autonomy support on students' motivations during game lessons in PE. Slingerland et al. (2014) investigated 216 middle school students’(91 girls) perceived competence (measured by children's physical self-perception profile) when they played a modified basketball game in a mixed-gender team and in a single-gender team. The average perceived competence score for all students was 2.75 (the total point is 4). Boys' had statistically significant higher perceived competence than girls’ did in both formats of teams. Girls had statistically significant perceived competence during the single-gender team play format. This study demonstrated the effect of MGs on students’ perceived competence need. Surprisingly, no similar studies solely focused on the relatedness need.

SDT was commonly utilized in intervention design to examine how the intervention affects motivations. For example, Smith et al. (2015) randomly divided 72 England middle school students into direct instruction and the TGM over 6-12 lessons in a rugby and a football unit. The authors compared all the SDT motivations pre- and post-intervention and found no significance differences in SDT motivation constructs between the two groups. The authors stated the possible reasons for the non-improvement in the post-intervention SDT questionnaires. They believed the invasion games in nature would result in low scores in SDT questionnaires, as Mandigo et al. (2008) stated that students rated the lowest SDT scores for invasion games among the four game categories. Moreover, the results may be contaminated by the fact that the students from England were already familiar with soccer and rugby before the study was conducted. Another reason was that teachers did not implement the TGM effectively. For example, the authors found that one teacher spent a similar amount of time in both skill practice and in game play as the control condition teacher did and the teacher spent even more time providing 
GAME TYPES ON PHYSICAL ACTIVITY AND MOTIVATION

94

knowledge and managing the activity. In TGM, teachers are supposed to spend more time in game play than skill practice, and using the questioning technique to have discussions and dialogue to prompt student learning instead of direct providing knowledge.

The intrinsic motivation inventory (IMI, Ryan, 1982) is a popular self-determination theory-based questionnaires used to measure participants' subjective experience related to a target activity in laboratory experiments (details about validation see chapter 3). The IMI includes: interest and enjoyment, perceived competence, effort/importance, perceived choice, pressure/tension, value/usefulness, and relatedness. The following two paragraphs will introduce the studies utilizing the two instruments to measure SDT.

Horn and Amorose (2000) utilized the first five IMI subscales to examine the relationships among athletes’ intrinsic motivation, gender, scholarship status, perceptions of the number of their teammates receiving scholarships, and perceptions of their coaches' behavior. Ntoumanis (2001) utilized the competence, effort, perceived choice, and relatedness subscales with motivation types (such as amotivation and external regulation) to measure students' motivations for participating in PE lessons.

Jones, Marshall, and Peters (2010) utilized the IMI to investigate if differences existed among 202 secondary school students’ intrinsic motivations in TGfU and direct instruction approach in basketball units over six weeks. The authors utilized the first six subscales of IMI. They found that students in TGfU soccer unit scored better than those in skill-based approach in terms of all the six IMI components. They also indicated that girls perceived the game-based activities to fulfill individual needs and to provide satisfaction more than boys did.

\section{Literature Review Conclusion}


GAME TYPES ON PHYSICAL ACTIVITY AND MOTIVATION

95

Many benefits of utilizing MGs, SSGs were found. For example, both types of games can be utilized as alternative training method for traditional conditioning (e.g., Gabbett, 2002; Reilly \& White, 2005). SSGs can also stimulate patterns of competitions and bring more variety mixing physical, technical, and tactical perspectives in running (e.g., Gabbett \& Mulvey, 2008).

Moreover, the concepts of transfer would happen by using the games as learning organizers.

In order to enhance training/practicing intensity during SSGs, coaches/teachers would have fewer players playing (e.g., Rampinini et al., 2007), and would use smaller pitch sizes (e.g., Casamichana \& Castellano, 2010), and provide encouragement (e.g., Coutts et al., 2004). As mentioned before, those factors must be considered to adjust training/practicing intensity, but it is not a simple rule, since other factors such as the total number of players or students, the available court spaces, the needs of other coach or teacher behaviors, must be considered to create the optimal balanced exercise intensity.

For MGs, coaches/teachers could make specific modifications for a specific purpose. For example, Hill-Haas et al. (2010) required that a score be counted only when all players from offensive team must be in the front two zones. The authors made the modification to encourage players to run actively to open space to attack. Mallo and Navarro (2008) found students would achieve more MVPA when no goalkeepers were allowed during game play. More studies are needed to investigate the impact of the size of goals on students' MVPA. On the contrary, to the benefits of MGs and SSGs, over-reliance on FSGs would result in low MVPA (Roberts \&Fairclough, 2011).

Researchers had utilized heart-rate monitors (e.g., Yelling et al., 2000), pedometers (e.g., Hannon \& Ratliffe, 2005), accelerometers (e.g., Arnett \& Lutz, 2003), and instrument (e.g., Harvey et al., 2015) to judge whether students spent more than 50\% of class time in MVPA. 
GAME TYPES ON PHYSICAL ACTIVITY AND MOTIVATION

96

Moreover, most the reviewed articles were able to demonstrate that with the proper use of games, students could achieve 50\% class time in MVPA.

A major drawback about those studies is that majority of those studies focused on invasion games (mainly on soccer followed by basketball). The present study will expand the literature by adding focus on net/wall games such as badminton. Another drawback about those studies is that most studies focused on SSGs and little focus was put on MGs. Moreover, many studies did not distinguish small-side games from MGs even though modification was made to SSGs. As a result, it is impossible to judge the attained MVPA was caused by the modifications made or by the use of SSGs. With the explicit definitions of the two kinds of game forms in the current study, the differences in terms of MVPA in the two types of game forms can be clearly distinguished. .

Studies in the literature review of the SDT part demonstrated that SDT is an ideal motivation theory to understand why students participate in physical activities. Studies have reached contradictory results about students’ motivations during SSGs and MGs. For example, both Mandigo et al. (2008) and Jones et al. (2010) found that students had better motivation during games lessons in PE. However, Smith et al. (2015) found no differences after the TGM intervention. It is not clear why the contradiction exists. All those SDT studies focused on middle school or high school students. The current study could further add literature to investigate college students' motivations during the different game plays. Moreover, none of these studies aside from Harvey et al. (2006) has been conducted in the US and none of these studies has been conducted in US physical education contexts. This is surprising given the public health focus on physical education in the US. 
GAME TYPES ON PHYSICAL ACTIVITY AND MOTIVATION

97

Finally, none of the reviewed studies has examined the MVPA and motivation differences during the three different games-MGs, SSGs, and FSGs. I will find out the differences in terms of MVPA and motivations in the three game forms. Moreover, it is interesting to find out what makes the differences in terms of MVPA and motivations, if differences exist. For MGs, it is interesting to know whether the modifications will keep students motivated and engaged. For example, will students in badminton classes be interested in playing a long and narrow badminton game without smash (focusing on drop shots and clear)? Will students in soccer classes like playing the game when two goals are placed on each side but no goalkeepers are present? How about the MVPA differences between the two MGs? Are there any differences in terms of MVPAs and motivations between SSGs and FSGs? I am interested to find answers for all of these questions. 
GAME TYPES ON PHYSICAL ACTIVITY AND MOTIVATION

98

\section{References}

Aguiar, M., Botelho, G., Lago, C., Maças, V., \& Sampaio, J. (2012). A review on the effects of soccer small-sided games. Journal of Human Kinetics,33, 103-113.

Ainsworth, B. E., Haskell, W. L., Herrmann, S. D., Meckes, N., Bassett Jr, D. R., Tudor-Locke, C., ... \& Leon, A. S. (2011). 2011 Compendium of physical activities: a second update of codes and MET values. Medicine and Science in Sports and Exercise, 43(8), 1575-1581.

Almond, L. (1986). Reflecting on themes: A games classification. Rethinking games teaching.

(D. Bunker, R. Thorpe, \& L. Almond, Eds.). England: University of Technology, Loughborough, Department of Physical Education and Sports Science.

American College Health Association. (2012). Healthy Campus 2020. Retrieved March 2014, from http://www.acha.org/HealthyCampus/index.cfm

Ames, C. (1992). Classrooms: Goals, structures, and student motivation. Journal of Educational Psychology, 84, 261-271.

Arbinaga, F. \& García, J. M. Motivación para el entrenamiento con pesas en gimnasios: un estudio piloto. Rev Int de Med y Ciencias de la Actividad Física ydel Deporte, 2003; 9. In http://cdeporte.rediris.es/revista/revista9/artmotivacion.html

Arnett, M. G. (2001). The effect of sport-based physical education lessons on physical activity. Physical Educator, 58, 158-167.

Arnett, M. G., \& Lutz, R. B. (2003). Measurement of moderate to vigorous physical activity of middle school girls, using Tritrac activity monitors during small-sided, game-based lessons. Measurement in Physical Education and Exercise Science, 7, 149-159. 
GAME TYPES ON PHYSICAL ACTIVITY AND MOTIVATION

99

Azevedo, R. (2009). Theoretical, conceptual, methodological, and instructional issues in research on metacognition and self-regulated learning: a discussion. Metacognition and Learning, 4, 87-95.

Baumeister, R. F., \& Leary, M. R. (1995). The need to belong: desire for interpersonal attachments as a fundamental human motivation. Psychological Bulletin, 117, 497-529.

Bell, K., Johnson, T. G., Shimon, J., \& Bale, J. (2013). The effects of game size on the physical activity levels and ball touches of elementary school children in physical education. Journal of Kinesiology and Wellness.

Boggiano, A. K., \& Ruble, D. N. (1979). Competence and the over justification effect: a developmental study. Journal of Personality and Social Psychology, 37, 1462- 1468.

Bompa, T. (1983) Theory and methodology of training. Dubusque, Iowa: Kendall/Hunt.

Bortoli, L., Bertollo, M., Comani, S., \& Robazza, C. (2011). Competence, achievement goals, motivational climate, and pleasant psychobiosocial states in youth sport. Journal of Sports Sciences, 29, 171-180

Bray, S. R., \& Born, H. A. (2004). Transition to university and vigorous physical activity: Implications for health and psychological well-being. Journal of American College Health, 52, 181-188.

Bredenkamp, J., \& Erdfelder, E. (1985). Multivariate Varianzanalyse nach dem V-Kriterium. Psychologische Beitrage.

Bunker, D., \& Thorpe, R. (1982). A model for the teaching of games in secondary schools. Bulletin of Physical Education, 18, 5-8. 
GAME TYPES ON PHYSICAL ACTIVITY AND MOTIVATION

100

Bunker, D., \& Thorpe, R. (1986).The curriculum mode. Rethinking games teaching. (R. Thorpe, D. Bunker, \& L. Almond, Eds.). Loughborough, UK: University of Technology, Department of Physical Education and Sports Science.

Burton, D., Lee, K., \&Younie, S. (2009). Understanding learning theories and strategies. In S. Younie, S. Capel, \& M. Leask (Eds.), Supporting teaching and learning in Schools (pp. 82-90). New York: Routledge.

Cameron, J., \& Pierce, W. D. (1994). Reinforcement, Reward, and Intrinsic Motivation: A MetaAnalysis. Review of Educational Research, 64, 363-423.

Carlson, S. A., Fulton, J. E., Lee, S. M., Maynard, L. M., Brown, D. R., Kohl III, H. W., \& Dietz, W. H. (2008). Physical education and academic achievement in elementary school: data from the early childhood longitudinal study. American Journal of Public Health, 98 , 721-727

Carroll, B., \& Loumidis, J. (2001). Children’s perceived competence and enjoyment in physical education and physical activity outside school. European Physical Education Review, 7(1), 24-43.

Casamichana, D., \& Castellano, J. (2010). Time-motion, heart rate, perceptual and motor behavior demands in small-sides soccer games: Effects of pitch size. Journal of sports sciences, 28(14), 1615-1623.

Caspersen, C. J., Pereira, M. A., \& Curran, K. M. (2000). Changes in physical activity patterns in the United States, by sex and cross-sectional age. Medicine and Science in Sports and Exercise, 32, 1601-1609.

CDC. (2010). The association between school-based physical activity, including physical education, and academic performance. U.S. Department of Health and Human Services. 
GAME TYPES ON PHYSICAL ACTIVITY AND MOTIVATION

101

CDC. (2013). Youth risk behavior surveillance-United States. MMWR, (64), SS-4.

Chrenka, L. (2001). Constructivism and the role of the teacher: misconstructing constructivism. Phi Delta Kappan, 82, 694-695.

Clemente, F., Couceiro, M., Martins, F. M., \& Mendes, R. (2012). The usefulness of small-sided games on soccer training. Journal of Physical Education and Sport, 12, 93-102.

Cohen, J. (1988). Statistical power analysis for the behavioral sciences (2nd ed.). Hillsdale, NJ: Erlbaum.

Contreras Jordan, O.R., Garcia Lopez, L. M., \& Ruiz Perez, L. (2003). Transfer of procedural knowledge from invasion games to hockey. Paper Presented at the 2nd International Conference: Teaching Sport and PE for Understanding, The University of Melbourne, Australia.

Couts AJ. Rowsell GJ. Physiological responses and time- motion characteristics of various small-sided soccer games in youth players. Journal of Sports Sciences, 2009. 27, 1-8.

Coutts AJ. Murphy AJ. Dascombe BJ. (2004). The effect of direct supervision of a strength coach on measures of muscular strength and power in young rugby league players. The Journal of Strength and Conditioning Research, 18, 157-164.

Crouter, S. E., Schneider, P. L., Karabulut, M., \& Bassett Jr, D. R. (2003). Validity of ten electronic pedometers for measuring steps, distance, and kcals. Medicine and Science in Sports and Exercise, 35(5), 283-286.

Deci, E. L. (1975).Intrinsic motivation. New York: Plenum Publishing Company.

Deci, E. L., \& Cascio, W. F. (1972). Changes in intrinsic motivation as a function of negative feedback and threats. In 1972 Eastern Psychological Association Meeting. Boston, Mass. 
GAME TYPES ON PHYSICAL ACTIVITY AND MOTIVATION

102

Deci, E. L., \& Ryan, R. M. (1985). The general causality orientations scale: self-determination in personality. Journal of Research in Personality, 19, 109-134.

Deci, E. L., \& Ryan, R. M. (2000). The 'what' and 'why' of goal pursuits: human needs and the self-determination of behavior. Psychological Inquiry, 11, 227-268.

Deci, E. L., \& Ryan, R. M. (2003). Intrinsic motivation inventory. Self-Determination Theory.

Deci, E. L., Eghrari, H., Patrick, B. C., \& Leone, D. R. (1994). Facilitating internalization: The self-determination theory perspective. Journal of Personality, 62, 119-142.

Dellal, A., Chamari, K., Pintus, A., Girard, O., Cotte, T., \& Keller, D. (2008). Heart rate responses during small-sided games and short intermittent running training in elite soccer players: a comparative study. The Journal of Strength and Conditioning Research, 22, 1449-1457.

Duarte, R., Araújo, D., Fernandes, O., Travassos, B., Folgado, H., Diniz, A., \& Davids, K. (2010). Effects of different practice task constraints on fluctuations of player heart rate in small-sided football games. The Open Sports Sciences Journal, 3, 13-15.

Dweck, C. S. (1986). Motivational processes affecting learning. American Psychologist, 41, 1040-1048.

Dweck, C. S., \& Leggett, E. L. (1988). A social-cognitive approach to motivation and personality. Psychological Review, 95, 256-274

Edmunds, J., Ntoumanis, N., \& Duda, J. L. (2008). Testing a self-determination theory-based teaching style intervention in the exercise domain. European Journal of Social Psychology, 38, 375-388.

Ellis, M. (1983). Similarities and differences in games: A system for classification. In Comunicaciónpresentadaen el Congreso Mundial AIESEP, Roma. 
GAME TYPES ON PHYSICAL ACTIVITY AND MOTIVATION

103

Enders, C. K., \& Tofighi, D. (2007). Centering predictor variables in cross-sectional multilevel models: a new look at an old issue. Psychological methods, 12, 121-139.

Epstein, j. (1989). Family structures and student motivation: A developmental perspective. Research on Motivation in Education, 3, 259-295.

Erdfelder, E., Faul, F., \& Buchner, A. (1996). GPOWER: A general power analysis program. Behavior Research Methods, Instruments, and Computers,28, 1-11.

Eston, R. G., Rowlands, A. V., \& Ingledew, D. K. (1998). Validity of heart rate, pedometry, and accelerometry for predicting the energy cost of children's activities. Journal of applied physiology, 84, 362-371.

Faul, F., Erdfelder, E., Lang, A. G., \& Buchner, A. (2007). GPower 3: A flexible statistical power analysis program for the social, behavioral, and biomedical sciences. Behavior Research Methods, 39, 175-191.

Feltz, D. L. (1988). Self-confidence and sports performance. Exercise and sport sciences reviews, $16(1), 423-458$.

Ford, P. R., Yates, I., \& Williams, A. M. (2010). An analysis of practice activities and instructional behaviours used by youth soccer coaches during practice: Exploring the link between science and application. Journal of Sports Sciences, 28, 483-495.

Gabbett, T. J. (2002). Training injuries in rugby league: an evaluation of skill-based conditioning games. The Journal of Strength and Conditioning Research, 16, 236-241.

Gabbett, T. J. (2006). Skill-based conditioning games as an alternative to traditional conditioning for rugby league players. The Journal of Strength and Conditioning Research, 20, 306315. 
GAME TYPES ON PHYSICAL ACTIVITY AND MOTIVATION

104

Gabbett, T. J., \& Mulvey, M. J. (2008). Time-motion analysis of small-sided training games and competition in elite women soccer players. The Journal of Strength and Conditioning Research, 22, 543-552.

Gamble, P. (2004). A skill-based conditioning games approach to metabolic conditioning for elite rugby football players The Journal of Strength and Conditioning Research, 18, 491497.

Gimeno, E.C.(2005). Transfer of tactical knowledge from invasion games to floorball. Journal of Human Movement Studies, 49, 193-213.

Grehaigne, J.F., Richard, J.F., \& Griffin, L. L. (2005). Teaching and learning team sports and games. Psychology Press.

Hagger, M. S., \& Chatzisarantis, N. L. (2009). Integrating the theory of planned behaviour and self-determination theory in health behaviour: A meta-analysis. British journal of health psychology, 14, 275-302

Hannon, J. C., \& Ratliffe, T. (2005). Physical activity levels in coeducational and singlegender high school physical education settings. Journal of Teaching in Physical Education, 24(2), 149-164.

Harter, S. (1978). Pleasure derived from challenge and the effects of receiving grades on children’s difficulty level choices. Child Development, 49, 788-799.

Harvey, S. (2009). A study of interscholastic soccer players’ perceptions of learning with Game Sense. Asian Journal of Exercise and Sport Science, 6, 29-38.

Harvey, S., \& Jarrett, K. (2014). A review of the game-centered approaches to teaching and coaching literature since 2006. Physical Education and Sport Pedagogy, 19, 278-300. 
GAME TYPES ON PHYSICAL ACTIVITY AND MOTIVATION

105

Harvey, S., Song, Y., Baek, J. H., \& van der Mars, H. (2015). Two sides of the same coin

Student physical activity levels during a game-centered soccer unit. European Physical Education Review, doi:10.1177/1356336X15614783.

Haskell, W. L., Lee, I. M., Pate, R. R., Powell, K. E., Blair, S. N., Franklin, B. A., \& Bauman, A. (2007). Physical activity and public health: updated recommendation for adults from the American College of Sports Medicine and the American Heart Association. Circulation, $116,1081-1096$

Healthy People 2020, Retrieved from https://www.healthypeople.gov/node/3504/data-details

Hill-Haas, S. V., Coutts, A. J., Dawson, B. T., \& Rowsell, G. J. (2010). Time-motion characteristics and physiological responses of small-sided games in elite youth players: the influence of player number and rule changes. The Journal of Strength and Conditioning Research, 24, 2149-2156.

Hoff J. Wisløff U. Engen LC. Kemi OJ. Helgerud J. (2002).Soccer specific aerobic endurance training. British Journal of Sports Medicine. 36, 218-221.

Holt, J. E., Ward, P., \&Wallhead, T. L. (2006). The transfer of learning from play practices to game play in young adult soccer players. Physical Education \& Sport Pedagogy, 11, $101-118$.

Horn, T. (2000). Intrinsic motivation: Relationships with collegiate athletes' gender, scholarship status, and perceptions of their coaches' behavior. Journal of Sport \& Exercise Psychology, 22, 63-84.

IBM Corp. Released 2013. IBM SPSS Statistics for Windows, Version 22.0. Armonk, NY: IBM Corp. 
GAME TYPES ON PHYSICAL ACTIVITY AND MOTIVATION

106

Jones, C., \& Farrow, D. (1999). The transfer of strategic knowledge a test of the games classification curriculum model. Bulletin of Physical Education 35, 103-123.

Jones, R., Marshall, S., \& Peters, D. (2010). Can We Play a Game Now? The Intrinsic Benefits of TGfU. European Journal of Physical and Health Education, 4, 57-63.

Jones, S., \& Drust, B. (2007). Physiological and technical demands of 4 vs. 4 and 8 vs. 8 games in elite youth soccer players. Kinesiology, 39,150-156

Keating, X., Guan, J., Pinero, J., \& Bridges, D. (2005). A meta-analysis of college students' physical activity behaviors. Journal of American College Health, 54, 116-125.

Kelly DM. Drust B (2008). The effect of pitch dimensions on heart rate responses and technical demands of small-sided soccer games in elite players. Journal of Science and Medicine in Sport. 12, 475-479.

Kelly, L. A., McMillan, D. G., Anderson, A., Fippinger, M., Fillerup, G., \& Rider, J. (2013). Validity of actigraphs uniaxial and triaxial accelerometers for assessment of physical activity in adults in laboratory conditions. BMC medical physics, 13, 1-19.

Kirk, D., Brooker, R., \&Braiuka, S. (2000). Teaching games for understanding: A situated perspective on student learning. Paper Presented at the American Educational Research Association Annual Meeting, New Orleans, April 2000.

Landry, J. B., \& Solmon, M. A. (2004). African American women's self-determination across the stages of change for exercise. Journal of Sport and exercise Psychology, 26, 457-469.

Lee, M.A., \& Ward, P. (2009). Generalization of tactics in tag rugby from practice to games in middle school physical education. Physical Education and Sport Pedagogy, 14, 189-207.

Light, R.L. (2013). Game sense: pedagogy for performance, participation and enjoyment. London: Routledge. 
GAME TYPES ON PHYSICAL ACTIVITY AND MOTIVATION

107

Mallo, J., \& Navarro, E. (2008). Physical load imposed on soccer players during small-sided training games. Journal of Sports Medicine and Physical Fitness, 48, 166-171.

Mandigo, J., Holt, N., Anderson, A., \& Sheppard, J. (2008). Children’s motivational experiences following autonomy-supportive games lessons. European Physical Education Review, 14, 407-425.

Markland, D., \& Tobin, V. (2004). A modification to the behavioural regulation in exercise questionnaire to include an assessment of amotivation. Journal of Sport and Exercise Psychology, 26, 191-196.

Marti, R. (2004). An investigation of tactical transfer in invasion/territorial games. Research Quarterly for Exercise and Sport, 75, 15-28.

Mauldon, E., Redfern, H. B., \&Mauldon, E. (1969). Games teaching: a new approach for the primary school. London: Macdonald \& Evans.

McAuley, E., Duncan, T., \& Tammen, V. V. (1989). Psychometric properties of the Intrinsic Motivation Inventory in a competitive sport setting: A confirmatory factor analysis. Research quarterly for exercise and sport, 60(1), 48-58.

McCormick, B., Hannon, J., Newton, M., Shultz, B., Miller, N., \& Young, W. (2012). Comparison of physical activity in small-sided basketball games versus full-sided games. International Journal of Sports Science and Coaching, 7, 689-698.

McKenzie TL (2012) SOFIT. System for Observing Fitness Instruction Time. Overview and Training Manual. San Diego, CA: San Diego State University.

Memmert, D., \& Harvey, S. (2010). Identification of non-specific tactical tasks in invasion games. Physical Education and Sport Pedagogy, 15, 287-305. 
GAME TYPES ON PHYSICAL ACTIVITY AND MOTIVATION

108

Memmert, D., \& Roth, K. (2007). The effects of non-specific and specific concepts on tactical creativity in team ball sports. Journal of Sports Sciences, 25, 1423-1432.

Mitchell, S. A., \& Oslin, J. L. (1998). An investigation of tactical transfer in net games.

European Journal of Physical Education, 4, 162-172.

Moore, L. L., Lombardi, D. A., White, M. J., Campbell, J. L., Oliveria, S. A., \& Ellison, R. C. (1991). Influence of parents' physical activity levels on activity levels of young children. The Journal of pediatrics, 118(2), 215-219.

Moss, P., Pence, A., Dahlberg, G., \&Gunilla, D. (1999). Beyond quality in early childhood education and care: postmodern perspectives. (G. Dahlberg, Ed.) (1st ed.). Philadelphia, PA: Psychology Press.

Mowling, C. M., Brock, S. J., Eiler, K. K., \& Rudisill, M. E. (2004). Student motivation in physical education breaking down barriers. Journal of Physical Education, Recreation \& Dance, 75, 40-45.

Mullan, E., Markland, D., \& Ingledew, D. K. (1997). A graded conceptualization of selfdetermination in the regulation of exercise behavior: Development of a measure using confirmatory factor analytic procedures. Personality and Individual Differences, 23, 745752.

Ng, M., Fleming, T., Robinson, M., Thomson, B., Graetz, N., Margono, C., \& Abraham, J. P. (2014). Global, regional and national prevalence of overweight and obesity in children and adults 1980-2013: A systematic analysis. Lancet (London, England), 384, 766-783.

Ntoumanis, N. (2001). A self-determination approach to the understanding of motivation in physical education. British journal of educational psychology,71, 225-242. 
GAME TYPES ON PHYSICAL ACTIVITY AND MOTIVATION

109

Ogden, C. L., Carroll, M. D., Kit, B. K., \&Flegal, K. M. (2014). Prevalence of Childhood and Adult Obesity in the United States, 2011-2012. Journal of the American Medical Association, 311, 806-814.

Oslin J., \& Mitchell, S. (2006). Game-centered approaches to teaching physical education. In D. Kirk, D. MacDonald, \& M. O’Sullivan (Eds.), Handbook of physical education (pp. 627651). London: Sage.

Oslin, J., \& Mitchell, S. (2006). Game-centered approaches to teaching physical education. In D. Kirk, D. MacDonald, \& M. O’Sullivan (Eds.), Handbook of physical education (pp. 627651). London: Sage.

Owen A., Twist C., \& Ford P. (2004). Small-sided games: The physiological and technical effect of altering pitch size and player numbers. Insight. 7, 50-53.

Paavola, S., Lipponen, L., \& Hakkarainen, K. (2004). Models of innovative knowledge communities and three metaphors of learning. Review of Educational Research, 74, 557576.

Pearman III, S. N., Valois, R. F., Sargent, R. G., Saunders, R. P., Drane, J. W., \&Macera, C. A. (1997). The impact of a required college health and physical education course on the health status of alumni. Journal of American College Health, 46, 77-85.

Pearson, P., Webb, P. \& Mckeen, K. (2005). Teaching games for understanding (TGFU)-10 years in Australia teaching games for understanding in the Asia pacific region, Hong Kong, 1-9.

Piaget, J. (1968). Six psychological studies. D. Elkind (Ed.). Random House 
GAME TYPES ON PHYSICAL ACTIVITY AND MOTIVATION

110

Piñar, M. I., Cárdenas, D., Alarcón, F., Escobar, R., \& Torre, E. (2009). Participation of minibasketball players during small-sided competitions. Revista de Psicología del Deporte, $18,445-449$.

Platt, D., Maxwell, A., Horn, R., Williams, M., \& Reilly, T. (2001). Physiological and technical analysis of 3 vs. 3 and 5 vs. 5 youth football matches. Insight. 23-24.

Rampinini E. Impellizzeri FM. Castagna C. Abt G. Chamari K. Sassi A. Marcora SM. (2007). Factors influencing physiological responses to small-sided soccer games. Journal of Sports Sciences, 25, 659-666.

Reilly, T., \& White, C. (2005). Small-sided games as an alternative to interval training for soccer players. Science and football V., 355-358

Reis, H. T., Sheldon, K. M., Gable, S. L., Roscoe, J., \& Ryan, R. M. (2000). Daily well-being: the role of autonomy, competence, and relatedness. Personality and Social Psychology Bulletin, 26, 419-435.

Roberts, S., \& Fairclough, S. (2012). A five-stage process for the development and validation of a systematic observation instrument the system for observing the teaching of games in physical education (SOTG-PE). European Physical Education Review, 18, 97-113.

Roberts, S., \&Fairclough, S. (2011). Observational analysis of student activity modes, lesson contexts and teacher interactions during games classes in high school (11-16 years) physical education. European Physical Education Review, 17, 255-268.

Rovegno, I., Nevett, M., Brock, S., \&Babar, M. (2001). Teaching and learning basic invasiongame tactics in 4th grade: a descriptive study from situated and constraints theoretical perspectives. Journal of Teaching in Physical Education, 20, 370-388. 
GAME TYPES ON PHYSICAL ACTIVITY AND MOTIVATION

111

Ryan, R. M. (1982). Control and information in the intrapersonal sphere: An extension of cognitive evaluation theory. Journal of personality and social psychology, 43, 450-462.

Ryan, R. M. (1995). Psychological needs and the facilitation of integrative processes. Journal of Personality, 63, 397-427

Ryan, R. M., \&Golick, W. S. (1986). Origins and pawns in the classroom: Self-report and projective assessments of individual differences in children’s perceptions. Journal of Personality and Social Psychology, 50, 550-558.

Ryan, R. M., Stiller, J. D., \& Lynch, J. H. (1994). Representations of relationships to teachers, parents, and friends as predictors of academic motivation and self-esteem. The Journal of Early Adolescence, 14, 226-249.

Sallis, J. (2000). Age-related decline in physical activity: a synthesis of human and animal studies. Medicine and Science in Sports and Exercise, 32, 1598-1600.

Shen, B., McCaughtry, N., Martin, J., \& Fahlman, M. (2009). Effects of teacher autonomy support and students’ autonomous motivation on learning in physical education. Research Quarterly for Exercise and Sport, 80, 44-53.

Slingerland, M., Haerens, L., Cardon, G., \& Borghouts, L. (2014). Differences in perceived competence and physical activity levels during single-gender modified basketball game play in middle school physical education. European Physical Education Review, $1356336 X 13496000$.

Smith, L., Harvey, S., Savory, L., Fairclough, S., Kozub, S., \& Kerr, C. (2015). Physical activity levels and motivational responses of boys and girls: A comparison of direct instruction and tactical games models of games teaching in physical education. European Physical Education Review, 21, 93-113. 
GAME TYPES ON PHYSICAL ACTIVITY AND MOTIVATION

112

Snowman, J., McCown, R., \& Biehler, R. (2012). Behavioral learning Theory: Operant Conditioning. In Psychology applied to teaching. Belmont, CA: Wadsworth Cengage Learning.

Strand, B., Egeberg, J., \& Mozumdar, A. (2010). Health-related fitness and physical activity courses in US colleges and universities. ICHPER-SD Journal of Research, 5, 17-20.

Strong, K., Mathers, C., Leeder, S., \& Beaglehole, R. (2005). Preventing chronic diseases: how many lives can we save? The Lancet, 366, 1578-1582.

Sun, H., \& Chen, A. (2010). A pedagogical understanding of the Self-Determination Theory in physical education. Quest, 62, 364-384.

Tassitano, R. M., Barros, M. V., Tenório, M., Bezerra, J., Florindo, A. A., \& Reis, R. S. (2010). Enrollment in physical education is associated with health-related behavior among high school students. Journal of school health, 80, 126-133.

Tessitore A. Meeusen R. Piacentini MF. Demarie S. Capranica L. (2006).Physiological and technical aspects of “6-aside”soccer drills. The Journal of Sports Medicine and Physical Fitness, 46, 36-42.

The 2008 Physical Activity Guidelines for Americans, Retrieved from http://health.gov/paguidelines/guidelines/summary.aspx)

Troiano, R. P., Berrigan, D., Dodd, K. W., Masse, L. C., Tilert, T., \& McDowell, M. (2008). Physical activity in the United States measured by accelerometer. Medicine and Science in Sports and Exercise, 40, 181-189.

Van Acker, R., Carreiro da Costa, F., De Bourdeaudhuij, I., Cardon, G., \&Haerens, L. (2010). Sex equity and physical activity levels in coeducational physical education: exploring the potential of modified game forms. Physical Education and Sport Pedagogy, 15, 159-173. 
GAME TYPES ON PHYSICAL ACTIVITY AND MOTIVATION

113

Vande Broek, G., Boen, F., Claessens, M., Feys, J., \&Ceux, T. (2011). Comparison of three instructional approaches to enhance tactical knowledge in volleyball among university students. Journal of Teaching in Physical Education, 30, 375-392.

Vanseenkiste, M., Simons, J., Lens, W., Sheldon, K. M., \&Deci, E. L. (2004). Motivating learning, performance, and persistence: The synergistic effects of intrinsic goal contents and autonomy-supportive contexts. Journal of Personality and Social Psychology, 87, 246-260.

Vansteenkiste, M., Simons, J., Soenens, B., \& Lens, W. (2001). How to become a persevering exerciser? Providing a clear, future intrinsic goal in an autonomy-supportive way. Journal of Sport and Exercise Psychology, 26, 232-249.

Vygotsky, L. (1978). Mind in society. The development of higher psychological processes. Harvard university press.

Weiss, M. R., \& Duncan, S. C. (1992). The relationship between physical competence and peer acceptance in the context of children's sports participation. Journal of Sport \& Exercise Psychology, 14(2), 177-191

Werner, P., Thorpe, R., \& Bunker, D. (1996). Teaching games for understanding: Evolution of a model. Journal of Physical Education, Recreation \& Dance, 67, 28-33.

Wharf Higgins, S. J., Lauzon, L. L., Yew, A. C., Bratseth, C. D., \& McLeod, N. (2010). Wellness 101: health education for the university student. Health Education, 110, 309-327.

Willams, G. G., Gagne, M., Ryan, R. M., \&Deci, E. L. (2002). Facilitating autonomous motivation for smoking cessation. Health Psychology, 21, 40-50. 
GAME TYPES ON PHYSICAL ACTIVITY AND MOTIVATION

114

Yelling, M., Penney, D., \& Swaine, I. L. (2000). Physical activity in physical education: A case study investigation. European Journal of Physical Education, 5, 45-66. 
GAME TYPES ON PHYSICAL ACTIVITY AND MOTIVATION

115

\section{Appendix C: West Virginia University Informed Consent Form}

You are being invited to participate in a research study about physical activity levels and motivation in different game contexts (MGs, small-sided games, and full-sided games) and different sports (badminton and soccer). This study is being conducted by Yang Song, a senior graduate student, from the College of Physical Activity and Sport Sciences (CPASS) at West Virginia University. The purpose of this study is to compare students’ physical activity levels and motivation in the different game contexts and sports. The findings of this study will help understand college students’ physical activity levels and motivation in different game contexts and sports. The findings may help CPASS teaching assistants adjust the amount of MGs, smallsided games and full-sided games when they teach a unit.

You will be asked to wear an accelerometer around your waist or wrist before you start to play in MGs, small-sided games, and full-sided games. Your instructor will only focus on one type of game on a single day. The accelerometer will collect your physical activity data. After

you finish the game play, you will finish a 18 items Intrinsic Motivation Inventory questionnaire, which takes about 7-10 minutes to finish. Data will be collected three times over your class.

There are no known risks to participate in the research study. There are no costs to you for participating in the study. The information collected may not benefit you directly, but the findings from the study will provide CPASS teaching assistants the data to adjust and justify the use of MGs, small-sided games, and full-sided games. The findings also help CPASS teaching assistants understand your motivation for participate, thus they can correspondently adjust to accommodate students in the future. 
GAME TYPES ON PHYSICAL ACTIVITY AND MOTIVATION

116

Participation in the study is anonymous. Please do not write your name on the questionnaire or anywhere else except in the bottom of this consent form. Please only write your WVU ID number on the questionnaire. Please be aware that no individual information will be disclosed.

Participation is completely voluntary. There is no penalty in any forms, and you may discontinue participation at any time.

Any questions regarding the research and research participants' rights, and whom to contact in the event of a research related injury to the participant, please contact Yang Song, primary research by email ysong3@mix.wvu.edu or by dialing 681-212-9598 


\section{Appendix D:Intrinsic Motivation Inventory}

This questionnaire was created to investigate the various motivations that participant do exercise. Please realize that this is not a test, there is not right or wrong answers. Moreover, your identity information is confidential, since it is coded by your WVU ID and your last 4 digit phone number. No individual answers will be checked, and we will only interested in how group-exercise motivation differ in different game contexts. Please use the scale below and indicate to what extent each of the following items are most true for you.

Not true

At all
Somewhat

true

$\begin{array}{lllllll}1 & 2 & 3 & 4 & 5 & 6 & 7\end{array}$

\section{Interest/Enjoyment}

I enjoyed doing this activity very much

This activity was fun to do.

I thought this was a boring activity. (R)

This activity did not hold my attention at all. (R)

I would describe this activity as very interesting.

I thought this activity was quite enjoyable.

While I was doing this activity, I was thinking about how much I enjoyed it.

\section{Perceived Competence}

I think I am pretty good at this activity.

I think I did pretty well at this activity, compared to other students.

After working at this activity for a while, I felt pretty competent.

I am satisfied with my performance at this task.

I was pretty skilled at this activity.

This was an activity that I could not do very well. (R)

\section{Effort/Importance}

I put a lot of effort into this.

I did not try very hard to do well at this activity. (R)

I tried very hard on this activity.

It was important to me to do well at this task.

I did not put much energy into this. (R)

*Note. The 18 items will be created by WVU Qualtrics system with the randomization setting. The order of the items will be different each time when the questionnaire is taken. Moreover, it is only for presentation purpose to show the titles-interest/enjoyment, perceived competence, and effort/importatnce. When participants take the questionnaire, the titles will not be shown. 